\title{
The Eocene-Oligocene transition: a review of marine and terrestrial proxy data, models and model-data comparisons
}

\author{
David K. Hutchinson ${ }^{1}$, Helen K. Coxall ${ }^{1}$, Daniel J. Lunt ${ }^{2}$, Margret Steinthorsdottir ${ }^{1,3}$, Agatha M. de Boer ${ }^{1}$, \\ Michiel Baatsen $^{4}$, Anna von der Heydt ${ }^{4,5}$, Matthew Huber ${ }^{6}$, Alan T. Kennedy-Asser ${ }^{2}$, Lutz Kunzmann ${ }^{7}$, \\ Jean-Baptiste Ladant ${ }^{8}$, Caroline H. Lear ${ }^{9}$, Karolin Moraweck ${ }^{7}$, Paul N. Pearson ${ }^{9}$, Emanuela Piga ${ }^{9}$, \\ Matthew J. Pound ${ }^{10}$, Ulrich Salzmann ${ }^{10}$, Howie D. Scher ${ }^{11}$, Willem P. Sijp ${ }^{12}$, Kasia K. Śliwińska ${ }^{13}$, Paul A. Wilson ${ }^{14}$, \\ and Zhongshi Zhang ${ }^{15,16}$
}

${ }^{1}$ Department of Geological Sciences and Bolin Centre for Climate Research, Stockholm University, Stockholm, Sweden

${ }^{2}$ School of Geographical Sciences, University of Bristol, Bristol, UK

${ }^{3}$ Department of Palaeobiology, Swedish Museum of Natural History, Stockholm, Sweden

${ }^{4}$ Institute for Marine and Atmospheric Research, Department of Physics, Utrecht University, Utrecht, the Netherlands

${ }^{5}$ Centre for Complex Systems Studies, Utrecht University, Utrecht, the Netherlands

${ }^{6}$ Department of Earth, Atmospheric, and Planetary Sciences, Purdue University, West Lafayette, USA

${ }^{7}$ Senckenberg Natural History Collections, Dresden, Germany

${ }^{8}$ Department of Earth and Environmental Sciences, University of Michigan, Ann Arbor, USA

${ }^{9}$ School of Earth and Ocean Sciences, Cardiff University, Cardiff, UK

${ }^{10}$ Department of Geography and Environmental Sciences, Northumbria University, Newcastle upon Tyne, UK

${ }^{11}$ School of the Earth, Ocean and Environment, University of South Carolina, Columbia SC, USA

${ }^{12}$ Climate Change Research Centre, University of New South Wales, Sydney, Australia

${ }^{13}$ Department of Stratigraphy, Geological Survey of Denmark and Greenland (GEUS), Copenhagen, Denmark

${ }^{14}$ University of Southampton, National Oceanography Centre, Southampton, UK

${ }^{15}$ Department of Atmospheric Science, China University of Geoscience, Wuhan, China

${ }^{16}$ NORCE Research and Bjerknes Centre for Climate Research, Bergen, Norway

Correspondence: David K. Hutchinson (david.hutchinson@geo.su.se)

Received: 3 May 2020 - Discussion started: 18 May 2020

Revised: 17 November 2020 - Accepted: 18 November 2020 - Published: 28 January 2021

\begin{abstract}
The Eocene-Oligocene transition (EOT) was a climate shift from a largely ice-free greenhouse world to an icehouse climate, involving the first major glaciation of Antarctica and global cooling occurring $\sim 34$ million years ago (Ma) and lasting $\sim 790 \mathrm{kyr}$. The change is marked by a global shift in deep-sea $\delta^{18} \mathrm{O}$ representing a combination of deep-ocean cooling and growth in land ice volume. At the same time, multiple independent proxies for ocean temperature indicate sea surface cooling, and major changes in global fauna and flora record a shift toward more cold-climateadapted species. The two principal suggested explanations of this transition are a decline in atmospheric $\mathrm{CO}_{2}$ and changes to ocean gateways, while orbital forcing likely influenced the precise timing of the glaciation. Here we review and syn-
\end{abstract}

thesise proxy evidence of palaeogeography, temperature, ice sheets, ocean circulation and $\mathrm{CO}_{2}$ change from the marine and terrestrial realms. Furthermore, we quantitatively compare proxy records of change to an ensemble of climate model simulations of temperature change across the EOT. The simulations compare three forcing mechanisms across the EOT: $\mathrm{CO}_{2}$ decrease, palaeogeographic changes and ice sheet growth. Our model ensemble results demonstrate the need for a global cooling mechanism beyond the imposition of an ice sheet or palaeogeographic changes. We find that $\mathrm{CO}_{2}$ forcing involving a large decrease in $\mathrm{CO}_{2}$ of ca. $40 \%$ ( $\sim 325 \mathrm{ppm}$ drop) provides the best fit to the available proxy evidence, with ice sheet and palaeogeographic changes playing a secondary role. While this large decrease is consistent 
with some $\mathrm{CO}_{2}$ proxy records (the extreme endmember of decrease), the positive feedback mechanisms on ice growth are so strong that a modest $\mathrm{CO}_{2}$ decrease beyond a critical threshold for ice sheet initiation is well capable of triggering rapid ice sheet growth. Thus, the amplitude of $\mathrm{CO}_{2}$ decrease signalled by our data-model comparison should be considered an upper estimate and perhaps artificially large, not least because the current generation of climate models do not include dynamic ice sheets and in some cases may be undersensitive to $\mathrm{CO}_{2}$ forcing. The model ensemble also cannot exclude the possibility that palaeogeographic changes could have triggered a reduction in $\mathrm{CO}_{2}$.

\section{Introduction}

\subsection{Scope of review}

Since the last major review of the Eocene-Oligocene transition (EOT; Coxall and Pearson, 2007) the fields of palaeoceanography and palaeoclimatology have advanced considerably. New proxy techniques, drilling and field archives of Cenozoic (66 Ma to present) climates, have expanded global coverage and added increasingly detailed views of past climate patterns, forcings and feedbacks. From a broad perspective, statistical interrogation of an astronomically dated, continuous composite of benthic foraminifera isotope records confirms that the EOT is the most prominent climate transition of the whole Cenozoic and suggests that the polar ice sheets that ensued seem to play a critical role in determining the predictability of Earth's climatological response to astronomical forcing (Westerhold et al., 2020). New proxy records capture near- and far-field signals of the onset of Antarctic glaciation. Meanwhile, efforts to simulate the onset of the Cenozoic "icehouse", using the latest and most sophisticated climate models, have also progressed. Here we review both observations and the results of modelling experiments of the EOT. From the marine realm, we review records of sea surface temperature, as well as deep-sea time series of the temperature and land ice proxy $\delta^{18} \mathrm{O}$ and carbon cycle proxy $\delta^{13} \mathrm{C}$. From the terrestrial realm we cover plant records and biogeochemical proxies of temperature, $\mathrm{CO}_{2}$ and vegetation change. We summarise the main evidence of temperature, glaciation and carbon cycle perturbations and constraints on the terrestrial ice extent during the EOT, and review indicators of ocean circulation change and deep-water formation, including how these changes reconcile with palaeogeography, in particular, ocean gateway effects.

Finally, we synthesise existing model experiments that test three major proposed mechanisms driving the EOT: (i) palaeogeography changes, (ii) greenhouse forcing and (iii) ice sheet forcing upon climate. We highlight what has been achieved from these modelling studies to illuminate each of these mechanisms and explain various aspects of the observations. We also discuss the limitations of these ap- proaches and highlight areas for future work. We then combine and synthesise the observational and modelling aspects of the literature in a model-data intercomparison of the available models of the EOT. This approach allows us to assess the relative effectiveness of the three modelled mechanisms in explaining the EOT observations.

The paper is structured as follows: Sect. 1.2 defines the chronology of events around the EOT and clarifies the terminology of associated events, transitions and intervals, thereby setting the framework for the rest of the review. Section 2 reviews our understanding of palaeogeographic change across the EOT and discusses proxy evidence for changes in ocean circulation and ice sheets. Section 3 synthesises marine proxy evidence for sea surface temperatures (SSTs) and deep-ocean temperature change. Section 4 synthesises terrestrial proxy evidence for continental temperature change, with a focus on pollen-based reconstructions. Section 5 presents estimates of $\mathrm{CO}_{2}$ forcing across the EOT, from geochemical and stomatal-based proxies. Section 6 qualitatively reviews previous modelling work, and Sect. 7 provides a new quantitative intercomparison of previous modelling studies, with a focus on model-data comparisons to elucidate the relative importance of different forcings across the EOT. Section 8 provides a brief conclusion.

\subsection{Terminology of the Eocene-Oligocene transition}

Palaeontological evidence has long established Eocene (56 to $34 \mathrm{Ma}$ ) warmth in comparison to a long-term Cenozoic cooling trend (Lyell and Deshayes, 1830, p. 99-100). As modern stratigraphic records improved, a prominent step in that cooling towards the end of the Eocene began to be resolved. This became evident in early oxygen isotope records $\left(\delta^{18} \mathrm{O}\right)$ derived from deep-sea benthic foraminifera, which show an isotope shift towards higher $\delta^{18} \mathrm{O}$ values (Kennett and Shackleton, 1976; Shackleton and Kennett, 1975), which was subsequently attributed to a combination of continental ice growth and cooling (Lear et al., 2008). In the 1980s the search was on for a suitable global stratotype section and point (GSSP) to define the Eocene-Oligocene boundary (EOB). Much of the evidence was brought together in an important synthesis edited by Pomerol and Premoli Silva (1986). The GSSP was eventually fixed at the Massignano outcrop section in the Marche region of Italy in 1992 (Premoli Silva and Jenkins, 1993) at the $19.0 \mathrm{~m}$ mark which corresponds to the extinction of the planktonic foraminifer family Hantkeninidae (Coccione, 1988; Nocchi et al., 1986). By the conventions of stratigraphy, Massignano is the only place where the EOB is defined unambiguously; everywhere else the EOB must be correlated to it, whether by biostratigraphy, magnetostratigraphy, isotope stratigraphy or other methods.

Coxall and Pearson (2007, p. 352) described the EOT as "a phase of accelerated climatic and biotic change lasting $500 \mathrm{kyr}$ that began before and ended after the E/O boundary". Recognising and applying this in practice turns out 


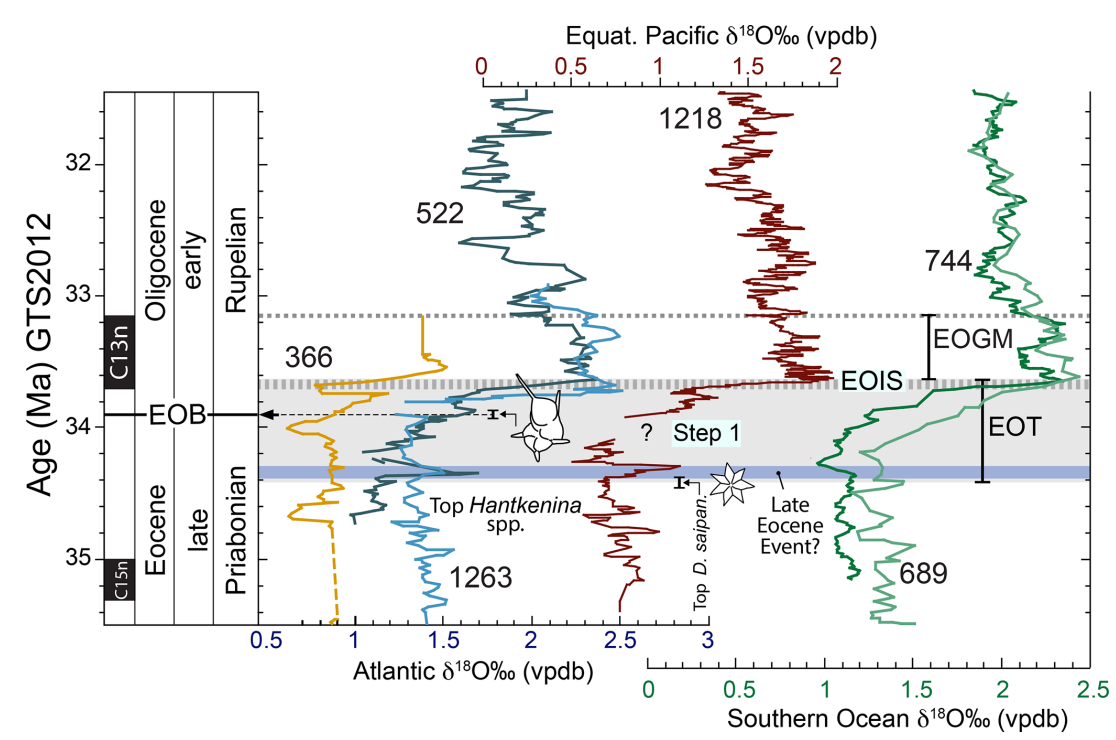

Figure 1. Oxygen stable isotope and chronostratigraphic characteristics of the Eocene-Oligocene transition (EOT) from deep marine records and EOT terminology on the GTS2012 timescale. Benthic foraminiferal $\delta^{18} \mathrm{O}$ from six deep-sea drill holes are shown: tropical Atlantic Site 366, South Atlantic sites 522 and 1263 (Zachos et al., 1996; Langton et al., 2016); Southern Ocean sites 744 and 689 (Zachos et al., 1996 ; Diester-Haass and Zahn, 1996) and equatorial Pacific Site 1218 (Coxall and Wilson 2011). Due to different sample resolutions, running means are applied using a three-point filter for sites 522, 689 and 1263; five-point filter for sites 366 and 744; and a seven-point filter for Site 1218. Timescale conversions were made by aligning common magnetostratigraphic tie points. The EOT is defined as a ca. $790 \mathrm{kyr}$ long phase of accelerated climatic and biotic change that began before and ended after the Eocene-Oligocene boundary (EOB) (after Coxall and Pearson, 2007). It is bounded at the base by the "top" D. saipanensis nannofossil extinction event and above by the EOIS- $\delta{ }^{18} \mathrm{O}$ maximum. Benthic data are all Cibicidoides spp. or "Cibs. equivalent" and have not been adjusted to seawater equilibrium values. "Step 1" comprises a modest $\delta^{18} \mathrm{O}$ increase linked to ocean cooling (Lear et al., 2008; Bohaty et al., 2012). The "top Hantkenina spp." marker corresponds to the position of this extinction event at DSDP Site 522 (including sampling bracket) with respect to the corresponding Site $522 \delta^{18} \mathrm{O}$ curve. That it coincides with the published calibrated age of this event ( $33.9 \mathrm{Myr})$ is entirely independent. The "late Eocene event" $\delta{ }^{18} \mathrm{O}$ maximum (after Katz et al., 2008) may represent a failed glaciation.

to be problematic due to variability in the pattern of $\delta^{18} \mathrm{O}$ between records and on different timescales. Widespread records now show the positive $\delta^{18} \mathrm{O}$ shift with increasing detail. A high-resolution record from Ocean Drilling Program (ODP) Site 1218 in the Pacific Ocean revealed two $\delta^{18} \mathrm{O}$ and $\delta^{13} \mathrm{C}$ "steps" separated by a more stable "plateau interval" (Coxall et al., 2005; Coxall and Wilson, 2011). The EOT brackets these isotopic steps with the EOB falling in the plateau between them (Coxall and Pearson, 2007; Coxall and Wilson, 2011; Dunkley Jones et al., 2008; Pearson et al., 2008). However, while two-step $\delta^{18} \mathrm{O}$ patterns have now been interpreted in other deep-sea records, thus far largely from the Southern Hemisphere (Fig. 1) (Bohaty et al., 2012; Borrelli et al., 2014; Coxall and Wilson, 2011; Langton et al., 2016; Pearson et al., 2008; Wade et al., 2012; Zachos et al., 1996), there is often ambiguity in their identification. In particular, while the second $\delta^{18} \mathrm{O}$ step, "Step 2" of Coxall and Pearson (2007), is an abrupt and readily correlated feature, the first step (Step 1 of Pearson et al., 2008; EOT-1 of Katz et al., 2008) is often less prominent than at Site 1218 (Fig. 1). Furthermore, some records have been interpreted to show more than two $\delta^{18} \mathrm{O}$ steps (e.g. Katz et al., 2008). Benthic $\delta^{13} \mathrm{C}$ records provide a powerful complementary strati- graphic tool. These also show a correlatable stepped pattern of increase across the EOT, although in detail $\delta^{18} \mathrm{O}$ and $\delta^{13} \mathrm{C}$ are not synchronous (Coxall et al., 2005; Zachos et al., 1996) and further complications arise in correlation to other sites (Coxall and Wilson, 2011). In attempting to synthesise the pattern across multiple sites, we suggest that attempts to define and correlate an initial "Step 1" are premature at this point and should await better-resolved records. Nonetheless, we maintain a tentative Step 1 in our terminology because it is important for differentiating phases of cooling vs ice growth during the EOT.

Settling on a consistent terminology for other features of the EOT is also problematic because usage of certain terms has changed through time. In order to clarify the definition of two key stratigraphic features, we recommend using the following terms: (i) for the basal Oligocene $\delta^{18} \mathrm{O}$ increase we suggest the term "earliest Oligocene oxygen isotope step" (EOIS) to denote the large isotope step that occurs well after the EOB and within the lower part of chron C13n (Fig. 1); (ii) we suggest the term "early Oligocene glacial maximum" (EOGM; Liu et al., 2004; Fig. 1) to denote the peak-to-peak isotope stratigraphic interval, corresponding to most of chron $\mathrm{C} 13 \mathrm{n}$ (starting at the top of the EOIS). Other terms for these 
Table 1. Summary of Eocene Oligocene terminology and approximate timings of events, as interpreted at the time of writing. Timescales referred to are GTS2012 (Gradstein et al., 2012) and CK95 (Cande and Kent, 1995).

\begin{tabular}{|c|c|c|c|c|c|c|}
\hline Event & Abbr. & Definition & Correlation & Timing & Comment & Also known as \\
\hline $\begin{array}{l}\text { Early } \\
\text { Oligocene } \\
\text { glacial } \\
\text { maximum }\end{array}$ & EOGM & $\begin{array}{l}\text { Period of cold cli- } \\
\text { mate/glaciation in the } \\
\text { early Oligocene cor- } \\
\text { responding to most of } \\
\text { magnetic chron } \mathrm{C} 13 \mathrm{n}\end{array}$ & $\begin{array}{l}\text { Peak-to-peak } \delta^{18} \mathrm{O} \\
\text { stratigraphic interval } \\
\text { starting at the top of } \\
\text { the EOIS \& extending } \\
\text { to another peak around } \\
\text { the top of } \mathrm{C} 13 \mathrm{n}\end{array}$ & $\begin{array}{l}33.65 \text { to } \sim 33.16 \mathrm{Ma}, \\
\sim 490 \mathrm{kyr} \text { duration }\end{array}$ & $\begin{array}{l}\text { Defined by Liu et } \\
\text { al. (2004). The end } \\
\text { of the EOGM may } \\
\text { correspond to a } \\
\text { second } \delta^{18} \mathrm{O} \text { peak, } \\
\text { sometimes referred } \\
\text { to as Oi-1b }\end{array}$ & $\begin{array}{l}\text { Oi-1 (Zachos et al., } \\
\text { 1996) including the } \\
\text { separate } \delta^{18} \mathrm{O} \text { maxima } \\
\text { Oi-1a and Oi-1b }\end{array}$ \\
\hline Chron C13n & C13n & $\begin{array}{l}\text { Interval of normal } \\
\text { magnetic polarity in } \\
\text { the early Oligocene } \\
\text { broadly correlative } \\
\text { with the EOGM }\end{array}$ & $\begin{array}{l}\text { Between specific mag- } \\
\text { netic reversals }\end{array}$ & $\begin{array}{l}33.705-33.157 \mathrm{Ma} \\
(\mathrm{GTS} 2012)\end{array}$ & $\begin{array}{l}\text { Very useful for corre- } \\
\text { lation \& dating when } \\
\text { available }\end{array}$ & - \\
\hline $\begin{array}{l}\text { Eocene- } \\
\text { Oligocene } \\
\text { transition }\end{array}$ & EOT & $\begin{array}{l}\text { A phase of acceler- } \\
\text { ated climatic \& biotic } \\
\text { change that began be- } \\
\text { fore and ended after the } \\
\text { EOB }\end{array}$ & $\begin{array}{l}\text { Stratigraphic interval } \\
\text { between the extinction } \\
\text { of Discoaster saipa- } \\
\text { nensis \& the top of the } \\
\text { EOIS }\end{array}$ & $\begin{array}{l}\text { Start: "top" D. saipa- } \\
\text { nensis extinction event; } \\
\text { end: end of EOIS } \delta^{18} \mathrm{O} \\
\text { maximum event; } \\
\text { duration } \sim 790 \mathrm{kyr}\end{array}$ & $\begin{array}{l}\text { Definition revised } \\
\text { here after Coxall and } \\
\text { Pearson (2007) }\end{array}$ & - \\
\hline $\begin{array}{l}\text { Earliest } \\
\text { Oligocene } \\
\text { oxygen } \\
\text { isotope step }\end{array}$ & EOIS & $\begin{array}{l}\text { Short period of rapid } \\
\delta^{18} \mathrm{O} \text { increase }(0.7 \% \text { } \\
\text { or more) that occurred } \\
\text { well after the EOB \& } \\
\text { within the lower part of } \\
\text { chron } \mathrm{C} 13 \mathrm{n}\end{array}$ & $\begin{array}{l}\text { Stratigraphically above } \\
\text { the EOB \& within the } \\
\text { lowermost part of chron } \\
\text { C13n }\end{array}$ & $\begin{array}{l}\text { The peak is at } \\
\sim 33.65 \mathrm{Ma} \\
\text { (GTS2012); } \\
\text { duration } \sim 40 \mathrm{kyr}\end{array}$ & $\begin{array}{l}\text { Herein defined as } \\
\text { the end of the EOT } \\
\text { and the start of the } \\
\text { EOGM }\end{array}$ & $\begin{array}{l}\text { The "Oil event" "... at } \\
\text { the base of Zone Oi1", } \\
\text { Miller et al. (1991); } \\
\text { Oi-1a of Zachos et } \\
\text { al. (1996) }\end{array}$ \\
\hline $\begin{array}{l}\text { Eocene } \\
\text { Oligocene } \\
\text { boundary }\end{array}$ & EOB & $\begin{array}{l}\text { The stratigraphic } \\
\text { boundary between the } \\
\text { Eocene and Oligocene } \\
\text { epochs defined at the } \\
\text { Massignano GSSP }\end{array}$ & $\begin{array}{l}\text { Denoted by the extinc- } \\
\text { tion of the planktonic } \\
\text { foraminifera Hantken- } \\
\text { inain the marine realm }\end{array}$ & $\begin{array}{l}\text { 33.9 Ma (GTS2012), } \\
\text { 33.7 Ma (CK95) }\end{array}$ & - & $\begin{array}{l}\text { Base Oligocene epoch; } \\
\text { base Rupelian stage }\end{array}$ \\
\hline Step 1 & - & $\begin{array}{l}\text { The first-step increase } \\
\text { in } \delta^{18} \mathrm{O} \text { occurring } \\
\text { shortly before the EOB } \\
\text { in some records }\end{array}$ & $\begin{array}{l}\text { Harder to identify \& } \\
\text { correlate than the EOIS }\end{array}$ & $\begin{array}{l}\sim 34.15 \mathrm{Ma} \\
\text { duration } \sim 40 \mathrm{kyr} .\end{array}$ & - & $\begin{array}{l}\text { EOT-1, Katz et } \\
\text { al. (2008); "precur- } \\
\text { sor glaciation", Scher } \\
\text { et al. (2011) }\end{array}$ \\
\hline $\begin{array}{l}\text { Late Eocene } \\
\text { event }\end{array}$ & - & $\begin{array}{l}\text { A transient late Eocene } \\
\text { cool or glacial event } \\
\text { near the start of the } \\
\text { EOT }\end{array}$ & $\begin{array}{l}\text { Transient interval of } \\
\text { positive } \delta^{18} \mathrm{O} \text { seen in } \\
\text { some records }\end{array}$ & $\begin{array}{l}\text { Onset is coincident } \\
\text { (within } 80 \mathrm{kyr} \text { analyt- } \\
\text { ical error; Coxall et } \\
\text { al., 2005) with the } D \text {. } \\
\text { saipanensis extinction } \\
(34.44 \mathrm{Ma}) \text { at Site } 1218\end{array}$ & $\begin{array}{l}\text { Defined by Katz et } \\
\text { al. }(2008) \text {; } \\
\text { defines the start of } \\
\text { the EOT as defined } \\
\text { herein }\end{array}$ & - \\
\hline $\begin{array}{l}\text { Priabonian } \\
\text { oxygen } \\
\text { isotope } \\
\text { maximum }\end{array}$ & PrOM & $\begin{array}{l}\text { A transient late Eocene } \\
\text { cool or glacial event }\end{array}$ & $\begin{array}{l}\text { Transient interval of } \\
\text { positive } \delta^{18} \mathrm{O} \text { seen } \\
\text { in some records well } \\
\text { below the EOT }\end{array}$ & $\begin{array}{l}\sim 37.3 \mathrm{Ma} ; \text { duration } \\
\sim 140 \mathrm{kyr}, \text { tentatively } \\
\text { placed within chron } \\
\text { C17n.1n }\end{array}$ & $\begin{array}{l}\text { Defined by Scher et } \\
\text { al. (2014) }\end{array}$ & - \\
\hline
\end{tabular}

features have been used inconsistently in the literature (Table 1). For example, the term "Oi-1" was originally defined (at DSDP Site 522) by Miller et al. (1991) as an isotope stratigraphic "zone" between one oxygen isotope peak and another, corresponding to a duration of several millions of years. Here there was a distinction between the "Zone Oi-1" and the "Oi-1 event", the latter being equivalent to our EOIS. Subsequent articles variously refer to Oi-1 as an extended isotope zone, the peak $\delta^{18} \mathrm{O}$ value at the base of that zone, an extended phase of high $\delta^{18} \mathrm{O}$ values in the lower Oligocene approximately synonymous with the EOGM, or the "step" that led up to the peak value (see discussion and references in Coxall and Pearson, 2007, p. 352). The terms "Oi-1a" and "Oi-1b”, originally defined by Zachos et al. (1996) as “... two distinct, 100 to $150 \mathrm{kyr}$ long glacial maxima ... separated by an "interglacial"', have also been inconsistently applied in the literature and are now arguably an impediment to clear communication. Due to this ambiguity, we avoid the term "Oi-1" here. Katz et al. (2008) referred to prominent oxygen isotope steps within the EOT as "EOT-1" and "EOT-2", which might seem a convenient nomenclature for the steps referred to here, but, whereas "EOT-1" arguably corresponds to the "Step 1" of Coxall and Pearson (2007), "EOT-2" was a separate feature identified in the St. Stephens Quarry record some 
way below the level identified as "Oi-1" (Katz et al., 2008, p. 330). Hence it is not appropriate to use "EOT-2" to denote the second step. Note, for clarity, the EOIS is not instantaneous and several records show some "intermediate" values; its inferred duration in the records presented here is in the tens of thousands of years (40 kyr at Site 1218; Coxall et al., 2005).

This brings us back to the definition of the "EOT". Based on the stratigraphic record from Tanzania, Dunkley Jones et al. (2008) and Pearson et al. (2008) placed the base of the EOT at the extinction of the tropical warm-water nannofossil Discoaster saipanensis, a reliable bioevent which they regarded as the first sign of biotic extinction associated with the late Eocene cooling. This extinction event has long been used to mark the base of nannofossil Zone NP21 (Martini, 1971) and more recently Zone CNE21 (Agnini et al., 2014). On the timescale used by Dunkley Jones et al. (2008) it was estimated to be $500 \mathrm{kyr}$ before the top of the EOIS. However, a subsequent calibration from ODP Site 1218 (Blaj et al., 2009) placed this event significantly earlier than previously suggested, which is supported by recent work in Java (Jones et al., 2019). In the record from Site 1218 the D. saipanensis extinction is coincident (within $80 \mathrm{kyr}$ analytical error; Coxall et al., 2005) with the base of a significant $\delta^{18} \mathrm{O}$ increase - possibly a "failed" glaciation - that seems to be visible in many of the records (including Tanzania) and has been termed the "late Eocene event" by Katz et al. (2008). It seems desirable to include these biotic and climatic events within the definition of the EOT rather than insist on an arbitrary 500 kyr duration. On the most commonly used current timescale, "Geological Timescale 2012" (GTS2012; Gradstein et al., 2012), the critical levels are calibrated as follows: top of the EOIS at $33.65 \mathrm{Ma}$, base of chron C13n at 33.705 Ma, EOB at 33.9 Ma and extinction of D. saipanensis at $34.44 \mathrm{Ma}$. Hence the stratigraphic interval of the EOT according to our preferred definition is now given an estimated duration of $790 \mathrm{kyr}$ (Fig. 1). This terminology and the alternatives are summarised in Table 1 and illustrated below in Fig. 1.

Combined $\delta^{18} \mathrm{O}$ and trace element investigations (see Sect. 3.2) have led to the suggestion that the $\delta^{18} \mathrm{O}$ increase commonly referred to as Step 1 (Fig. 1) is mostly attributable to ocean cooling, with subordinate ice sheet growth, whereas the more prominent $\delta^{18} \mathrm{O}$ increase at the end of the EOT (i.e. the EOIS in our terminology) largely represents ice growth with a little further cooling (Bohaty et al., 2012; Katz et al., 2008; Lear et al., 2008). Estimates of the combined total sea-level fall across the EOT are of the order of $70 \mathrm{~m}$ (Miller et al., 2008; Wilson et al., 2013), and microfacies and palaeontological records from shelf environments (Houben et al., 2012) are consistent with this generalisation. A recent shallow marine sediment record also indicates the onset of major glaciation at $\sim 33.7 \mathrm{Ma}$ (Gallagher et al., 2020), in agreement with deep-sea records. The EOIS is the sharpest feature in most records, culminating with the highest ben- thic $\delta^{18} \mathrm{O}$ values of the Eocene and Oligocene. It is widely suggested that it signifies the initiation of major sustained Antarctic glaciation, most likely an early East Antarctic Ice Sheet (EAIS) (Bohaty et al., 2012; Coxall et al., 2005; Galeotti et al., 2016; Miller et al., 1987; Shackleton and Kennett, 1975; Zachos et al., 1992). The EOGM is interpreted as an approximately $500 \mathrm{kyr}$ long glacial maximum, with lower values visible in some records (Zachos et al., 1996; Liu et al., 2004) (Fig. 1). Oxygen isotope maxima in the late Eocene imply substantial ephemeral precursor glaciations in the approach to the EOT (Galeotti et al., 2016; Houben et al., 2012; Katz et al., 2008; Scher et al., 2011, 2014). The oldest and most prominent of these hypothesised transient glacial events occurred at $\sim 37.3 \mathrm{Ma}$ (within magnetochron $\mathrm{C} 17 \mathrm{n}$ ) and is referred to as the Priabonian oxygen isotope maximum (PrOM) Event (Scher et al., 2014). The "late Eocene event" of Katz et al. (2008) at $\sim 34.15$ Ma may be regarded as the second, the third being $\delta^{18} \mathrm{O}$ Step 1 at $\sim 34 \mathrm{Ma}$ (the "precursor glaciation" of Scher et al., 2011). Nevertheless, differences between $\delta^{18} \mathrm{O}$ curves from different water depths and ocean regions, combined with increasing detail in individual records afforded by high-resolution sampling, emphasise that the EOT cannot be adequately understood as a series of discrete events because it is clearly imprinted by orbitally paced variability throughout (Coxall et al., 2005).

A detailed discussion of the Hantkenina extinction and associated bioevents at the EOB was provided by Berggren et al. (2018, p. 30-32). The highest stratigraphic occurrence of the planktonic foraminifera family Hantkeninidae denotes the EOB in its type section (Nocchi et al., 1986). This is thought to have involved simultaneous extinction of all five morphospecies and two genera of late Eocene hantkeninids (Coxall and Pearson, 2007) (Fig. 1). Insofar as the principles of biostratigraphy require a particular species to denote a biozone boundary, the commonest species, Hantkenina alabamensis, is used to define the base of Zone O1 (Berggren et al., 2018; Berggren and Pearson, 2005; Wade et al., 2011). The extinction of $H$. alabamensis can be considered the "primary marker" for worldwide correlation of the EOB. It occurs at a slightly higher (later) level than another set of prominent planktonic foraminifer extinctions, namely Turborotalia cerroazulensis and related species. DSDP Site 522 (South Atlantic), thus far, is one of the few deep-sea records to have both a detailed $\delta^{18} \mathrm{O}$ stratigraphy and planktonic foraminifera assemblages that capture these evolutionary events. Here, the Hantkenina extinction horizon occurs approximately twothirds of the way through the EOT (Fig. 1). It occurs at a similar relative position in the hemipelagic EOT sequence in Tanzania (Pearson et al., 2008), also in unpublished data from Indian Ocean ODP Site 757 (Coxall et al., unpublished). This finding implies that the extinction of the hantkeninids was approximately synchronous, although its cause is currently unknown. Existing constraints on the hantkeninid extinction horizon remain rather coarse in terms of sampling resolution compared to many isotopic records, and the matter will ben- 
efit greatly from incoming high-resolution records from Site U1411, which boasts both excellent (glassy) preservation and orbital level sampling.

Dating and correlation of non-marine records, which usually lack $\delta^{18} \mathrm{O}$ stratigraphy, is more challenging, and there are far fewer well-dated records on land. Here a strict concept of the EOT is difficult to apply and relies on correlations using other stratigraphic approaches, including magnetostratigraphy and palynomorph or mammal tooth biostratigraphy, which have been cross-calibrated in a few marine and marginal-marine sections (Abels et al., 2011; Dupont-Nivet et al., 2007, 2008; Hooker et al., 2004). Central Asian sections are the exception, where even the step features of the EOT can be identified using magneto-, bio- and cyclostratigraphy (Xiao et al., 2010). Moreover, combined $\delta^{18} \mathrm{O}$ and clumped isotope analyses on freshwater gastropod shells from a terrestrial EOT section in the south of England have permitted the first direct correlation of marine and nonmarine realms and identified coupling between cooling and hydrological changes in the terrestrial realm (Sheldon et al., 2016). This finding suggests a close timing and causal relation between the earliest Oligocene glaciation and a major Eurasian mammalian turnover event called the "Grande Coupure" (Hooker et al., 2004; Sheldon et al., 2016). During the Grand Coupure, many endemic European mammal species became extinct and were replaced by Asian immigrant species. These changes have been attributed to a combination of climate-driven extinction and species dispersal due to the closing of Turgai Strait, which provided a greater connection between Europe and Asia (Akhmetiev and Beniamovski, 2009; Costa et al., 2011; Hooker et al., 2004).

In shallow-water carbonate successions, the EOB has traditionally been approximated by the prominent extinctions of a series of long-ranging larger benthic foraminifers (LBFs), often called orthophragminids (corresponding to the families Discocylinidae and Asterocyclinidae; Adams et al., 1986). The general expectation was that these extinctions likely occurred at the time of maximum ice growth and sea-level regression - in our terminology the EOIS. However evidence from Tanzania (Cotton and Pearson, 2011) and Indonesia (Cotton et al., 2014) suggest that the extinctions occurred within the EOT. In Tanzania the extinctions occur quite precisely at the level of the EOB, hinting that the EOB itself may have had a global cause affecting different environments, possibly independent of the events that caused the isotope increases (Cotton and Pearson, 2011).

The definition of the EOT used here excludes the longterm Eocene cooling trend. That trend began in the Ypresian (early Eocene) and continued through much of the Lutetian and Bartonian (middle Eocene, albeit interrupted by the middle Eocene climatic optimum (MECO); Bohaty and Zachos 2003) and Priabonian (late Eocene; Cramwinckel et al., 2018; Inglis et al., 2015; Liu et al., 2018; Śliwińska et al., 2019; Zachos et al., 2001). In particular, prominent extinctions in various marine groups occurred around the begin- ning of the Priabonian (late Eocene), possibly connected with global cooling (e.g. Wade and Pearson, 2008; note that the base of the Priabonian has recently been defined in the Alano section in Italy; Agnini et al., 2020). These data are excluded by our definition from the EOT but may be part of the same general long-term pattern. In some stratigraphic records, especially terrestrial ones, it may not be easy to distinguish these longer-term events from the EOT.

\section{Proxy evidence for palaeogeography, ocean circulation and terrestrial ice evolution}

Here we discuss proxy evidence for the global palaeogeography of the EOT (Sect. 2.1), including the state and evolution of ocean gateways (Sect. 2.2), and proxy evidence for ocean circulation (Sect. 2.3) and Antarctic glaciation (Sect. 2.4). We then briefly discuss the timing of the Northern Hemisphere glaciation (Sect. 2.5).

\subsection{Tectonic reconstruction}

The tectonic evolution of the southern continents, opening a pathway for the Antarctic Circumpolar Current (ACC), has long been linked with long-term Eocene cooling and the EOT (Kennett et al., 1975). However, there remain major challenges in reconstructing the palaeogeography at or around the EOT, requiring a series of methodological steps (Baatsen et al., 2016; Kennett et al., 1975; Markwick, 2007, 2019; Markwick and Valdes, 2004; Müller et al., 2008). The first step is to use modern geography and relocate the continental and ocean plates according to a plate tectonic evolution model, used in software such as GPlates (Boyden et al., 2011). This software uses the interpretation of seafloor spreading and palaeomagnetic data to reconstruct relative plate motion (e.g. Scotese et al., 1988) and an absolute reference frame to position the plates relative to the Earth's mantle (e.g. Dupont-Nivet et al., 2008). Currently, there are two such absolute reference frames: one based on a global network of volcanic hot spots (Seton et al., 2012) and one based on a palaeomagnetic reference frame (van Hinsbergen et al., 2015; Torsvik et al., 2012). Importantly, these two reference frames give virtually the same continental outlines, but the orientation of the continents is shifted. This results in differences in continental positions between the reference frames of up to $5-6^{\circ}$ (Baatsen et al., 2016) around the EOT, creating an uncertainty in reconstructing palaeogeography, especially in southern latitudes between 40 and $70^{\circ} \mathrm{S}$, where important land and ocean geological archives exist. This latitudinal uncertainty also impacts the reconstruction of Antarctic glaciation, since glacial dynamics are highly sensitive to latitude.

After the plate tectonic reconstruction has been applied, adjustments are needed to capture the age-depth evolution of the seafloor (Crosby et al., 2006) and seafloor sedimentation rate (Müller et al., 2008). Adjusting land topography is more difficult and requires knowledge of palaeo-altimetry, includ- 
ing processes such as plate collision processes, uplift, subsidence and erosion. Several publicly available reconstructions exist for the Eocene; Markwick (2007) reconstructed palaeotopography for the late Eocene (38 Ma), while Sewall et al. (2000) and more recently (Zhang et al., 2011) and Herold et al. (2014) have generated palaeotopographies for the early Eocene ( $~ 55$ to $50 \mathrm{Ma})$. These are based on the hot spot reference frame. Baatsen et al. (2016) have recently created a palaeogeographic reconstruction of the late Eocene using the Palaeomagnetic reference frame. Such efforts to develop realistic palaeogeography for each time slice represent a major undertaking in blending geomorphic evidence with tectonic evolution and thus include many specific details that are beyond the scope of this review.

Recently, a stage-by-stage palaeogeographic reconstruction of the entire Phanerozoic has been made publicly available in digital format (Scotese and Wright, 2018). This includes snapshots of the Priabonian (35.9 Ma) and Rupelian (31 Ma). Another stage-by-stage reconstruction of Cenozoic palaeogeography evolution originates from Markwick (2007); this reconstruction has been incorporated into a modelling study of climate dependence on palaeogeography (Farnsworth et al., 2019; Lunt et al., 2016), and palaeogeography changes across the EOT (Kennedy et al., 2015). However, the most recent versions of the (Markwick, 2007) palaeogeography reconstructions are proprietary and are thus not included in this paper. Therefore, we present a summary of late Eocene (38 Ma) palaeogeography in Fig. 2 from the publicly available datasets of Baatsen et al. (2016) and Scotese and Wright (2018). Our aim here is not to evaluate these reconstructions, but to present them such that their differences can be taken as broadly indicative of the uncertainties in palaeogeography at this time.

The reconstructions contain several notable regions of uncertainty which we briefly mention. They include (i) the Tibetan Plateau and the Indian subcontinent, where there are clear disagreements between the reconstructions, (ii) the Turgai Strait and Tethys region, which has far greater shallow marine shelf regions in the Baatsen et al. (2016) reconstruction, (iii) the Fram Strait, which is arguably closed by the Eocene-Oligocene transition but is open in both reconstructions (Lasabuda et al., 2018), and (iv) the Rocky Mountains and North American continent exhibit key differences in elevation and coastlines, which has implications for EoceneOligocene climate evolution (Chamberlain et al., 2012). A full review of these uncertainties is beyond the scope of this paper, however we briefly discuss some impacts of these palaeogeography uncertainties on terrestrial temperature reconstructions in Sect. 4, while we discuss the impacts on ocean circulation in Sect. 2.2 and 2.3.

\subsection{Southern Ocean gateways}

A long-held hypothesis on the cause of the EOT glaciation is that Antarctica cooled because of tectonic opening of South- ern Ocean gateways (Barker and Burrell, 1977; Kennett, 1977). This mechanism suggests that the onset of the ACC reorganised ocean currents from a configuration of subpolar gyres with strong meridional heat transport to predominantly zonal flow, thereby causing thermal isolation of Antarctica (Barker and Thomas, 2004). The hypothesis is supported by foraminiferal isotopic evidence from deep-sea drill cores in the Southern Ocean, which indicate a shift from warm to cold currents (Exon et al., 2004). As such, there has been considerable effort to reconstruct the tectonic history of the Southern Ocean gateways.

The Drake Passage opening has been dated to around $50 \mathrm{Ma}$ (Livermore et al., 2007) or even earlier (Markwick, 2007); however it was likely shallow and narrow at this time. The timing of the transition to a wide and deep gateway, potentially capable of sustaining a vigorous ACC, occurred on a timescale of tens of millions of years. Even with substantial widening of Drake Passage, several intervening ridges in the region are likely to have blocked the deep circumpolar flow (Eagles et al., 2005). These barriers may not have cleared until the Miocene at around 22 Ma (Barker and Thomas, 2004; Dalziel et al., 2013). The evolution of the Tasman Gateway is better constrained. Geophysical reconstructions of continent-ocean boundaries (Williams et al., 2011) place the opening of a deep (greater than $\sim 500 \mathrm{~m}$ ) Tasman Gateway at $33.5 \pm 1.5 \mathrm{Ma}$ (Scher et al., 2015; Stickley et al., 2004). Marine microfossil records suggest the circumpolar flow was initially westward (Bijl et al., 2013). Multiproxy-based evidence from ODP Leg 189 suggests that the opening of the Tasman Gateway significantly preceded Antarctic glaciation and might therefore not have been its primary cause (Huber et al., 2004; Stickley et al., 2004; Wei, 2004). The results also indicate that the gateway deepening at the EOT initially produced an eastward flow of warm surface waters into the southwestern Pacific, not of cold surface waters as previously assumed. Subsequently, the Tasman Gateway steadily opened during the Oligocene, hypothesised to cross a threshold when the northern margin of the ACC aligned with the westerly winds (Scher et al., 2015), triggering the onset of an eastward-flowing ACC at around $30 \mathrm{Ma}$. However, the westerly winds can also shift position due to changes in orographic barriers or an increase in the meridional temperature gradient after glaciation. Thus, the opening of Southern Ocean gateways approximately coincides with the EOT, but with large uncertainty on the timing and implications. We discuss modelling of this mechanism in Sect. 6.1.

\subsection{Meridional overturning circulation}

Throughout much of the Eocene, deep-water formation is suggested to have occurred dominantly in the Southern Ocean and the North Pacific (Ferreira et al., 2018), based on numerical modelling and supported by stable and radiogenic isotope work (Cramer et al., 2009; McKinley et al., 2019; Thomas et al., 2014). Compilations of $\delta^{18} \mathrm{O}$ and 
(a) 36 Ma Scotese and Wright (2018) Geography
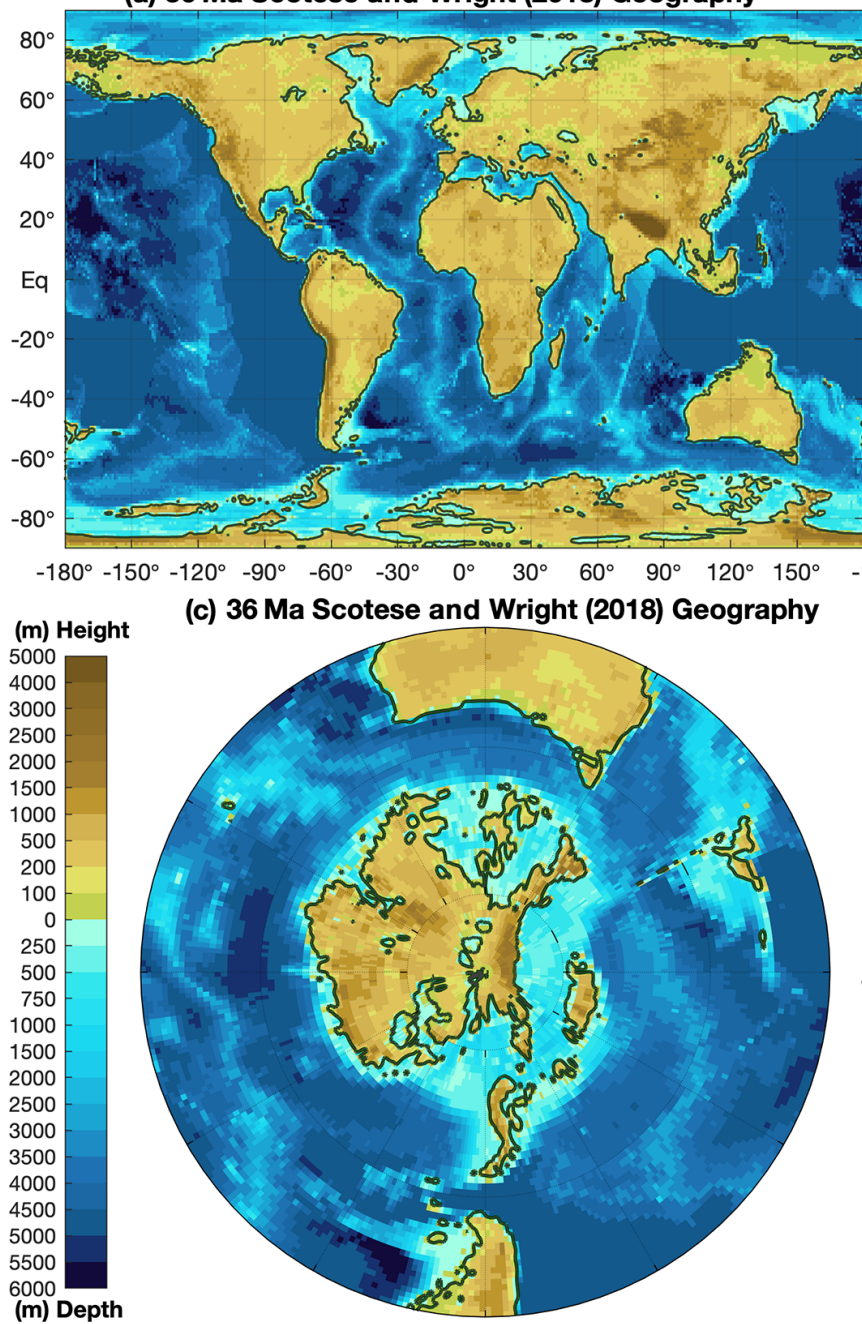

(c) $36 \mathrm{Ma}$ Scotese and Wright (2018) Geography

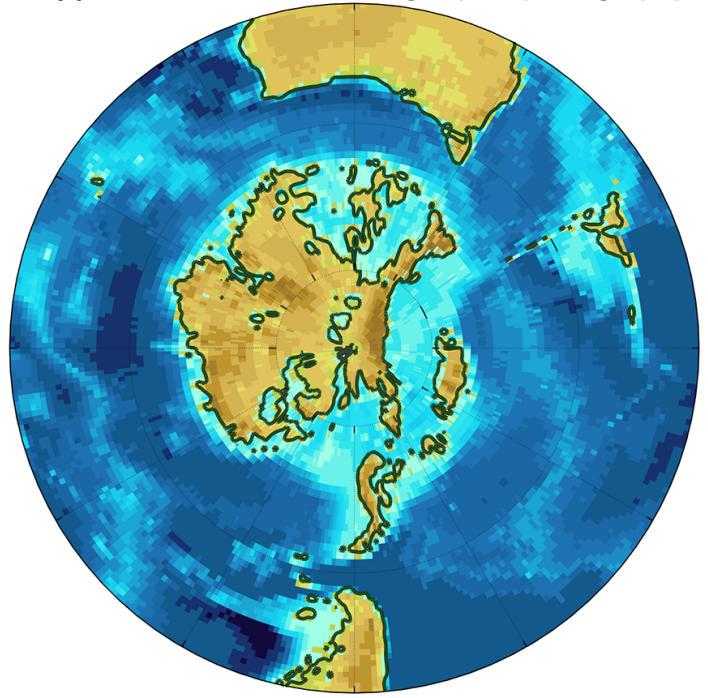

(b) 38 Ma Baatsen (2016) Geography

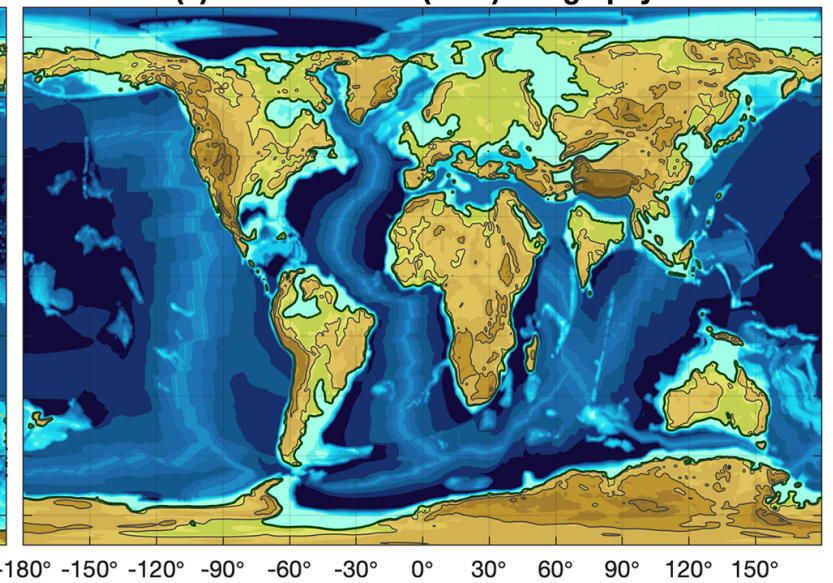

(d) $38 \mathrm{Ma}$ Baatsen (2016) Geography

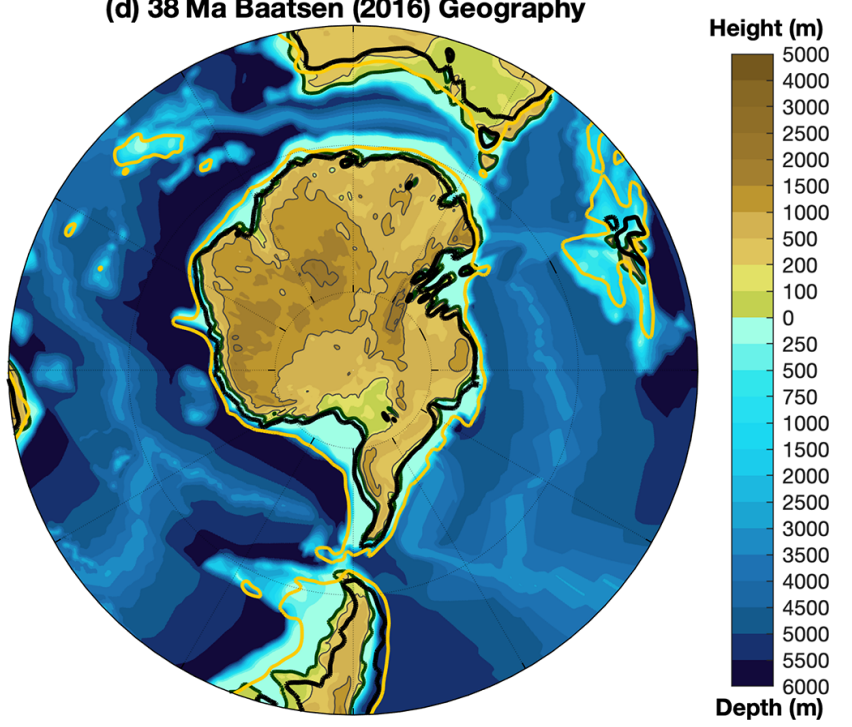

Figure 2. Palaeogeography in the late Eocene showing two alternative reconstructions. Panels (a) and (c) use the hot spot reference frame, using the Scotese and Wright (2018) palaeogeography at $36 \mathrm{Ma}$, while panels (b) and (d) use the palaeomagnetic reference frame showing the reconstruction of Baatsen et al. (2016) at $38 \mathrm{Ma}$. These two reconstructions use different methodologies and are presented as broadly indicative of the uncertainties in palaeogeography at this time. Also shown in panel (d) are post-EOT coastlines at 30 Ma (black contours) and $1000 \mathrm{~m}$ depth (orange contours), which illustrate the widening of the Southern Ocean gateways during the 8 Myr interval around the EOT.

$\delta^{13} \mathrm{C}$ throughout the Atlantic Basin suggest that the Atlantic meridional overturning circulation (AMOC) either started up or strengthened at the EOT (Borrelli et al., 2014; Coxall et al., 2018; Katz et al., 2011). This view of the AMOC expansion is supported by a decrease in South Atlantic $\varepsilon_{\mathrm{Nd}}$ around the EOT (Via and Thomas, 2006). Significant seafloor spreading was occurring in the Southern Hemisphere, such that these changes in ocean circulation have previously been explained by the opening of Southern Ocean gateways (Borrelli et al., 2014). However, studies of deep-sea sediment drifts suggest that some kind of North Atlantic overturning operated from the middle Eocene (Boyle et al., 2017; Hohbein et al., 2012). This earlier onset is supported by climate modelling that suggested that AMOC fluctuations in the middle
Eocene are linked to obliquity forcing cycles (Vahlenkamp et al., 2018a, b). Moreover, interactions between the Arctic and Atlantic oceans are gaining interest as potential triggers of a late Eocene proto-AMOC (Hutchinson et al., 2019). Data from the Labrador Sea and western North Atlantic margin indicate that North Atlantic waters became saltier and denser from 37 to $33 \mathrm{Ma}$ (Coxall et al., 2018). This densification may then have strengthened or even triggered an AMOC, suggesting a possible forcing mechanism for Antarctic cooling that predates the EOT and Southern Ocean gateway openings.

Proxy records suggest that the Arctic Ocean was much fresher during the Eocene than the present day, with typical surface salinities around 20-25 psu and periodic excursions 
to very low salinity conditions $(<10 \mathrm{psu})$ (Brinkhuis et al., 2006; Kim et al., 2014; Waddell and Moore, 2008). Outflow of this fresh surface water into the North Atlantic can potentially prohibit deep-water formation (Baatsen et al., 2020; Hutchinson et al., 2018). A new line of evidence suggests that deepening of the Greenland-Scotland Ridge around the EOT may have enabled North Atlantic surface waters to become saltier (Abelson and Erez, 2017; Stärz et al., 2017), by allowing a deeper exchange between the basins. A related hypothesis derived from sea-level and palaeo-shoreline estimates in the Nordic seas is that the Arctic likely became isolated during the Oligocene (Hegewald and Jokat, 2013; O'Regan et al., 2011). Thus a gradual constriction of the connection between the Arctic and Atlantic presents a newly hypothesised priming mechanism for establishment of a well-developed AMOC (Coxall et al., 2018; Hutchinson et al., 2019).

\subsection{Antarctic glaciation}

Although transient glacial events on Antarctica are proposed for the late Eocene, the most significant long-term glaciations likely began on East Antarctica in the Gamburtsev Mountains and other highlands (Young et al., 2011) as a result of rapid global cooling in the early Oligocene around 33.7 Ma (EOGM, Fig. 1). Evidence for glacial discharge into open ocean basins in the earliest Oligocene is long established, with ice-rafted debris appearing in deep-sea Southern Ocean sediment cores (Zachos et al., 1992). Since these initial results, efforts have continued to document and understand early Cenozoic Antarctic ice dynamics (Barker et al., 2007; Francis et al., 2008; McKay et al., 2016). Combining perspectives from marine geology, geophysics, geochemical proxies and modelling, these efforts have largely focused on the evolution and stability of the early Oligocene Antarctic ice sheets and estimates of ice volume contributions to sea-level change. Other important developments in the study of Antarctic ice include modelled thresholds for Antarctic glaciation (DeConto et al., 2008; Gasson et al., 2014) and improved reconstructions of Eocene-Oligocene subglacial bedrock topography (from airborne radar surveys). These bedrock reconstructions are important for reconstructing the nucleation centres of precursor ice sheets (Scher et al., 2011, 2014) and subsequent development of continent-sized ice sheets (Bo et al., 2009; Thomson et al., 2013; Wilson et al., 2013; Wilson and Luyendyk, 2009; Young et al., 2011).

Evidence for glaciation in the Weddell Sea and Ross Sea suggest that there was an increase in physical weathering over West Antarctica around the EOT (Anderson et al., 2011; Ehrmann and Mackensen, 1992; Huang et al., 2014; Olivetti et al., 2015; Scher et al., 2011; Sorlien et al., 2007). However, in the Ross Sea, evidence suggests that an expansion over West Antarctica in Marie Byrd Land occurred after the EOT (Olivetti et al., 2013), while in the Weddell Sea sedimentation rates were still lower than in recent times, suggesting the West Antarctic Ice Sheet was not expanded to modern proportions (Huang et al., 2014). This is consistent with approximations of ice volume based upon oxygen isotopes (Bohaty et al., 2012; Lear et al., 2008) and is supported by the record of relatively diverse vegetation around at least coastal regions of Antarctica through the Oligocene (Francis et al., 2008).

Recent evidence has emerged of transient precursor Antarctic glaciations that occurred in the late Eocene (Carter et al., 2017; Escutia et al., 2011; Passchier et al., 2017; Scher et al., 2014), suggesting a "flickering" transition out of the greenhouse. Importantly, several Southern Ocean sites revealed evidence that Antarctic glaciation induced crustal deformation and gravitational perturbations resulting in local sea-level rise close to the young Antarctic Ice Sheet (Stocchi et al., 2013). Finally, detailed core sedimentary records drilled close to Antarctica in the western Ross Sea invoke a transition from a modestly sized highly dynamic late Eocene-early Oligocene ice sheet, existing from $~ 34$ $32.8 \mathrm{Ma}$, to a more stable continental-scale ice sheet thereafter, which calved at the coastline (Galeotti et al., 2016).

\subsection{Northern Hemisphere glaciation}

While there is clear evidence for Antarctic glaciations at the EOT, the question of contemporaneous Northern Hemisphere glaciation is contentious. The prevailing view is that the Oligocene represented a non-modern-like state with only Antarctica glaciated (Westerhold et al., 2020; Zachos et al., 2001). Glaciation in mountain areas around the globe is suggested to have followed through the Miocene and Pliocene, with evidence for the first significant build-up of ice on Greenland (in the southern highlands) traced to the late Miocene, sometime between 7.5 and $6 \mathrm{Ma}$ (Bierman et al., 2016; Larsen et al., 1994; Maslin et al., 1998; Pérez et al., 2018) or as early as $11 \mathrm{Ma}$ (Helland and Holmes, 1997). Northern Hemisphere glaciation intensified during the late Pliocene $(\sim 2.7 \mathrm{Ma})$, when large terrestrial glaciers began rhythmically advancing and retreating across North America, Greenland and Eurasia (Bailey et al., 2013; Ehlers and Gibbard, 2007; Lunt et al., 2008; Maslin et al., 1998; Raymo, 1994; De Schepper et al., 2014; Shackleton et al., 1984). It is important to note that a delay in Northern Hemisphere glaciation relative to Antarctica is predicted by climate models the stabilising effect of the hysteresis in the height-mass balance feedback becomes weaker with greater distance from the poles (Pollard and DeConto, 2005), because with decreasing latitude summers become warmer for a given radiative forcing (DeConto et al., 2008).

Nevertheless, a series of studies (Tripati et al., 2005, 2008; Tripati and Darby, 2018) argue that bipolar glaciation was triggered in the Eocene and/or Oligocene. This suggestion is based on two lines of evidence from the sedimentary record: (i) estimates of global seawater $\delta^{18} \mathrm{O}$ values (Tripati et al., 2005) and (ii) identification of ice-transported sediment grains inferred to have originated from Greenland in 
both interior Arctic Ocean and subarctic Atlantic sediment cores associated with the EOT (Eldrett et al., 2007), or earlier (middle Eocene) (St. John, 2008; Tripati and Darby, 2018; Tripati et al., 2008). Certainly, several lines of evidence provide support for winter sea ice in the Arctic from the middle Eocene (Darby, 2014; St. John, 2008; Stickley et al., 2009) and perennial sea ice from $13 \mathrm{Ma}$ (Krylov et al., 2008). It is possible that small mountain glaciers on east Greenland, perhaps comparable to the modern Franz Josef and Fox glaciers of New Zealand (which extend from the Southern Alps through lush rain forest), reached sea level during cooler orbital phases of the Eocene, intensifying in the late Eocene and early Oligocene (Eldrett et al., 2007). Yet the results of a recent detailed analysis of expanded EOT sections from the North Atlantic's modern-day "Iceberg Alley" on the Newfoundland margin are inconsistent with the presence of extensive ice sheets on southern and western Greenland and the northeastern Canadian Arctic, contradicting the suggestion of extensive early Northern Hemisphere glaciation in favour of a unipolar icehouse climate state at the EOT (Spray et al., 2019). Furthermore, it is unlikely that ice growth on land in the Northern Hemisphere was sufficiently extensive to impact global seawater $\delta^{18} \mathrm{O}$ budgets or sea level at the EOT (Coxall et al., 2005; Lear et al., 2008; Mudelsee et al., 2014). Marine SSTs and floral records from the subarctic and Arctic imply sustained warm temperatures and extensive lowland temperate vegetation well into the middle Miocene (O'Regan et al., 2011), which are not readily reconciled with large continental ice sheets fringing Greenland and other Arctic landmasses then or before this time.

From a theoretical perspective, climate and ice sheet modelling suggest that the $\mathrm{CO}_{2}$ threshold for Northern Hemisphere ice sheet inception is fundamentally lower than for Antarctica (DeConto et al., 2008; Gasson et al., 2014), implying that the climate must be cooler to glaciate Greenland than Antarctica. This is also consistent with evidence that the modern Greenland Ice Sheet is highly sensitive to climatic warming and that Greenland may have been almost ice-free for extended periods even in the Pleistocene (Schaefer et al., 2016). This asymmetry between the Northern and Southern hemispheres in susceptibility to glaciation has been attributed to (i) the lower latitudes of the continents encircling the Arctic Ocean relative to the Antarctic, together with different ocean and atmospheric circulation patterns (DeConto et al., 2008; Gasson et al., 2012), and (ii) the ice sheet carrying capacity of the continents; it has been argued that Greenland topography was low during the Palaeogene compared to Antarctica, and extensive mountain building, providing highaltitude terrain needed for glaciation, did not occur until the late Miocene-Pliocene (Gasson et al., 2012; Japsen et al., 2006; Solgaard et al., 2013).

But even on the question of Greenland topography there is uncertainty. Reconstructions of plate kinematics in suspected ice sheet nucleation sites (e.g. northern Greenland, Ellesmere Island) are equivocal. Recent work on the plate kinematic history of the Eurekan orogeny, taking into account crustal shortening (Gurnis et al., 2018), indicates a period of significant compression in northern Greenland and Ellesmere from 55 to $35 \mathrm{Ma}$ (Gion et al., 2017) that was probably associated with uplift (Piepjohn et al., 2016). These latest tectonic insights are compatible with insights from apatite fission track and helium data that support the onset of a rapid phase of exhumation of the east Greenland margin around $30 \pm 5 \mathrm{Ma}$ (Bernard et al., 2016; Japsen et al., 2015). Together, these approaches support a view of high mountains on Greenland and Ellesmere that began eroding in the late Eocene to early Oligocene with a greater possibility of supporting glaciers.

\section{Marine observations}

\subsection{Sea surface temperature observations}

A key requirement for understanding the cause and consequences of the Eocene-Oligocene climatic transition is good spatial and temporal constraints on global temperatures, and our most numerous and well-resolved records of this undoubtedly come from the oceans. Quantitative reconstruction of sea surface and deep-ocean temperatures has been ongoing for decades. This requires use of various geochemical proxies, both to provide independent support for absolute temperature estimates and because different proxy options are available for different ocean and sedimentary settings, and deep-sea versus surface ocean water masses. Each method has its own limitations and uncertainties, resulting in a currently patchy but steadily improving view of global change. Quantitative assemblage-based SST proxies akin to transfer functions are not available because there are no living plankton relatives of those from the EOT. For a thorough review of pre-Quaternary marine SST proxies, and their strengths and weaknesses, see Hollis et al. (2019).

While SST is more heterogeneous than the deep sea, reconstruction of it in the EOT is in some ways currently more achievable than bottom water temperatures because more proxies are available, although there are still multiple confounding factors to consider. Classical marine $\delta^{18} \mathrm{O}$ palaeothermometry extracted from the calcium carbonate shells of fossil planktonic (surface-floating) foraminifera is especially complicated because of the combining influences of (i) compromised fossil preservation under the shallow late Eocene ocean calcite compensation depth, limiting the availability of planktonic records, and (ii) increasing $\delta^{18} \mathrm{O}$ of seawater as a consequence of ice sheet expansion, which enriches ocean water and thus increases calcite $\delta^{18} \mathrm{O}$ - a signal which can otherwise indicate cooling. However, a growing number of clay-rich hemipelagic marine sequences containing exceptionally well-preserved (glassy) fossil material are yielding $\delta^{18} \mathrm{O}$ palaeotemperatures that provide useful SST perspectives. $\delta^{18} \mathrm{O}$ SSTs derived from glassy foraminifera (Haiblen et al., 2019; Norris and Wilson, 1998; Pearson et al., 2001; Wilson et al., 2002; Wilson and Norris, 2001) contrast 
greatly from those measured on recrystalised "frosty" material (Sexton et al., 2006). A detailed compilation of glassy versus recrystalised foraminiferal $\delta^{18} \mathrm{O}$ proxies around the EOT is given in Piga (2020).

Planktonic foraminifera $\mathrm{Mg}$ / Ca palaeothermometry provides another means of quantifying SSTs (Evans et al., 2016; Lear et al., 2008); however such records are even more sparse than $\delta^{18} \mathrm{O}$ equivalents due to the scarcity of appropriate EOT fossils. This method is especially useful since, in theory, unlike $\delta^{18} \mathrm{O}$ it should be independent of Antarctic glaciation and, when coupled with $\delta^{18} \mathrm{O}$ palaeothermometry, past variations in the $\delta^{18} \mathrm{O}$ composition of seawater, and thus ice volume changes may also be estimated (Lear et al., 2004, 2008; Mudelsee et al., 2014). The two key existing records are from Tanzania (Lear et al., 2008) and the Gulf of Mexico (Evans et al., 2016; Wade et al., 2012). The Tanzanian planktonic $\mathrm{Mg} / \mathrm{Ca}$ record provides cornerstone evidence for a permanent $2.5^{\circ} \mathrm{C}$ tropical surface and bottom water cooling, and therefore likely global cooling, associated with the Step 1 of the EOT (Fig. 1). The Gulf of Mexico Mg / Ca temperature record resembles the biomarker-derived (i.e. TEX 86 ; see below) SST record from this site (Wade et al., 2012). Both imply a distinct and slightly larger surface cooling of $3-4{ }^{\circ} \mathrm{C}$ limited to Step 1. To what extent secular change in seawater $\mathrm{Mg} / \mathrm{Ca}$ reconstruction might have influenced these actual numbers is an ongoing question (Evans et al., 2018). Clumped isotope palaeothermometry (Ghosh et al., 2006; Zaarur et al., 2013), also independent of seawater $\delta^{18} \mathrm{O}$, is still in its infancy, but this is a third method applicable to calcareous microfossils that will help address some of these problems. Thus far only one clumped isotope $\left(\Delta_{47}\right)$ record from Maud Rise spans the EOT (Petersen and Schrag, 2015). This record shows cooling preceding the EOT, and then relatively minor changes across the EOT. Early to middle Eocene clumped isotope SST records are consistent with other proxies, specifically cooler values at high southern latitudes compared to the early and middle Eocene (Evans et al., 2018). Many new SST records based on $\mathrm{Mg} / \mathrm{Ca}$ and $\Delta_{47}$ are expected in coming years.

In some regions, Eocene-Oligocene age sediments lack biogenic calcium carbonates (e.g. Bijl et al., 2009). Therefore low- and non-calcareous areas, like the Arctic and highlatitudes of the North Atlantic and North Pacific, have suffered for lack of palaeotemperature data. However, the development of independent organic proxies based on biomarkers such as alkenones ( $U_{37}^{K^{\prime}}$ index; Brassell et al., 1986) and glycerol dialkyl glycerol tetraethers (GDGTs) from the membrane lipids of Thaumarchaeota TEX $_{86}$ index; Schouten et al., 2002), which can be preserved in high-sedimentation settings close to continental margins or restricted basins where carbonate is often scarce, has helped fill this gap. Importantly, these organic biomarkers are often the only marine archive for palaeothermometry at high latitudes, where SST constraints are particularly useful for model-data comparisons.
While the $U_{37}^{K^{\prime}}$ index is well established, the TEX 86 index is relatively new and its accuracy as a palaeotemperature proxy is under critical review. There have been several different TEX $\mathrm{T}_{86}$ indices developed, with different SST calibrations (e.g. TEX ${ }_{86}^{\prime}$ by Sluijs et al., 2009; $\mathrm{TEX}_{86}^{H}$ and $\mathrm{TEX}_{86}^{L}$ by Kim et al., 2010; Bayspar by Tierney and Tingley, 2015). As suggested by some of the recent studies conducted on cultures of Thaumarchaeota, GDGT composition may be sensitive not only to SST but also to other factors such as oxygen $\left(\mathrm{O}_{2}\right)$ concentration (Qin et al., 2015) or ammonia oxidation rate (Hurley et al., 2016). Furthermore, there is uncertainty in the source of the GDGTs used for SST estimations, i.e. their production level in the water column and possible summer biases, and therefore their value as an SST proxy. Recent reviews are available for both the palaeotemperatures $U_{37}^{K^{\prime}}$ (Brassell, 2014) and TEX 86 (Hurley et al., 2016; Pearson and Ingalls, 2013; Qin et al., 2015; Tierney and Tingley, 2015). Despite these issues, in some studies where both $U_{37}^{K^{\prime}}$ and TEX $_{86}$ indices were applied, temperature estimations show remarkably similar results (Liu et al., 2009), suggesting that $\mathrm{TEX}_{86}$, after an evaluation of the source and the distribution of GDGTs (Inglis et al., 2015), can successfully be applied as a palaeotemperature proxy. $\mathrm{TEX}_{86}$ is especially useful at lower latitudes, since the $U_{37}^{K^{\prime}}$ index saturates at about $29^{\circ} \mathrm{C}$ (Müller et al., 1998).

Cross-latitude biomarker proxy records $\left(U_{37}^{K^{\prime}}\right.$ and $\mathrm{TEX}_{86}$ ) suggest that SSTs were higher than today in both the late Eocene and early Oligocene SSTs, with annual means of up to $20^{\circ} \mathrm{C}$ at both $60^{\circ} \mathrm{N}$ and $60^{\circ} \mathrm{S}$ respectively and low meridional temperature gradients (Hollis et al., 2009; Liu et al., 2009; Wade et al., 2012). One record from the Gulf of Mexico (Wade et al., 2012) suggests consistently higher SSTs derived from $\mathrm{TEX}_{86}$ than from inorganic proxies (Hollis et al., 2009, 2012; Liu et al., 2009). Where records span the EOT (i.e. $\sim 33-34 \mathrm{Ma}$ ), between 1 and $5^{\circ} \mathrm{C}$ of surface cooling in both hemispheres is found. To date, temperature records from the high northern latitudes are sparse, but coverage from the high southern latitudes is richer, where several records suggest a cooling of subantarctic waters across the EOT of 4 to $8^{\circ} \mathrm{C}$, although some records are indistinguishable from $0^{\circ} \mathrm{C}$ change (Fig. 3). In the low-latitude Pacific, Atlantic and Indian Ocean tropical SSTs were significantly warmer than today in the late Eocene, with SSTs up to $31^{\circ} \mathrm{C}$ (Liu et al., 2009) or even $\sim 33^{\circ} \mathrm{C}$ (Lear et al., 2008; Wade et al., 2012). One $\mathrm{TEX}_{86}$ record from the Gulf of Mexico implies gradual surface cooling of $3-4{ }^{\circ} \mathrm{C}$ between $\sim 34$ and $33 \mathrm{Ma}$ (Wade et al., 2012). TEX 86 data from Site 803 in the tropical Pacific show a large transient cooling of up to $6{ }^{\circ} \mathrm{C}$ across the EOT; however, such a large change in tropical temperatures is regarded as unrealistic and is more likely caused by a reorganisation of the water column (Liu et al., 2009). We therefore do not include Site 803 in our compilation of temperature change across the EOT (Fig. 3).

Newly available records from the North Atlantic region are starting to challenge earlier evidence of homogeneous bipo- 
(a) Late Eocene SST proxies

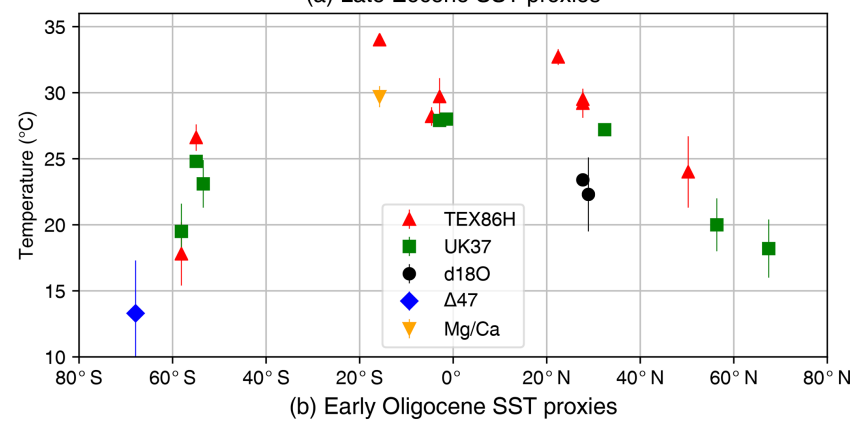

(b) Early Oligocene SST proxies
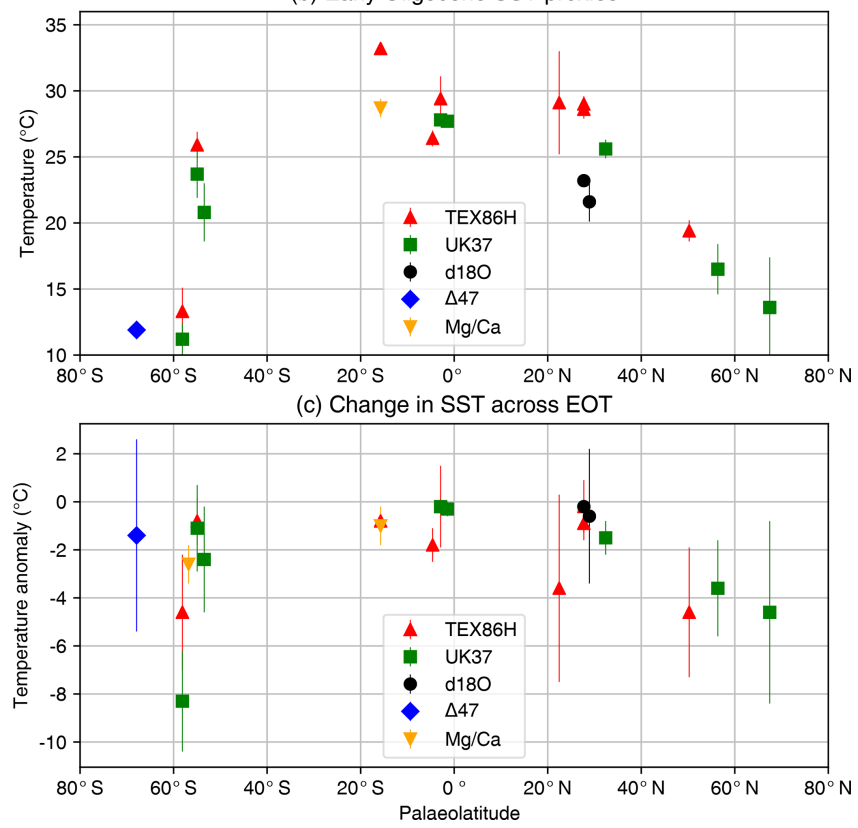

Figure 3. Summary of sea surface temperature (SST) change across the EOT from proxies $\mathrm{TEX}_{86}^{H}, U_{37}^{K^{\prime}}, \delta^{18} \mathrm{O}, \Delta_{47}$, and $\mathrm{Mg} / \mathrm{Ca}$. (a) Late Eocene, (b) early Oligocene and (c) change in SST across the EOT. Data shown in panels (a) and (b) are only from locations that record a temperature signal on both sides of the EOT. Data compiled from Bohaty et al. (2012), Cramwinckel et al. (2018), Inglis et al. (2015), Kobashi et al, (2004), Lear et al. (2008), Liu et al. (2009, 2018), Pearson et al. (2007), Petersen and Schrag (2015), Piga (2020), Śliwińska et al. (2019), Wade et al. (2012) and Zhang et al. (2013). The late Eocene value was calculated as an average between 38 and $33.9 \mathrm{Ma}$ (pre-EOT), while the early Oligocene value was calculated as the average between 33.9 and $30 \mathrm{Ma}$ (post-EOT), and the change across the EOT is the difference between these values. The data compilation is provided in digital form in Table S1 in the Supplement.

lar cooling (Liu et al., 2018; Śliwińska et al., 2019). Furthermore, comparison of a uniquely well-resolved record from the Newfoundland margin, western North Atlantic (Liu et al., 2018), with data from the subantarctic South Atlantic confirms this in new detail, leading the authors to the conclusion that surface ocean cooling during the EOT was strongly asymmetric between hemispheres. Liu et al. (2018) interpret this finding as evidence for "transient thermal decoupling of the North Atlantic Ocean from the southern high latitudes", as a result of changes in ocean-circulation-driven heat transport associated with Antarctic glaciation. Recent $\mathrm{TEX}_{86}$ data spanning the Oligocene suggest that the low meridional gradient similar to the late Eocene persists well after the EOT and that warming occurs in the late Oligocene despite an apparent decrease in $\mathrm{CO}_{2}$ (O'Brien et al., 2020).

Here we present a new compilation of SST change across the EOT (Fig. 3; Table S1 in the Supplement). For this compilation, we define two windows of time averaging: one for the late Eocene ( 38 to $33.9 \mathrm{Ma}$ ) and one for the early Oligocene (33.9 to $30 \mathrm{Ma}$ ), with the change across the EOT defined as the difference between the two windows. The compilation includes only SST proxy records that record a signal in both the late Eocene and early Oligocene. We chose these broad averages in order to incorporate data from as wide a geographical region as possible, and to apply a consistent methodology to both SST and terrestrial temperature change. A consequence of this choice is that the averaging may dampen the peak-topeak signal of EOT SST change in high-resolution records or increase uncertainty in certain records. However, by choosing longer windows, our averaging method provides a clear picture of the lasting climate change from the late Eocene to the early Oligocene. A summary of SST records across the EOT is shown in Fig. 3. The data are plotted against their palaeolatitude at $34 \mathrm{Ma}$, derived using the palaeomagnetic reference frame of Torsvik et al. (2012) and van Hinsbergen et al. (2015).

\subsection{Deep-sea temperature changes}

As described in Sect. 1.2, the Eocene-Oligocene climate transition is defined by high-resolution benthic foraminiferal oxygen isotope $\left(\delta^{18} \mathrm{O}\right)$ records from deep-sea sites (Coxall et al., 2005; Zachos et al., 1996). These records describe a benthic $\delta^{18} \mathrm{O}$ increase of about $1.5 \%$, a combination of deep-sea cooling and terrestrial ice growth. While surface ocean temperature changes have been constrained using organic and inorganic proxies (Sect. 3.1), there are fewer proxies for deep-sea temperature, and, thus, the picture of deepocean cooling remains uncertain. This is because, on its own, it is impossible to deconvolve the temperature and ice volume components of $\delta^{18} \mathrm{O}$ records, and hence quantify the timing, magnitude and spatial distribution of deep-ocean temperature change through the climate transition. Indeed, an early interpretation of the Cenozoic benthic oxygen isotope record suggested that the $\delta^{18} \mathrm{O}$ increase at the EOT represented a pure cooling signal (Shackleton and Kennett, 1975), whereas numerous lines of evidence have since shown that a substantial component of the $\delta^{18} \mathrm{O}$ shift reflects the glaciation of Antarctica (e.g. Zachos et al., 1996). Independent palaeotemperature proxies provide a potential means to deconvolve the two contributors to $\delta^{18} \mathrm{O}$ records, and benthic foraminiferal $\mathrm{Mg} / \mathrm{Ca}$ palaeothermometry has been applied to several marine EOT sections (Billups and Schrag, 2003; 
Bohaty et al., 2012; Katz et al., 2008; Lear et al., 2000, 2004, 2008, 2010; Peck et al., 2010; Pusz et al., 2011; Wade et al., 2012). Yet calculating absolute bottom water temperatures from benthic foraminiferal $\mathrm{Mg} / \mathrm{Ca}$ ratios requires an estimate of the $\mathrm{Mg} / \mathrm{Ca}$ ratio of seawater, while $\mathrm{Mg}$ partitioning into foraminiferal calcite shows modest sensitivity to temperature at low temperatures and is subject to the competing influence of seawater carbonate chemistry (Evans et al., 2018; Lear et al., 2015). Relative temperature trends over short time intervals are generally considered more robust than absolute temperatures, although the residence time of calcium in seawater ( 1 Myr; Broecker and Peng 1982) compared with the duration of the entire climate transition $(\sim 500 \mathrm{kyr})$ adds some uncertainty to calculated relative temperature changes across the EOT. High-resolution reconstructions of seawater $\mathrm{Mg} / \mathrm{Ca}$ are therefore required to improve both absolute and relative temperature changes using $\mathrm{Mg} / \mathrm{Ca}$ palaeothermometry.

Furthermore, although the benthic foraminiferal $\mathrm{Mg} / \mathrm{Ca}$ palaeothermometer appears to capture the long-term cooling trend since the early Eocene climatic optimum, the concomitant $\sim 1 \mathrm{~km}$ deepening of the calcite compensation depth (CCD) hinders its use across the EOT (Coxall et al., 2005; Lear et al., 2004). Specifically, the increase in bottom water calcite saturation state across the EOT acts to increase benthic foraminiferal $\mathrm{Mg} / \mathrm{Ca}$ and mask the deep-sea cooling signal (Coxall et al., 2005; Lear et al., 2004). Attempts have been made to use $\mathrm{Li} / \mathrm{Ca}$ to correct this $\Delta \mathrm{CO}_{3}^{2-}$ effect from $\mathrm{Mg} / \mathrm{Ca}$ records (Lear et al., 2010; Peck et al., 2010; Pusz et al., 2011), but this approach brings with it additional uncertainties including the species-specific sensitivities to both temperature and $\Delta \mathrm{CO}_{3}^{2-}$. An alternative, and perhaps more robust approach at present, is to combine planktonic $\delta^{18} \mathrm{O}$ records with salinity-independent sea surface palaeotemperature records to calculate the change in the surface water $\delta^{18} \mathrm{O}$ $\left(\delta^{18} \mathrm{Osw}\right)$. The overall change in surface $\delta^{18} \mathrm{Osw}$ across the EOT has been estimated using planktonic $\delta^{18} \mathrm{O}$ and $\mathrm{Mg} / \mathrm{Ca}$ at many sites, including a section in Tanzania containing exceptionally well-preserved (glassy) foraminifera (Lear et al., 2008). The similarity between this $\Delta \delta^{18}$ Osw estimate from the Indian Ocean $(\sim 0.6 \%$; Lear et al., 2008$)$ and those from other sites, for example the Southern Ocean (Bohaty et al., 2012) and the southeast Atlantic (Peck et al., 2010), suggests that the surface $\delta^{18}$ Osw change is dominated by a global (ice volume) signal. If we can assume that the surface $\delta^{18} \mathrm{Osw}$ signal is dominated by the ice volume signal (as opposed to a local change in the salinity), then these records can be used in conjunction with the benthic $\delta^{18} \mathrm{O}$ records to estimate changes in bottom water temperature across the climate transition (Kennedy et al., 2015). As noted above, interbasin similarities suggest this assumption holds true at Indian Ocean, Southern Ocean and southeast Atlantic sites, whereas sites in the Pacific and North Atlantic are not as clearly constrained. The associated estimated volume of Antarctic ice depends upon the assumed isotopic composition of the ice sheet, but it was likely between 70 and $110 \%$ of the size of the modern-day Antarctic Ice Sheet (Bohaty et al., 2012; Lear et al., 2008), representing a sea-level difference to the modern day of approximately -18 to $+6 \mathrm{~m}$. Spatial heterogeneities in the deep-ocean temperature history may therefore be inferred by calculating inter-site offsets in benthic foraminiferal $\delta^{18} \mathrm{O}$ records (Abelson and Erez, 2017; Bohaty et al., 2012; Cramer et al., 2009).

There is a growing consensus that Step 1 of the EOT was associated with a cooling of both deep waters and lowlatitude surface waters of the order of $2{ }^{\circ} \mathrm{C}$, while the increase in global ice volume was relatively minor (Bohaty et al., 2012; Lear et al., 2004, 2008, 2010; Peck et al., 2010; Pusz et al., 2011). We note that the combination of this magnitude of cooling and an overall increase in $\delta^{18} \mathrm{Osw}$ of $\sim 0.6 \%$ is enough to account for the average $\sim 1.0 \%$ o shift in benthic foraminiferal $\delta^{18} \mathrm{O}$ observed in deep-sea records (Mudelsee et al., 2014). However, this overall shift across the entire climate transition ignores the apparent $\delta^{18} \mathrm{O}$ "overshoot" (Zachos et al., 1996) observed in some high-resolution records at the base of the EOGM (Coxall and Pearson, 2007). Determining whether the overshoot reflects deep-sea cooling, a transient further increase in global ice volume or a combination of the two has implications for our understanding of Antarctic Ice Sheet dynamics and indeed the cause of the EOT itself. Unfortunately, it is Step 2 (EOIS) of the transition into the EOGM where the CCD reaches its maximum depth and benthic foraminiferal $\mathrm{Mg} / \mathrm{Ca}$ records appear most compromised by the $\Delta \mathrm{CO}_{3}^{2-}$ effect (Lear et al., 2004, 2010), even at depths above the implied depth of CCD deepening (Peck et al., 2010), so we currently have no robust and direct evidence of deep-ocean cooling across this step. Future work may go some way to address these problems using clumped isotopes or by generating high-resolution $\mathrm{B} / \mathrm{Ca}$ records across the transition, and by using deep infaunal benthic species (e.g. Elderfield et al., 2012). However, by combining benthic and planktonic records, it appears that the EOGM in the deep Pacific Ocean reflects, at least in part, a transient cooling of deep waters associated with the major expansion of the Antarctic Ice Sheet (Kennedy et al., 2015).

An additional complication is that the $\mathrm{Mg} / \mathrm{Ca}$ composition of seawater may itself have shifted during the EOT, as suggested by incoming constraints from other proxies, including paired $\mathrm{Mg} / \mathrm{Ca}$ and clumped isotope temperature constraints in shallow-living larger benthic foraminifera (Evans et al., 2018). Further investigation into this possibility is required, which could ultimately help identify $\mathrm{Mg} / \mathrm{Ca}$ adjustment factors needed to improve the ability to extract palaeotemperature estimates for this geological time interval.

\section{The terrestrial realm at the EOT}

There are several proxy indicators of past terrestrial climate change. These include geochemical indices, leaf mar- 
gin analysis, the Climate Leaf Analysis Multivariate Program (CLAMP) (Yang et al., 2011) and pollen assemblages (see review in Hollis et al., 2019). Here we focus on pollen assemblages as a broad indicator of terrestrial change across the EOT, because an EOT synthesis of these data already exists (Pound and Salzmann, 2017). This dataset, a global palaeobiome reconstruction of pollen and spore assemblages, indicates that the terrestrial realm of the late Eocene and early Oligocene has a vegetation distribution that in general indicates a warmer and wetter world than today. The response of the terrestrial realm to the EOT is more heterogeneous than the marine realm, and biome changes do not record a uniform global response (Pound and Salzmann, 2017). Terrestrial biomes record not only global climate change but also regional changes due to local factors. These include orographic uplift, which reduces local temperature and changes regional precipitation patterns. Further changes in precipitation are induced by the retreat of a number of inland seaways due to sea-level changes and tectonics (Chamberlain et al., 2012; Dupont-Nivet et al., 2008; Kocsis et al., 2014; Sheldon et al., 2016). These complicating factors mean that changes in vegetation must be interpreted within the context of local palaeo-environmental changes. However, there are some emerging terrestrial records that record a significant temperature drop and perturbation of the hydrological cycle, consistent with global cooling. Thus, we present the terrestrial records on a continent-by-continent basis below, with a summary of temperature change across the EOT shown in Fig. 4. As for the marine data, we derive a temperature change across the EOT by taking the difference between a late Eocene window ( 38 to $33.9 \mathrm{Ma}$ ) and an early Oligocene window (33.9 to 30 Ma). The data in Fig. 4 are plotted against palaeolatitude at $34 \mathrm{Ma}$, using the palaeomagnetic reference frame of Torsvik et al. (2012) and van Hinsbergen et al. (2015). For a summary of strengths and limitations of deriving quantitative climate estimates from the pre-Quaternary plant record, see Hollis et al. (2019).

\subsection{North America}

In North America, the palaeobiome distribution of the EOT ranges from tropical mangroves, swamps and forests in the south of the continent to cool-temperature forests at the high latitudes (Breedlovestrout et al., 2013; Pound and Salzmann, 2017; Wolfe, 1985, 1994). Gradual cooling and drying from the middle Eocene until the late Oligocene allowed the mixed coniferous and deciduous broadleaf forests to become more dominant (Wing, 1987). Fossil leaves found in Washington state (Breedlovestrout et al., 2013) indicate no clear temperature trend from the middle Eocene to the EOT. Instead variations are attributed to differing palaeo-altitude, combined with a gradual long-term cooling. Pollen records from Texas indicate a long-term cooling and aridification from the middle Eocene to the early Oligocene (Yancey et al., 2003), whereas pollen records from $5^{\circ}$ longitude further east

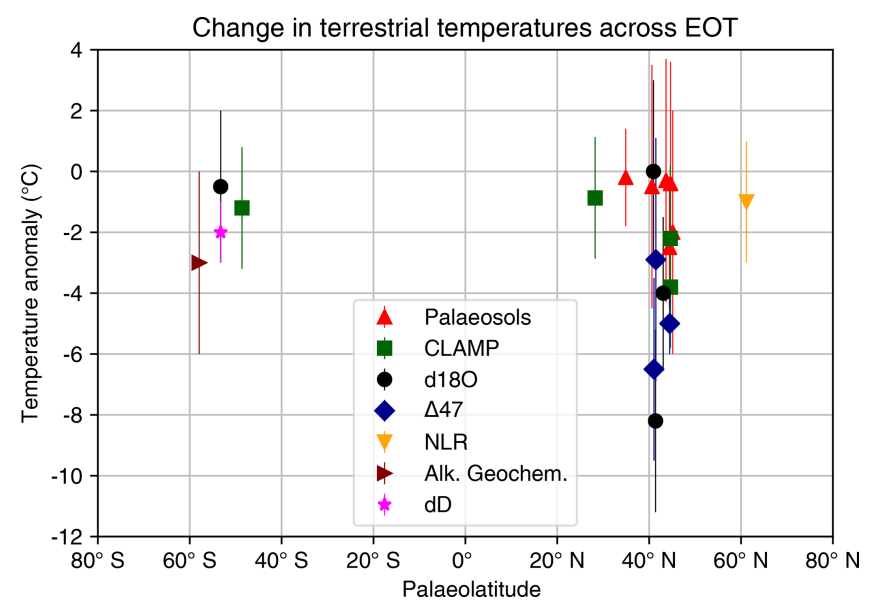

Figure 4. Summary of terrestrial air temperature change across the EOT from proxies palaeosols, CLAMP, $\delta^{18} \mathrm{O}, \Delta_{47}$, nearest living relative (NLR), alkaline geochemistry and $\delta \mathrm{D}$ (hydrogen isotopes). Data are compiled from Boardman and Secord (2013), Colwyn and Hren (2019), Eldrett et al. (2009), Fan et al. (2017), Gallagher and Sheldon (2013), Héran et al. (2010), Herman et al. (2017), Hinojosa and Villagrán (2005), Hren et al. (2013), Kohn et al. (2004), Kvaček et al. (2014), Lielke et al. (2012), Meyers (2003), Page et al. (2019), Passchier et al. (2013), Roth-Nebelsick et al. (2017), Sheldon and Tabor (2009) and Zanazzi et al. (2007). Where possible, we apply the same method as in Fig. 3; i.e. the "late Eocene" is taken the average temperature from 38 to $33.9 \mathrm{Ma}$, the "early Oligocene" is taken as the average from 33.9 to $30 \mathrm{Ma}$ and the temperature change shown here is the difference. However, in a number of cases only a relative temperature change across the EOT was given in the original literature. We therefore limit our compilation to temperature anomaly only. The compilation shown above is provided in digital form in Table S2 in the Supplement.

show no turnover at the EOB boundary (Oboh-Ikuenobe and Jaramillo, 2003). Pollen from the far north Yukon Territory shows a transition from warmer-adapted angiosperm forests in the Late Eocene to cooler-adapted gymnosperm forests during the Early Oligocene (Ridgway and Sweet, 1995).

In Oregon, well-dated floras and marine invertebrates show no evidence for a rapid change at the EOT (Retallack et al., 2004), but rather a gradual cooling during the early to middle Oligocene. By contrast, palaeosols indicate a $2.8 \pm 2.1^{\circ} \mathrm{C}$ drop across the EOT in the same region (Gallagher and Sheldon, 2013). Isotopic data from horse teeth indicate a $8 \pm 3.1{ }^{\circ} \mathrm{C}$ drop in mean annual temperature (MAT) across the EOT, but with a $400 \mathrm{kyr}$ lag behind the marine realm (Zanazzi et al., 2007), though part of this shift is due to changes in the hydrological cycle (Chamberlain et al., 2012; Hren et al., 2013). Moreover, a clumped isotope study of Fan et al. (2017) records a decrease of $\sim 7^{\circ} \mathrm{C}$ across the EOT in the north central USA, similar to the findings of Zanazzi et al. (2007). Conversely a study on White River mammals interprets no significant change in MAT but an aridification of the local environment (Boardman and Secord, 2013). This 
conclusion is in line with palaeosol studies, which suggest a change in vegetation structure from a forest to a more open environment (Retallack, 1983).

Oxygen isotope analyses in the western North American Cordillera suggest the changing hydrological regime of North America (Chamberlain et al., 2012) was influenced by factors other than large-scale climate. Rising orography, starting in British Colombia at $\sim 50 \mathrm{Ma}$ and moving south to Nevada by $\sim 23 \mathrm{Ma}$, shifted the North American monsoon further south during this time. This impacts not only terrestrial oxygen isotopes but also the regional vegetation creating an aridification not linked to global climatic events (Chamberlain et al., 2012). There is a significant increase in dust deposition in the foothills of the North American Cordillera (Fan et al., 2020), suggesting cooling and aridification. No response to the EOT is evident from North American mammals (Figueirido et al., 2012; Prothero, 2012, 2004), while fossil Equidae analyses from North America indicate that horses had a browsing diet before, at and after the EOT (Mihlbachler et al., 2011). One study argues that North American mammals had already adapted to Oligocene-like cold and arid conditions prior to the EOT (Eronen et al., 2015), suggesting that any further environmental change at the EOT would not be expressed in changes to these species.

\subsection{South America}

Late Eocene and early Oligocene palaeobiome distributions of South America indicate tropical evergreen rainforest in the north and cool-temperate biomes in the south (Pound and Salzmann, 2017). In South America there was a greater change in vegetation from the middle Eocene into the late Eocene, rather than at the EOT (Barreda and Palazzesi, 2007). Patagonian pollen floras from the middle Eocene to the end of the early Oligocene are termed the "mixed palaeoflora". These show a long-term cooling trend rather than a step change at the EOT (Quattrocchio et al., 2013). Phytolith and oxygen isotope records from Patagonia show no change in vegetation across the EOT (Kohn et al., 2004, 2015; Strömberg et al., 2013). However, this view has recently been challenged by a higher-stratigraphic-resolution study of phytoliths and magnetic properties, pointing to a clearer ecosystem change (Selkin et al., 2015). A recent stable isotope hydrology study from Patagonia indicates rapid cooling during the EOT (Colwyn and Hren, 2019). Faunal turnovers in South America began at approximately 42$39 \mathrm{Ma}$ (Woodburne et al., 2014). This not only relates to the end of the MECO but also correlates with the appearance of rodents from Africa. The mammal turnover associated with the EOT is no more dramatic than those during the late Eocene or late Oligocene (Woodburne et al., 2014). The Amazonian region had a diverse, primarily frugivorous fauna during the EOT, suggesting productive stable forest (Negri et al., 2009). To summarise, there are some indications of significant cooling in South America at the EOT, but overall the signal is mixed, with both faunal and plant-based proxies suggesting a heterogeneous response.

\subsection{Africa}

Vegetation in Africa shows little change in structure from the late Eocene into the early Oligocene, but there is a documented drop in palm diversity (Jacobs et al., 2010; Pan et al., 2006; Pound and Salzmann, 2017). There are significant gaps in the palaeobotanical record for Africa over this time interval, with most information coming from the region between $10^{\circ}$ north and south of the Equator (Jacobs et al., 2010; Pound and Salzmann, 2017). One exception is the Fayum Depression in Egypt, which contains macrofossil and microfossil evidence for tropical vegetation in the late Eocene (Tiffney and Wing, 1991; Wing et al., 1995).

\subsection{Eurasia}

In Eurasia there was a progressive change from paratropical evergreen forests in the middle Eocene to warmtemperate evergreen and deciduous mixed forests by the early Oligocene (Collinson and Hooker, 2003; Teodoridis and Kvaček, 2015). The palaeobiome reconstructions show a dominance of subtropical and warm-temperate mixed forests throughout Eurasia, with seasonal biomes in the Iberian Peninsula and arid biomes in central Asia (Pound and Salzmann, 2017). A change from a diverse mixed broadleaved to a cooler conifer-dominated pollen flora in North Atlantic cores through the Eocene indicates increasing seasonality in Europe (Eldrett et al., 2009). However, leaf floras from Bulgaria show no significant change in vegetation at the EOT (Bozukov et al., 2009). There is a greater change in Iberian pollen floras from the early to late Oligocene than at the EOT (Postigo Mijarra et al., 2009). Between the late Eocene and early Oligocene no change in MAT or precipitation is reconstructed in the Ebro Basin in Spain, but there is a decrease in chemical weathering across the EOT (Sheldon et al., 2012).

In Germany and Czechia, macrofloras show a stepwise disappearance of subtropical species and immigration of evergreen and deciduous warm-temperate species during the late Eocene (Kunzmann et al., 2016). The first mixed evergreen-deciduous forest in azonal biomes is recorded prior to the EOT from Roudníky $(35.4 \pm 0.9 \mathrm{Ma}$; Kvaček et al., 2014), referring to a latest Eocene cooling event (Teodoridis and Kvaček, 2015). However, evergreen broadleaved forests were still present in the early Oligocene (Kovar-Eder, 2016; Teodoridis and Kvaček, 2015), indicating the low impact of global EOT changes in terrestrial central Europe. Most of the subtropical-to-warm-temperate genera survived in that region until the Miocene climatic optimum (Mai, 1995). Based on proxies from macrofloras, MAT was almost stable at the EOT (Teodoridis and Kvaček, 2015), with ongoing prevailing seasonality in precipitation and a curtailment of the growing season (Moraweck et al., 2019). While 
cold-month mean temperatures (CMMTs) in the Priabonian mostly exceed $10^{\circ} \mathrm{C}$, the lower limit for the growing season, the earliest Oligocene floras from Schleenhain and Haselbach (Germany) indicate CMMTs below $10^{\circ} \mathrm{C}$ and a growing season length of 9-11 months (Moraweck et al., 2019).

Recent investigations on late Eocene and earliest Oligocene macrofloras in SE Tibet and Yunnan revealed multiple lines of evidence for the modernisation of the vegetation by establishment of present-day genera and families (Linnemann et al., 2017; Su et al., 2018). Regional vegetation change across EOT from subtropical to temperate and partly cool temperate in SW China has been argued to be influenced by the uplift of the Tibetan Plateau (Su et al., 2018). An Eocene appearance of a modern subtropical or tropical aspect of vegetation is also recorded from Chinese low-latitude floras (Hainan; Guangdong), indicating an Eocene establishment of monsoonal climate linked to Tibetan uplift (Jin et al., 2017). However, the evolution of the Tibetan Plateau at the EOT is currently under debate. Earlier studies suggested that a proto-Tibetan highland of more than $4000 \mathrm{~m}$ elevation existed in the late Eocene based on stable isotope palaeoaltimetry (Cyr et al., 2005; Quade et al., 2011; Rowley and Currie, 2006). New data-model comparisons have cast doubt on these estimates, finding that the stable isotope palaeoaltimetry is influenced by different atmospheric circulation patterns than previously thought (Botsyun et al., 2019; Quade et al., 2020). These studies suggest a lower palaeo-altimetry of the Tibetan Plateau (less than $3000 \mathrm{~m}$ ) in the late Eocene (Botsyun et al., 2019; Quade et al., 2020).

Aside from palaeo-altimetry, the timing of environmental changes suggests that climate change at the EOT had a distinct impact on Tibetan environments (Dupont-Nivet et al., 2007). Northeastern Tibet (Xining Basin) shows significant changes at the EOT in the depositional environments (Dupont-Nivet et al., 2008), pollen and clumped isotopic temperatures (Hoorn et al., 2012; Page et al., 2019), and accumulation rates (Abels et al., 2011). Furthermore, temperature changes in the Xining Basin are too sudden to be driven by changes in basin altitude (Page et al., 2019). The timing of the large temperature drop suggests a coeval decrease in regional temperature linked to EOT glaciation and monsoonal rainfall (Page et al., 2019). Mongolian and northwestern Chinese faunal records indicate a large mammal turnover at the EOT: the "Mongolian Remodelling" (Kraatz and Geisler, 2010; Meng and McKenna, 1998; Sun et al., 2014), synchronous with the Grand Coupure in Europe. Significant depositional environment change in southwestern Mongolia is also shown by Sun and Windley (2015).

Freshwater gastropods from southern Britain show that growing season temperatures (spring-summer) may have dropped from around 34 to about $20^{\circ} \mathrm{C}$ across the EoceneOligocene boundary (Hren et al., 2013). This has been translated into a MAT drop of $4-6^{\circ} \mathrm{C}$ (Hren et al., 2013), which is comparable to the $U_{37}^{K^{\prime}}$ estimated SST change from the highlatitude North Atlantic ODP Site 913, but not the smaller
SST change at the more comparable latitude ODP Site 336 (Liu et al., 2009). Summer temperatures for the Hampshire Basin fell by around $4{ }^{\circ} \mathrm{C}$ during the EOT (Grimes et al., 2005) but did not drop again during the EOIS (see Sect. 1.2). Palaeosols of the Hampshire Basin show minimal changes in temperature but an increase in precipitation (Sheldon and Tabor, 2009). Some of the discrepancies between these temperature signals may be due to differences in sampling rates during key events of the EOT.

\subsection{Australia and New Zealand}

In Australia, the EOT is associated with the loss of rarer taxa in pollen records rather than significant turnovers (Macphail, 2007). There is a diversity drop from the middle to late Eocene into the latest Eocene-early Oligocene (Martin, 2006). A recent review of the distribution of palaeobiomes in Australia showed no change between the late Eocene and the early Oligocene (Pound and Salzmann, 2017), though data coverage is sparse apart from the south of the continent. However, a recent study of rainforest flora in southeastern Australia shows a transition from warm-temperature rainforests in the late Eocene to cool-temperature rainforests in the early Oligocene (Korasidis et al., 2019). Those biome flora suggest a shift in MAT from $14-20^{\circ} \mathrm{C}$ in the late Eocene to $10-14{ }^{\circ} \mathrm{C}$ in the early Oligocene (Korasidis et al., 2019). Terrestrial palaeoclimate reconstructions of temperature also show a cooling at around $36 \mathrm{Ma}$ (Pound and Salzmann, 2017). The New Zealand records show a warm humid forest with a gradual turnover of palynomorphs through the late Eocene and the early Oligocene (Homes et al., 2015; Pocknall, 1991).

\subsection{Antarctica}

On Antarctica it is known that from the equable climates of the middle Eocene there was a progressive drop in plant diversity and stature, from evergreen forests to low-lying vegetation (Francis et al., 2008; Pound and Salzmann, 2017). Changing $\delta^{13} \mathrm{C}$ measurements from late Eocene leaves and pollen have been interpreted as decreasing moisture availability on the Antarctic Peninsula (Griener et al., 2013). Vegetation at Wilkes Land, East Antarctic, changed from an early Eocene subtropical to a cool temperate forest, indicating a $5^{\circ} \mathrm{C}$ decline in MAT (Pross et al., 2012). A further change towards a less diverse, cool-temperate shrubland and forest indicates further cooling at Wilkes Land at the onset of the Oligocene (Strother et al., 2017). Other evidence supporting decreasing moisture availability is demonstrated by a shift from chemical weathering in a humid environment to physical weathering associated with a colder, more arid regime (Basak and Martin, 2013; Dingle et al., 1998; Ehrmann and Mackensen, 1992; Robert and Kennett, 1997; Wellner et al., 2011). This aridification of the Antarctic continent is attributable to a partly glaciated continent in the late Eocene. 
A new bedrock topography for Antarctica allows for an early Oligocene ice sheet of greater areal extent than today (Wilson et al., 2012), raising the possibility that the temperature component of the EOT $\delta^{18} \mathrm{O}$ increase was more modest than previously suggested (Wilson et al., 2013).

\section{$5 \mathrm{CO}_{2}$ and carbon cycle dynamics}

The concentration of carbon dioxide in the atmosphere $\left(p \mathrm{CO}_{2}\right)$ is a primary driver of global climate change on geological timescales (Berner and Kothavala, 2001; Foster et al., 2017; Royer et al., 2004), and changes in $p \mathrm{CO}_{2}$ have been linked to the phase of acute climate change at the EOT (DeConto and Pollard, 2003; Heureux and Rickaby, 2015; Pearson et al., 2009; Steinthorsdottir et al., 2016). However atmospheric $p \mathrm{CO}_{2}$ reconstructions for the EOT are sparse; variable; and, in some cases, contradictory and not readily reconciled with palaeotemperature proxy records or numerical model hindcasts (Beerling and Royer, 2011; Heureux and Rickaby, 2015; Pagani et al., 2005; Pearson et al., 2009; Royer et al., 2004; Zhang et al., 2013). New well-resolved $p \mathrm{CO}_{2}$ records with strong age control are pressingly needed. Four proxies have been identified as particularly useful for Cenozoic $p \mathrm{CO}_{2}$ reconstructions by the Intergovernmental Panel on Climate Change (IPCC, 2013). These are the marine carbon and boron isotope proxies, and the terrestrial palaeosol carbon and stomatal density proxies (Beerling and Royer, 2011). Below, we discuss the development and state of the art of existing EOT $p \mathrm{CO}_{2}$ records constructed using marine and terrestrial proxies.

\subsection{Marine $p \mathrm{CO}_{2}$ proxies}

To date, the most detailed pre-Pleistocene climate records are derived from marine geochemical proxies, including boron isotopes $\left(\delta^{11} \mathrm{~B}\right)$ in planktonic foraminiferal calcite (Anagnostou et al., 2016; Foster et al., 2012; Greenop et al., 2017; Pearson et al., 2009; Pearson and Palmer, 1999, 2000) and carbon isotopes $\left(\delta^{13} \mathrm{C}\right)$ in marine organic biomarkers (Heureux and Rickaby, 2015; Liu et al., 2009; Pagani et al., 2005, 2011; Zhang et al., 2013). Each proxy has its own limitations and uncertainties, which initially led to divergent estimates of $p \mathrm{CO}_{2}$ using these different proxies. However, recent efforts to address such uncertainties and limitations have led to a more coherent picture of the evolution of $p \mathrm{CO}_{2}$ through the Cenozoic from marine proxies.

While the theoretical basis of the boron isotope proxy is well understood, a major uncertainty in reconstructing surface ocean $\mathrm{pH}$ is estimating the boron isotopic composition of seawater (Greenop et al., 2017). A further major uncertainty comes into play when a second carbonate system parameter (e.g. total alkalinity) is required to calculate $p \mathrm{CO}_{2}$ from seawater $\mathrm{pH}$, as well as the major ion composition of seawater, which impacts key dissociation constants. Nevertheless, significant progress has been made to reduce these uncertainties (Anagnostou et al., 2016; Greenop et al., 2017; Sosdian et al., 2018). For the Eocene $\mathrm{pCO}_{2}$ estimates, seawater $\delta^{11} \mathrm{~B}$ has been estimated using the $\delta^{11} \mathrm{~B}-\mathrm{pH}$ relationship, while self-consistent estimates of the second carbonate parameter have been determined using Earth system modelling (Anagnostou et al., 2016). For the alkenone $\delta^{13} \mathrm{C}$ proxy, there are many factors that can impact algal growth conditions, and inaccurate temperature reconstructions have also been known to bias $p \mathrm{CO}_{2}$ reconstructions (Pagani et al., 2011; Zhang et al., 2013). Algal carbon-concentrating mechanisms may also lead to biased $\mathrm{pCO}_{2}$ reconstructions when using the alkenone $\delta^{13} \mathrm{C}$ proxy in low- $\mathrm{CO}_{2}$ intervals of the Neogene but are unlikely to be a significant issue at the EOT (Zhang et al., 2013).

The boron isotope proxy suggests atmospheric $p \mathrm{CO}_{2}$ was $1400 \pm 470 \mathrm{ppm}$ in the early Eocene and decreased by several hundred parts per million through the Eocene over several million years (Anagnostou et al., 2016). In the late Eocene (Bartonian-Priabonian), $p \mathrm{CO}_{2}$ reconstructions are variable, but the boron isotope and alkenone proxy both indicate $\mathrm{pCO}_{2}$ concentrations around $1000 \mathrm{ppm}$ (Anagnostou et al., 2016; Zhang et al., 2013). The EOT itself appears to be associated with a further, and perhaps steeper, decline in $p \mathrm{CO}_{2}$, with both proxies supporting the passing of a modelled glaciation threshold of $\sim 750 \mathrm{ppm}$ (DeConto and Pollard, 2003; Pagani et al., 2011; Pearson et al., 2009; Zhang et al., 2013), although this modelled threshold itself is highly uncertain (Gasson et al., 2014). A $\delta^{11}$ B-based record from Tanzania sediments also suggests an intriguing transient $\mathrm{pCO}_{2}$ increase associated with the second $\delta^{18} \mathrm{O}$ step (Pearson et al., 2009).

\subsection{Terrestrial proxies}

The stomatal $\mathrm{CO}_{2}$ proxy is based on the empirically and experimentally demonstrated inverse relationship between the density of stomata on the leaf surfaces of most land plants and $p \mathrm{CO}_{2}$ (Beerling, 1998; Franks et al., 2014; Hincke et al., 2016; Konrad et al., 2008; Kürschner et al., 2008; McElwain and Chaloner, 1995; Royer et al., 2001; Steinthorsdottir et al., 2016, 2019, 2021, 2011, 2013; Steinthorsdottir and Vajda, 2015; Wagner et al., 1996; Woodward, 1987). Previous studies using the stomatal proxy method of $p \mathrm{CO}_{2}$ reconstructions for the time intervals on either side of the EOT (here Bartonian-Rupelian) are still relatively few, derived from mostly low-resolution datasets consisting of a variety of fossil plant taxa, and marred by limitations in chronological accuracy and correlation to marine records. Consequently, the $p \mathrm{CO}_{2}$ records have so far been highly heterogeneous.

The three current methods of stomatal $p \mathrm{CO}_{2}$ reconstruction (e.g. McElwain and Steinthorsdottir, 2017; Steinthorsdottir et al., 2021) include (1) the semiquantitative stomatal ratio method, which compares the stomatal density (SD) or stomatal index (SI - the percentage of stomata relative to all leaf epidermal cells) of fossil plants with the SD or SI of its nearest living relative (NLR), to estimate palaeo- $p \mathrm{CO}_{2}$ 


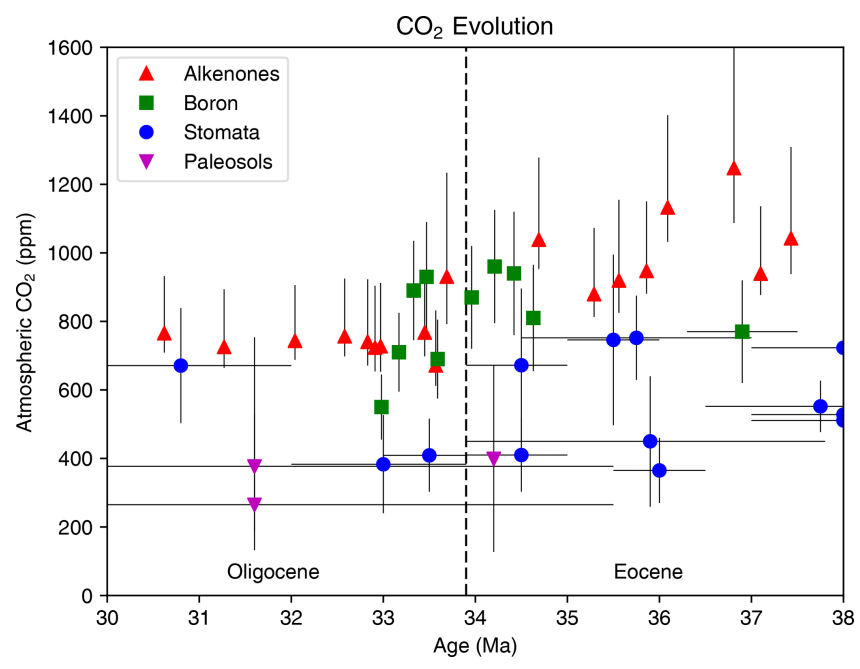

Figure 5. Atmospheric $\mathrm{CO}_{2}$ evolution from 44 to $24 \mathrm{Ma}$ from the compilation of Foster et al. (2017), incorporating data from its original data sources (Anagnostou et al., 2016; Doria et al., 2011; Erdei et al., 2012; Franks et al., 2014; Pearson et al., 2009; RothNebelsick et al., 2012, 2014; Steinthorsdottir et al., 2016, 2019; Zhang et al., 2013).

(McElwain and Chaloner, 1995); (2) the empirical transfer function method, using experimental datasets of NLR responses to variations in $p \mathrm{CO}_{2}$ (e.g. Kürschner et al., 2008; Wagner et al., 1996); and (3) mechanistic gas exchange modelling, which requires numerous additional parameters such as palaeotemperature and leaf $\delta^{13} \mathrm{C}$ (Franks et al., 2014; Konrad et al., 2008). All of these methods have been applied to reconstruct $p \mathrm{CO}_{2}$ records spanning the EoceneOligocene (Foster et al., 2017; Fig. 5), with the highestresolution dataset produced using the stomatal ratio method (Steinthorsdottir et al., 2016). Due to the semiquantitative approach and potential inter-method variability, these estimates are considered to be less robust in their absolute values of $p \mathrm{CO}_{2}$ than the marine estimates (Sect. 5.1). However, stomatal records are a valuable indicator of relative change of $p \mathrm{CO}_{2}$ in the terrestrial realm, especially in data-poor intervals, including several stages of the Eocene and Oligocene (Beerling and Royer, 2011; Foster et al., 2017).

Early results based on datasets of the gymnosperms Ginkgo biloba and Metasequoia glyptostroboides from the USA suggested that $p \mathrm{CO}_{2}$ was more or less stable between 300 and $450 \mathrm{ppm}$ during the Eocene and Oligocene (Royer et al., 2001) - however, the fossil leaf record was of toolow resolution to draw strong conclusions. Another early study, based on data gathered mainly from published images of fossil Ginkgo specimens from Russia and the USA, suggested a decrease in $p \mathrm{CO}_{2}$ across the EOT (Retallack, 2001 ), from $\sim 1300 \mathrm{ppm}$ in the Bartonian to $\sim 420 \mathrm{ppm}$ at the EOT and $\sim 330 \mathrm{ppm}$ in the Rupelian. A further stomatal dataset from Germany, based on fossil angiosperm leaves from the species Eotrigonobalanus furcinervis (Fagacaeae) and Laurophyllum acutimontanum (Lauraceae), again of low temporal resolution, suggested that $p \mathrm{CO}_{2}$ was higher before than after the EOT (Roth-Nebelsick et al., 2004). A more recent study from a temporally restricted sedimentary succession in Canada suggested high but decreasing $p \mathrm{CO}_{2}$ at the Bartonian-Priabonian boundary (from $\sim 1000-700 \mathrm{ppm}$ to $\sim 450 \mathrm{ppm}$ ), based on a dataset of Metasequoia fossil needles (Doria et al., 2011), but does not include the EOT or the Rupelian. In contrast, a study based on various angiosperm species using a leaf gas exchange model suggested more modest as well as stable $p \mathrm{CO}_{2}$ of $\sim 470 \mathrm{ppm}$ during the Bartonian and Priabonian, decreasing to $\sim 400 \mathrm{ppm}$ after the EOT in the Rupelian (Grein et al., 2013). A subsequent study from the same region compiled all data in broad temporal bins and reconstructed early Oligocene-early Miocene $p \mathrm{CO}_{2}$ to $\sim 400 \mathrm{ppm}$ throughout, despite significant changes in stomatal densities (Roth-Nebelsick et al., 2012, 2014). Two studies with restricted temporal ranges reconstructed $p \mathrm{CO}_{2}$ in the Bartonian, indicating 400-500 ppm using Metasequoia from Canada (Maxbauer et al., 2014) and $\sim 390$ ppm using the podocarp conifer Nageia maomingensis from China (Liu et al., 2016).

Recently, a new relatively high-resolution dataset consisting of Eotrigonobalanus furcinervis from Germany was published, including data points thought to be temporally located immediately before and after the EOT (Steinthorsdottir et al., 2016). The results show $p \mathrm{CO}_{2}$ of $\sim 650 \mathrm{ppm}$ in the Bartonian, decreasing to $\sim 550-400 \mathrm{ppm}$ in the Priabonian and $\sim 410 \mathrm{ppm}$ at the EOT and the earliest Rupelian (Steinthorsdottir et al., 2016). This higher-resolution record shows a distinct $\sim 40 \%$ Bartonian-Priabonian decrease in $p \mathrm{CO}_{2}$, highly comparable to the marine isotope temperature records, but reaching stable levels by the EOT and not recording a significant $p \mathrm{CO}_{2}$ decrease at the EOT proper, unlike in the marine temperature records (Steinthorsdottir et al., 2016; Zachos et al., 2001, 2008). This discrepancy between $p \mathrm{CO}_{2}$ and temperatures suggests that there are factors other than greenhouse forcing that contribute to the threshold climate response of glaciation. New results based on Lauraceae leaf fragments from the Southern Hemisphere (Australia and New Zealand) further confirm late Eocene $p \mathrm{CO}_{2}$ mostly in the order of 550-450 ppm but are not sufficiently chronologically well constrained to confirm falling $p \mathrm{CO}_{2}$ prior to the EOT (Steinthorsdottir et al., 2019).

Other results show a significant decrease in stomatal density values (indicating increasing $p \mathrm{CO}_{2}$ ) of extinct Platanus neptuni before the EOT (Moraweck et al., 2019). This unexpected trend, contradictory to the stomata density$p \mathrm{CO}_{2}$ relation previously recorded, is not yet understood but is consistent with the suggestion that $p \mathrm{CO}_{2}$ change prior to the EOT caused plant responses. Further, $p \mathrm{CO}_{2}$ reconstructed using a mechanistic gas exchange model of Konrad et al. (2008) applied to two fossil species from northern central Europe, Rhodomyrtophyllum reticulosum and Platanus neptuni, records no significant decrease across the EOT 
(Moraweck et al., 2019), in agreement with Steinthorsdottir et al. (2016), but does not record decreasing $p \mathrm{CO}_{2}$ before the EOT. It should be noted that the gas exchange model of Konrad et al. (2008) has recently been tested with modern material and was shown to produce the most accurate $p \mathrm{CO}_{2}$ estimates when used with multiple species, to derive a consensus $p \mathrm{CO}_{2}$ (Grein et al., 2013).

When focusing on datasets from central Europe, terrestrial plant-based $p \mathrm{CO}_{2}$ records support the plant-derived temperature records by indicating no abrupt decrease or environmental change across the EOT (Kunzmann et al., 2016; Teodoridis and Kvaček, 2015). A detectable but not fundamental change in vegetation, temperatures and $p \mathrm{CO}_{2}$ is however evident from the interval prior to the EOT (Kunzmann et al., 2016; Kvaček et al., 2014; Steinthorsdottir et al., 2016; Teodoridis and Kvaček, 2015). Preliminary results of MAT estimations based on sedimentary GDGT values from some central German sites are in accordance with temperature estimates from plant fossils, i.e. based on CLAMP and the NLR approach. In combination these data refer to a successive decrease in MAT across the Priabonian and the EOT but not to a significant drop during the EOT.

\subsection{Synthesis of EOT $p \mathrm{CO}_{2}$ change}

The most recent marine records indicate $p \mathrm{CO}_{2}$ of $\sim 1000 \mathrm{ppm}$ in the Bartonian-Priabonian, decreasing to $\sim 700-800$ ppm into the Rupelian. Stomatal proxy-based $p \mathrm{CO}_{2}$ records generally indicate elevated BartonianPriabonian $p \mathrm{CO}_{2}$ of $\sim 500-1000 \mathrm{ppm}$, decreasing $\sim 40 \%$ before the EOT to $p \mathrm{CO}_{2}$ of $\sim 400 \mathrm{ppm}$ and continuing in the Rupelian with $p \mathrm{CO}_{2}$ of $\sim 400 \mathrm{ppm}$ or lower. The direction and approximate magnitude of $p \mathrm{CO}_{2}$ change leading up to the EOT is therefore consistent between proxies, even though the stomatal records consistently yield lower $p \mathrm{CO}_{2}$ levels than the marine proxies. We consider the higher $p \mathrm{CO}_{2}$ estimates based on marine proxies to be the most robust indicator of $p \mathrm{CO}_{2}$ at this time, since they have been shown to reproduce ice-core $\mathrm{CO}_{2}$ well (Foster and Rae, 2016) and to agree better with the available modelling evidence from warm climate simulations of the Eocene and estimated thresholds for glaciation of Antarctica (section 6.2). Some terrestrial records also indicate a decrease in $\mathrm{CO}_{2}$, but the decrease is more gradual and long term than in the marine records.

\section{Insights into the EOT from modelling studies}

In this section we qualitatively synthesise previous modelling studies that have focused on the EOT. In particular, we discuss the modelled response to changing palaeogeography (Sect. 6.1) and to changes in $\mathrm{CO}_{2}$ (Sect. 6.2). Finally, we describe carbon cycle models that have explored mechanisms behind $\mathrm{CO}_{2}$ changes at the EOT (Sect. 6.3).

\subsection{Modelling the response to changing palaeogeography at the EOT}

The widening of the Southern Ocean Drake Passage and Tasman Gateway has long been considered as a primary driver for the initiation of the AMOC and Antarctic glaciation at the EOT (Sect. 2.2). Many climate modelling studies have tested the effect of opening these Southern Ocean gateways and found cooling effects on the southern high latitudes (Cristini et al., 2012; Elsworth et al., 2017; England et al., 2017; Mikolajewicz et al., 1993; Sijp et al., 2009, 2014; Sijp and England, 2004; Toggweiler and Bjornsson, 2000; Viebahn et al., 2016; Yang et al., 2014). These studies have variously found that opening Southern Ocean gateways can decrease southward heat transport (e.g. Sijp et al., 2009), trigger the onset of an AMOC (e.g. Yang et al., 2014) and enable some degree of cooling over Antarctica. However, these approaches do not reconcile the timing and evolution of the gateway evolution of the EOT, since they employed either modern-day or idealised geography with specific gateway perturbations. In contrast, climate model simulations that do employ Eocene boundary conditions indicate that Southern Ocean gateway opening caused only a modest change in ocean poleward heat transport and could therefore not be directly responsible for the initiation of the AIS (Goldner et al., 2014; Huber et al., 2004; Huber and Nof, 2006; Huber and Sloan, 2001; Sijp et al., 2011; Zhang et al., 2011). Furthermore, opening the Southern gateways under Eocene-like $\mathrm{CO}_{2}$ forcing may result in a weaker ACC than under pre-industrial conditions (Lefebvre et al., 2012). The long-term evolution of Southern Ocean gateway opening has been found to cause $\sim 3{ }^{\circ} \mathrm{C}$ of bottom water cooling (Sijp et al., 2014), which may explain some of the observed benthic cooling (Sect. 3.2). However, Drake Passage opening probably affected deep-ocean temperatures and the strength of the ACC. Hill et al. (2013) showed that, despite deep-water connections through both Drake Passage and the Tasman Gateway, a coherent ACC could not develop until the Australian continent was sufficiently equatorward such that it no longer inhibited strong zonal flow in the Southern Ocean.

Imposing an ice sheet in a climate model has been shown to have a significant impact on the ocean circulation and deep-water formation regions (Goldner et al., 2014; Kennedy et al., 2015). In particular, the presence of an Antarctic Ice Sheet may enhance westerly winds over the Southern Ocean, leading to enhanced Southern Ocean deep-ocean formation and benthic cooling (Goldner et al., 2014). This result suggests that Southern Ocean gateway changes play a secondary role to radiative forcing, since the ocean circulation change are a consequence of the glaciation, rather than a cause. Other ocean gateways may also play an important role. In the late Eocene continental configuration, the Central American Seaway and the Tethys gateway, connecting the Indian and Atlantic oceans, were wider than today. The importance of the open Tethys gateway for the EOT circulation has not received 
much attention, but Zhang et al. (2011) found that the tropical seaways need to be sufficiently constricted before the southern high latitudes can cool substantially. This cooling is related to a transition from an ocean circulation with Southern Hemisphere deep-water formation to the modern-like circulation with deep-water formation in the North Atlantic.

Recently, focus has shifted to the role of Arctic-Atlantic gateways around the EOT. The evolution of the ArcticAtlantic gateways has been shown to have a strong influence on the salinity of the North Atlantic and therefore on the AMOC (Hutchinson et al., 2019; Roberts et al., 2009; Stärz et al., 2017; Vahlenkamp et al., 2018b). The deepening of the Greenland-Scotland Ridge at the EOT has been proposed as a trigger for the AMOC (Abelson and Erez, 2017; Stärz et al., 2017). According to this hypothesis, the deepening changes the flow across the ridge from a shallow unidirectional flow to a deeper bi-directional flow which allows salty subtropical water to penetrate further north and enables North Atlantic sinking. Hutchinson et al. (2019) recently proposed that it is the tectonic closing of the shallow Barents Sea gateway, just prior to the EOT, that initiated the AMOC, by closing off the pathway of extremely fresh Arctic water to the North Atlantic. This theory suggests that the North Atlantic reconnected to the Arctic when the Fram Strait opened in the early Miocene (Jakobsson et al., 2007). In the Hutchinson et al. (2019) study, Southern Ocean gateways changes, Greenland-Scotland Ridge changes and $\mathrm{CO}_{2}$ forcing changes could not similarly overcome the freshening effect of the Arctic to allow an AMOC. However, their study did not test the feedback of these circulation changes on the carbon cycle, making it unclear what the climatic impact of the Arctic closure would have been. Using an Earth system model, Vahlenkamp et al. (2018a, b) experimented with similar changes in the North Atlantic gateways to investigate an alternative idea of significant AMOC behaviour since the early-middle Eocene. They were able to initiate an AMOC when the Greenland-Scotland Ridge reached a threshold depth of deeper than $200 \mathrm{~m}$, but only when the Arctic Ocean brackish water outlets were shut off from the North Atlantic. Timing of changes in Arctic-Atlantic "plumbing", thus, appears to be a critical factor in allowing an AMOC to start up in the warm Palaeogene and constitutes a key area for future research.

In all these studies, it is assumed that the final state of the simulation is the only steady solution for those boundary conditions. While there is no consensus yet (Nof et al., 2007), the present-day climate is thought to have two global circulation modes; the observed AMOC with sinking in the north and a southern-sinking-only mode with no AMOC (Liu et al., 2017; Srokosz and Bryden, 2015). In continental geometries other than the present day, different circulation patterns and co-existing equilibria may be possible but have not been systematically searched for so far (Baatsen et al., 2018). In coupled Eocene simulations, centres of deepwater formation include the North and South Pacific (Hutchinson et al., 2018;
Thomas et al., 2014) and the North and South Atlantic (Huber et al., 2003; Huber and Sloan, 2001). Conceptual climate models have suggested a potential role for meridional overturning circulation transitions in the EOT (Tigchelaar et al., 2011).

\subsection{Modelling the response to $\mathrm{CO}_{2}$ decrease at the EOT}

A reduction in atmospheric $\mathrm{CO}_{2}$ is hypothesised to be a primary cause of the EOT, because it can plausibly both explain long-term cooling during the Eocene and provide a trigger for the glaciation of Antarctica (DeConto and Pollard, 2003). Although proxy reconstructions of atmospheric $\mathrm{CO}_{2}$ during the Eocene have large uncertainties (Sect. 5), there is general agreement that climate cooled and $\mathrm{CO}_{2}$ declined through the Eocene (Anagnostou et al., 2016; Foster et al., 2017), making long-term $\mathrm{CO}_{2}$ drawdown from the atmosphere a prime underlying forcing mechanism for the EOT. Furthermore, $\mathrm{CO}_{2}$-forced climate-ice sheet model experiments yield $\delta^{18} \mathrm{O}$ series (DeConto and Pollard, 2003) that closely match the overall form of our best-resolved EOT datasets (Coxall et al., 2005; Coxall and Wilson, 2011).

A long-standing problem in modelling the Eocene climate is to reproduce the low meridional temperature gradient recorded in observations. Proxies suggest that high-latitude SSTs were more than $20^{\circ} \mathrm{C}$ warmer than present day during the early Eocene (Bijl et al., 2009), terrestrial anomalies were $20-40^{\circ} \mathrm{C}$ warmer (Huber and Caballero, 2011) and tropical temperatures were some $5-10^{\circ} \mathrm{C}$ warmer (Huber, 2008; Huber and Sloan, 2000). Evidence of frost-intolerant flora and fauna at high latitudes (Greenwood and Wing, 1995) provides a challenge to explain how the climate maintained such a low meridional temperature gradient.

When climate models are forced using proxy-data-based estimates of Eocene $\mathrm{CO}_{2}$, they generally fail to capture these flatter meridional temperature gradients (Huber et al., 2003; Roberts et al., 2009; Shellito et al., 2003). One method that has been used to address this high-latitude cold bias is to increase the $\mathrm{CO}_{2}$ to extremely high values (2240 or $4480 \mathrm{ppm}$ ) (Cramwinckel et al., 2018; Eldrett et al., 2009; Huber and Caballero, 2011; Winguth et al., 2010). These extremely high $\mathrm{CO}_{2}$ experiments yield an improved match to high-latitude temperature proxies and temperature gradients (Huber and Caballero, 2011; Lunt et al., 2012). Because these extremely high $\mathrm{CO}_{2}$ concentrations are greater than those implied by proxies, this finding also suggests that modelled climate sensitivity to $\mathrm{CO}_{2}$ forcing may be too low, probably because of positive feedbacks that are either missing or too weak in the models. Several missing feedbacks suggested recently are those associated with cloud physics and/or greenhouse gases in addition to $\mathrm{CO}_{2}$ (Beerling et al., 2011; Kiehl and Shields, 2013; Sagoo et al., 2013; Zhu et al., 2019). We also note that recent proxy data from the warmest regions of the tropics (Tanzania, Java) indicate tropical temperatures of up to 
$35^{\circ} \mathrm{C}$ in the middle-late Eocene (Evans et al., 2018; Pearson et al., 2007). These temperatures imply a somewhat larger meridional gradient than previously suggested, helping to reduce the magnitude of (but not eliminate) the model-data mismatch. In addition, several models have now achieved lower meridional temperature gradients through a combination of higher resolution, which tends to increase poleward heat transport, and improved Eocene boundary conditions (Baatsen et al., 2020; Hutchinson et al., 2019; Zhu et al., 2019). A recent model-data comparison demonstrates that the Oligocene retains a low meridional temperature gradient similar to the late Eocene, which is not well explained by currently available climate models (O'Brien et al., 2020). In the Oligocene, $\mathrm{CO}_{2}$ proxy estimates are lower than in the Eocene, making it arguably more difficult to model the low temperature gradient with realistic $\mathrm{CO}_{2}$ forcing $\left(\mathrm{O}^{\prime}\right.$ Brien et al., 2020), although the $\mathrm{CO}_{2}$ proxies carry large uncertainty.

Despite the challenges faced in modelling the early Eocene, the observed cooling during the Eocene of bottom waters (Zachos et al., 2001), high-latitude SSTs (Bijl et al., 2009) and terrestrial temperatures can plausibly be explained by a reduction in $\mathrm{CO}_{2}$ in climate model simulations (Eldrett et al., 2009; Liu et al., 2009). Furthermore, crossing a $\mathrm{CO}_{2}$ threshold of Antarctic glaciation may also explain several degrees of bottom water cooling, through consequent shifts in Southern Ocean winds and changes to Southern Ocean circulation (Goldner et al., 2014). A key challenge to adequately testing the $\mathrm{CO}_{2}$ forcing hypothesis is to derive a threshold level of $\mathrm{CO}_{2}$ for glaciation from climate model reconstructions. The first study to do so found a glaciation threshold of around $780 \mathrm{ppm}$ (DeConto and Pollard, 2003), in approximate agreement with $\mathrm{CO}_{2}$ proxies. However, a recent intercomparison of Eocene climate models used to force an ice sheet model found that this threshold varied significantly between models, from roughly 560 to 920 ppm (Gasson et al., 2014). Differences in the lapse-rate feedback were identified as the leading cause of this spread, although there were also differences in the palaeogeographic boundary conditions.

All ice sheet modelling studies of the EOT to date have used prescribed climate states to force the glaciation. Likewise, coupled ocean-atmosphere-sea ice models currently prescribe ice sheets as either present or absent. Running a full-complexity climate model synchronously with an ice sheet model remains a major technical challenge and has yet to be implemented for the Eocene or Oligocene. However, innovative asynchronous coupling, such as the "matrix method" (Pollard, 2010), has shown some promise by allowing a better representation of the ice-albedo feedback, leading to a similar yet slightly revised upward glaciation threshold of $\sim 900$ ppm (Ladant et al., 2014b).

\subsection{Carbon cycle modelling}

A slow decline in atmospheric $\mathrm{CO}_{2}$ remains a likely priming mechanism for the inception of large ice sheets on Antarc- tica, and this pivotal transition in Cenozoic climate was associated during the EOT with pronounced rapid perturbation to the global carbon cycle as indicated by a transient increase in ocean $\delta^{13} \mathrm{C}$ and a permanent deepening of the CCD (Coxall et al., 2005). Thus, numerical carbon cycle model experiments provide useful insight into forcing mechanisms and feedback processes involved.

Many hypotheses have been posited to explain the carbon cycle perturbations at the EOT (Armstrong McKay et al., 2016; Coxall et al., 2005; Coxall and Wilson, 2011; Merico et al., 2008). Some of the leading hypotheses include a shift from shelf to basin carbonate fractionation (Opdyke and Wilkinson, 1988), increases in organic carbon burial (Olivarez Lyle and Lyle, 2006), feedbacks between ice sheet coverage and silicate weathering (Zachos and Kump, 2005), and an ecological shift from calcareous to siliceous plankton (Falkowski et al., 2004). Carbon cycle box models suggest that the best fit to observations is achieved by a shift from shelf to basin carbonate fractionation (Armstrong McKay et al., 2016; Merico et al., 2008). In this interpretation of events, the fall in sea level due to Antarctic glaciation (i) reduces the global flux of carbonate into shallow water (reef, bank and shelf) sediments and (ii) exposes fresh, readily dissolved shelf carbonate sediments around the world to rapid subaerial weathering (Merico et al., 2008). The first of these two mechanisms drives the sustained CCD deepening from the Eocene to Oligocene, and the second drives a one-off dump of carbonate into the ocean that explains the observed initial transient overshoot behaviour (Zachos and Kump, 2005) and, because the shelf carbonate reservoir is enriched in ${ }^{13} \mathrm{C}$ relative to pelagic carbonate reservoir (Swart, 2008; Swart and Eberli, 2005), the transient increase in benthic $\delta^{13} \mathrm{C}$ (Armstrong McKay et al., 2016; Merico et al., 2008). If the isotopic fractionation between these two carbonate sediment reservoirs is modest, however, shelf-basin fractionation can only fully explain the transient increase in oceanic $\delta^{13} \mathrm{C}$ if the one-off dump of weathered shelf carbonate is questionably large (Merico et al., 2008). In their follow-up study, Armstrong McKay et al. (2016) considered this problem in detail and concluded that, unless shelf carbonates were substantially enriched in ${ }^{13} \mathrm{C}$ relative to pelagic carbonates (by $\sim 3 \%$ o), an additional process must also have contributed, with sequestration of ${ }^{12} \mathrm{C}$-enriched carbon into carbon capacitors, and possibly increased ocean ventilation, offering the best fit to the palaeorecords when combined with shelfbasin fractionation.

Palike et al. (2012) investigated causes of carbon cycle changes over the Eocene using the intermediate-complexity climate model cGENIE. They suggest several mechanisms are needed to explain the CCD change in addition to the shelf-basin fractionation hypothesis above: (i) perturbations to continental weathering and solute input to the deep ocean, or (ii) changes in the partition of organic carbon flux between labile (organic carbon that is readily available for oxidation and driving carbonate dissolution) and refractory (carbon 
that is more resistant to degradation and largely preserved and buried).

The longer-term decline in $\mathrm{CO}_{2}$ over the Eocene needs to be reconciled with the negative feedback between silicate weathering and surface temperature (Walker et al., 1981). Higher $\mathrm{CO}_{2}$ causes warming and enhances the hydrological cycle, which leads to an increase in silicate weathering. The increase in weathering eventually lowers $\mathrm{CO}_{2}$ and subsequent cooling, creating a dynamic equilibrium. This silicate weathering feedback is regulated by tectonic processes (Raymo and Ruddiman, 1992), since mountain ranges give rise to greater weathering than low-lying regions (Maher and Chamberlain, 2014).

A climate model study suggests that opening and deepening of the Drake Passage could lower atmospheric $\mathrm{CO}_{2}$ via the silicate weathering feedback (Elsworth et al., 2017). They suggested that the gateway transition enhanced the AMOC, leading to greater precipitation over land regions and a warmer Northern Hemisphere, both of which enhance silicate weathering and thus drawdown of $\mathrm{CO}_{2}$ (Maher and Chamberlain, 2014). However, this study used modern geography with selected gateway perturbations, whereas climate models using palaeogeography from the late Eocene have yielded different patterns of overturning (Baatsen et al., 2020; Hutchinson et al., 2019). Furthermore, a hypothesised change in silicate weathering must be weighed against the CCD record, because silicate weathering changes have implications for carbonate weathering and bicarbonate ion supply to the ocean (Armstrong McKay et al., 2016; Merico et al., 2008). Fyke et al. (2015) found opening Drake Passage led to a decrease in Atlantic carbon storage and an increase in Pacific and Southern Ocean storage, due to the enhancement of a modern-like AMOC. This led to an overall increase in global carbon storage in the ocean, though their implied drop in atmospheric $\mathrm{CO}_{2}$ is relatively small (10-30 ppm). Incorporating carbon cycle processes into full-complexity climate models with Eocene or Oligocene palaeogeography thus remains an outstanding challenge (e.g. Goddéris et al., 2014).

Experiments using cGENIE report an increase in carbon re-mineralisation near the ocean surface when temperatures are very warm, such as in the early Eocene (John et al., 2013, 2014). The more temperature-dependent re-mineralisation resulted in a shallower CCD and a decrease in organic carbon burial, an effect which then decreased over the Eocene as temperatures decreased. This modelled mechanism is consistent with tropical records of $\delta^{13} \mathrm{C}$ during the Eocene (John et al., 2013, 2014), providing a positive feedback on carbon dioxide changes, in opposition to the silicate weathering feedback.

\section{Model-data intercomparison of temperature change across the EOT}

Until this point, this review paper has synthesised the existing literature but has not presented any new quantitative analysis. Furthermore, we have in general presented the proxy and model-derived insights separately. Here, we combine the information from proxies and models and present a new model-data comparison and quantitative analysis of the mechanisms behind temperature change at the EOT. This section is in two parts: (Sect. 7.1) a quantitative intercomparison of temperature change across the EOT from a subset of these previous studies, in which we identify those changes that are robust across models, and (Sect. 7.2) a comparison of the modelled temperature changes with proxy SST and surface air temperature (SAT) data, in which we assess which models best fit the proxy reconstructions and which mechanisms most likely explain the observed proxy temperature changes.

\subsection{Intercomparison of modelled SAT change across the EOT}

Here we present an intercomparison of some previous model results of SAT change across the EOT. We use SAT data because they provide a consistent surface temperature over both ocean and land regions that reflects changes across the globe. They also enable comparison with proxies of both marine and terrestrial data to be readily included. We include models and studies for which the authors have provided their model results in digital form. The models and simulations included in this intercomparison are shown in Table 2. This itself is a subset of the simulations that were available - here we show only the simulations that allow us to compare the response of the models to a consistent forcing, for as many models as possible.

We first consider pairs of simulations that represent the response of the climate system to a perturbation in forcing that may have occurred across the EOT. These pairs can broadly be divided into three categories corresponding to three forcings: a $\mathrm{CO}_{2}$ decrease, an increase in the volume and extent of the Antarctic Ice Sheet, and a palaeogeographic change. These three forcings are hereafter referred to as $\mathrm{CO}_{2}$, ICE and GEO forcing respectively. Although these forcing factors are in reality interdependent (for example the ice sheet change may itself be caused by a $\mathrm{CO}_{2}$ change), for the purposes of modelling they are treated as independent mechanisms.

For the $\mathrm{CO}_{2}$ forcing, we consider a halving of atmospheric $\mathrm{CO}_{2}$, which for most models is from 1120 to $560 \mathrm{ppmv}$. However, for GFDL this is from 800 to $400 \mathrm{ppmv}$, and for NorESM-L there are $\mathrm{CO}_{2}$ simulations at 980 and $560 \mathrm{ppmv}$. For the NorESM-L case, we scale the anomaly by a factor of $\log (2) / \log (980 / 560)$ in order to approximate the radiative forcing of halving $\mathrm{CO}_{2}$. We emphasise here that halving 


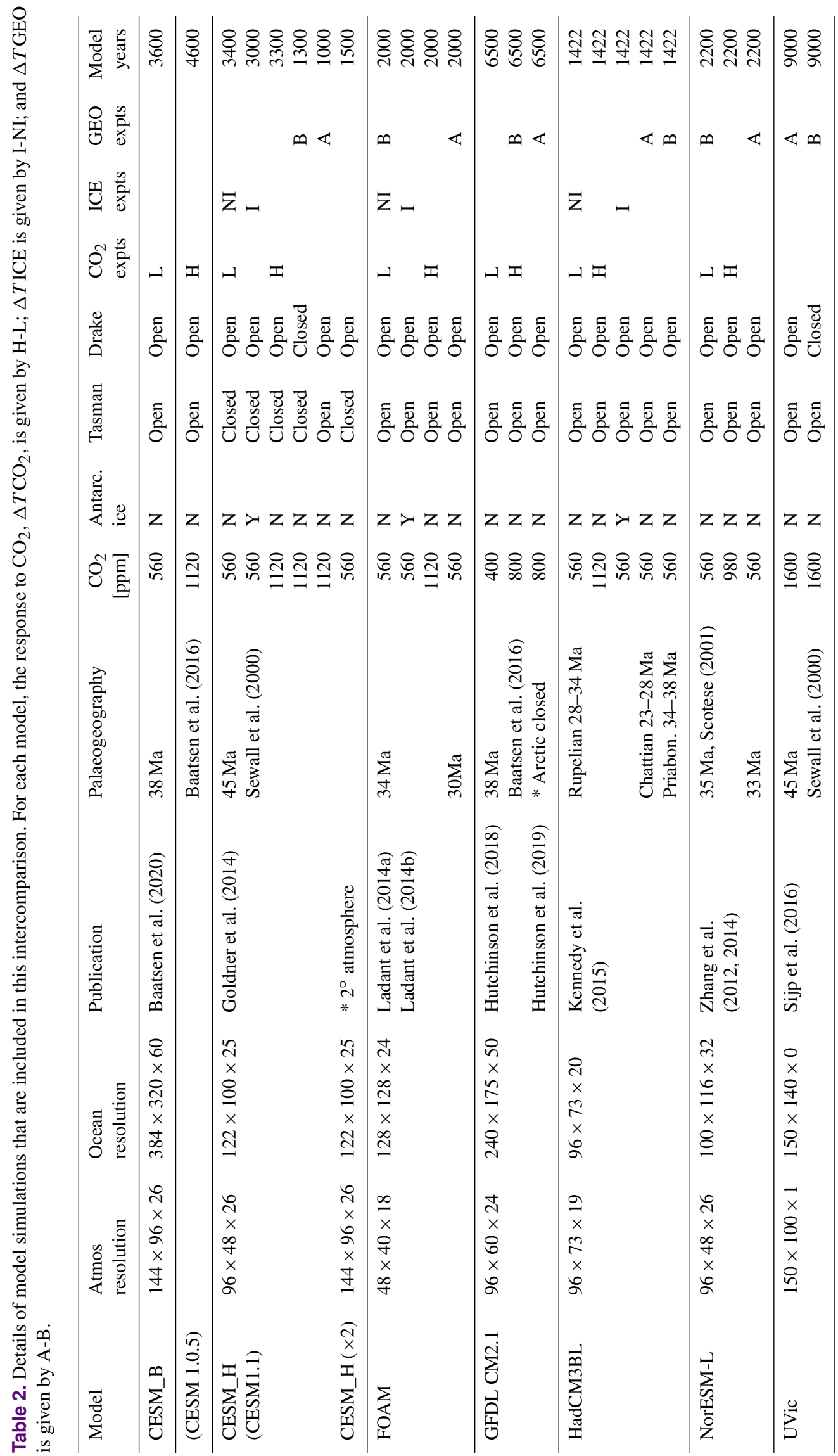


$\mathrm{CO}_{2}$ is not intended to be a realistic forcing perturbation for the EOT, but rather a standardised experimental protocol that can be used to establish the $\mathrm{CO}_{2}$ climate sensitivity of the models. For the ice sheet forcing, we consider a change from an ice-free Antarctic to an ice sheet similar in volume and area to that of today. However, the configuration of these ice sheets, and the ice-free state, does vary from model to model (see Fig. S1 in the Supplement). The palaeogeographic forcing is less consistent across the models and includes modelled changes to gateways only (CESM and UVic), to west Antarctic geography (FOAM) or to global palaeogeography (HadCM3BL) (see Fig. S3 in the Supplement).

Before examining the SAT response of the system to these three forcings, it is useful to explore the absolute temperatures in the model simulations. The annual global mean SAT in each simulation is shown in Fig. 6, while the spatial patterns for each individual model are shown in Figs. S1-S3 in the Supplement. In terms of global mean surface temperature, the models fall approximately into two groups: (i) a cooler group - consisting of CESM_H, FOAM, HadCM3BL and NorESM-L - with global mean surface temperatures of around $17-19^{\circ} \mathrm{C}$ at $560 \mathrm{ppm}$ and $21-23^{\circ} \mathrm{C}$ at $1120 \mathrm{ppm}$ and (ii) a warmer group consisting of CESM_B, CESM_H $(\times 2)$ and GFDL CM2.1, where temperatures are roughly $4{ }^{\circ} \mathrm{C}$ warmer for the equivalent level of $\mathrm{CO}_{2}$ (Fig. 6). A common factor in this split is that the warmer models have higher horizontal resolution $\left(\sim 1^{\circ}\right.$ ocean for CESM_B and GFDL CM2.1; $2^{\circ}$ atmosphere for CESM_H $(\times 2)$ and CESM_B $)$, although this is likely to depend strongly on the individual model and boundary conditions used. It is also clear from Fig. 6 and Figs. S1-S3 that the $\mathrm{CO}_{2}$ forcing has a much greater effect on global mean SST than the ice or palaeogeographic forcing.

The SAT responses of each of the individual models to the three forcings $-\Delta T_{\mathrm{CO}_{2}}, \Delta T_{\mathrm{ICE}}$ and $\Delta T_{\mathrm{GEO}}-$ are shown in Figs. S1, S2 and S3 respectively. We also include the annual mean sea ice distribution in each of $\mathrm{CO}_{2}$, ICE and GEO experiments in Figs. S4, S5 and S6 in the Supplement respectively. It is important to highlight that the changes shown have not necessarily been chosen to best represent the EOT transition. In particular, the $\mathrm{CO}_{2}$ forcing shown is a halving of $\mathrm{CO}_{2}$ in all models, and, although some proxy $\mathrm{CO}_{2}$ estimates are not inconsistent with this change (Pagani et al., 2011; Pearson et al., 2009), the data come with large uncertainties, albeit more so for absolute concentrations than for relative changes. In Sect. 7.3 we will explore this further, but here we recognise that the model responses are highly idealised, and we treat them as sensitivity studies.

\subsubsection{SAT response to $\mathrm{CO}_{2}$ decrease, $\Delta T_{\mathrm{CO}_{2}}$}

Here we consider the response to halving $\mathrm{CO}_{2}$ in the absence of an ice sheet. There appear to be two different modes of SAT response to a halving of $\mathrm{CO}_{2}$ (Fig. S1). In the first mode, CESM_H, CESM_B, FOAM and GFDL respond with cool-

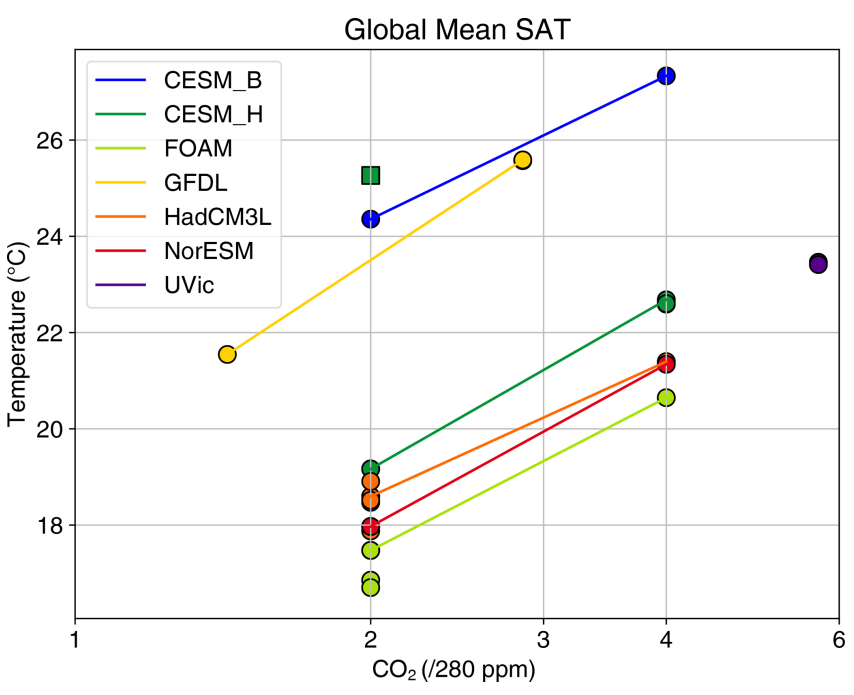

Figure 6. Global mean surface air temperature (SAT) for all models included in this intercomparison as a function of $\mathrm{CO}_{2}$ concentration. The lines join simulations from a single model at different $\mathrm{CO}_{2}$ concentrations. References for each model are CESM_H: Goldner et al. (2014); UVic: Sijp et al. (2016); FOAM: Ladant et al. (2014a, b); GFDL: Hutchinson et al. (2018, 2019); HadCM3BL: Kennedy et al. (2015); NorESM-L: Zhang et al. (2014); and CESM_B: Baatsen et al. (2020). The dark green square is an additional simulation of CESM_H with $2^{\circ}$ atmosphere resolution (Table 2).

ing over all the globe, with greatest cooling at the higher latitudes. In the second mode, HadCM3BL and NorESM-L respond with cooling in most regions (with greatest cooling in the North Pacific), but with warming in the Pacific sector of the Southern Ocean. In HadCM3BL, this is associated with a switch in regions of deep-water formation from dominant sinking in the South and North Atlantic at high $\mathrm{CO}_{2}$ to dominant sinking in the South Pacific and North Atlantic at low $\mathrm{CO}_{2}$. The onset of sinking in the South Pacific at low $\mathrm{CO}_{2}$ leads to increased heat transport from the equatorial Pacific southwards, to such an extent that it leads to net warming in the Pacific sector of the Southern Ocean, despite the decrease in $\mathrm{CO}_{2}$. Similar but weaker changes in ocean circulations happen in the NorESM-L. However, this warming response is highly sensitive to the boundary conditions, with other qualitatively similar simulations behaving very differently in the region, with some showing only cooling (Kennedy-Asser et al., 2019). In CESM, a switch in the mode of ocean circulation does not occur, with deep-water formation in the Pacific sector of the Southern Ocean at both high and low $\mathrm{CO}_{2}$ (albeit increased in intensity at low $\mathrm{CO}_{2}$ ). Similarly, for GFDL there is no switch, with deep-water formation in the South and North Pacific at high and low $\mathrm{CO}_{2}$, and for FOAM there is no switch, with deep-water formation predominantly in the North Pacific at high and low $\mathrm{CO}_{2}$. The patterns of change in HadCM3BL and NorESM-L are remarkably similar except in the Arctic, where NorESM-L shows much more cooling 
than HadCM3BL. In this region FOAM also has very little cooling. This is because both HadCM3BL and FOAM have Arctic sea ice in both high- and low- $\mathrm{CO}_{2}$ simulations, which maintains the SST close to $0^{\circ} \mathrm{C}$.

The ensemble mean SAT change due to a halving of $\mathrm{CO}_{2}$ is shown in Fig. 7a. This shows that the greatest cooling is in the North Pacific and in the Atlantic and Indian sectors of the Southern Ocean. Most of the regional cooling is "robust" in that all models show a change of the same sign and are all within $\pm 2{ }^{\circ} \mathrm{C}$ of the ensemble mean change. Exceptions are in the South Pacific (because some models show warming rather than cooling) and in the North Pacific and Arctic (because there is large variability in the amount of cooling predicted). Overall, the zonal mean cooling is approximately symmetric about the Equator, with equatorial cooling of $-2.6^{\circ} \mathrm{C}$ and mid-high-latitude cooling of $-5.0^{\circ} \mathrm{C}$. While this symmetry is at odds with an inferred northward migration of the Intertropical Convergence Zone from dust geochemistry (Hyeong et al., 2016), we stress that this result reflects the fact that the far-field cooling induced by imposing an Antarctic Ice Sheet (see Fig. 7b) is much smaller than the global cooling induced by $\mathrm{CO}_{2}$ forcing in these models.

\subsubsection{SAT response to Antarctic ice, $\Delta T_{\text {ICE }}$}

The three models that have carried out simulations with and without an Antarctic Ice Sheet show differing responses to the forcing (Fig. S2). CESM shows a cooling around the margins of Antarctica and in the Pacific and Atlantic sectors of the Southern Ocean, FOAM shows cooling around the margins of Antarctica but warming throughout much of the Southern Ocean, and HadCM3BL shows cooling in the Southern Ocean except in the southern Pacific. The mechanisms behind the changes are described in the respective papers. In brief, Kennedy et al. (2015) attribute the warming in the Pacific sector of the Southern Ocean in HadCM3BL to an increased $\mathrm{N}-\mathrm{S}$ pressure gradient close to the polar front leading to stronger westerlies, intensification of the Ross Sea gyre and a resulting increase in oceanic poleward heat transport. Goldner et al. (2014) focus on changes to deep-ocean temperatures, highlighting the importance of increased easterly winds around the margins of Antarctica and resulting Ekman transport for bringing cold water to depths. They do not discuss mechanisms for the warming around Australia. Ladant et al. (2014a) do not discuss the mechanism of SST change following glaciation, but Ladant et al. (2014b) do, for a similar pair of simulations. In their model, the presence of the Antarctic Ice Sheet enhances the strength of the Antarctic Circumpolar Current, and as a result the Ross Gyre and Weddell Gyre initiate. They also highlight the importance of sea ice changes in amplifying the changes in SSTs. More recent work (Kennedy-Asser et al., 2019) has highlighted that the particularly strong Southern Ocean warming response in the HadCM3BL simulations could be an artefact of insufficient spin-up, with very long simulations showing a more muted (a) ensemble mean $2 x-4 x$

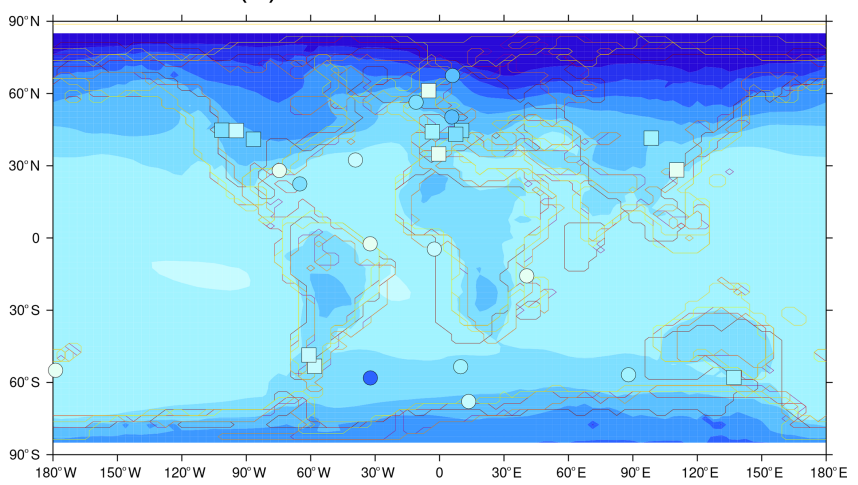

(b) ensemble mean 2xice-2x

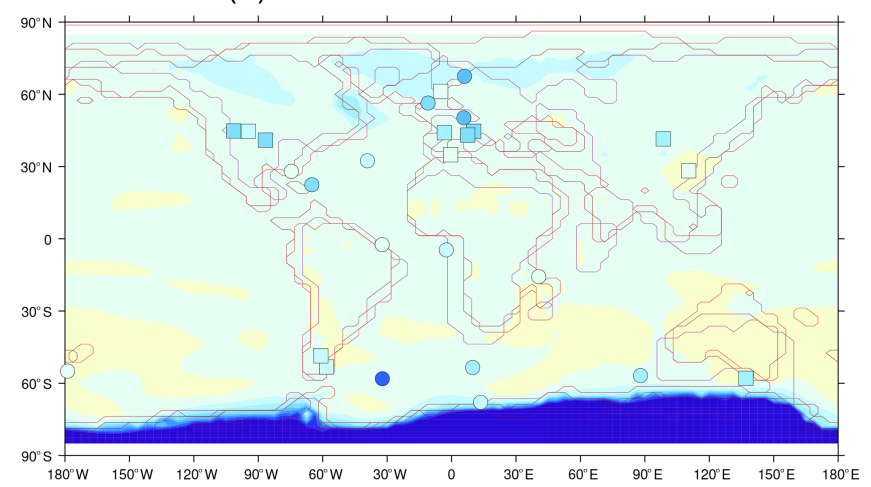

(c) ensemble mean postEOT-preEOT

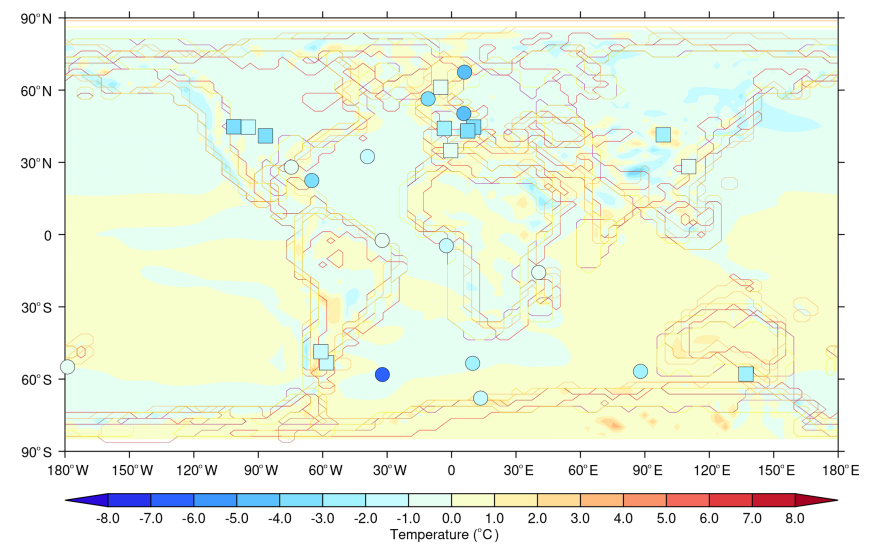

Figure 7. Ensemble mean modelled SAT response to (a) $\mathrm{CO}_{2}$ halving $\left(\Delta T \mathrm{CO}_{2}\right)$, (b) onset of ice on Antarctica ( $\left.\triangle T \mathrm{ICE}\right)$ and (c) palaeogeographic change ( $\Delta T$ GEO) across the EOT. The continental outlines for all models in each ensemble are shown. The marine proxy data are shown as filled circles, while the terrestrial proxy data are shown as filled squares.

temperature response. As a result, these HadCM3BL results should be treated with caution.

In terms of the ensemble mean (Fig. 7b), there are only a few regions where there is a robust SST signal. Robust cooling in response to the addition of the Antarctic Ice Sheet is found around the margins of the East Antarctic Ice Sheet, in the Drake Passage, south of southern Africa, and in the tropi- 
cal and North Atlantic. There is a seemingly robust warming east of Australia, but this is a small region and as such it is unclear if it occurs by chance.

\subsubsection{SAT response to palaeogeographic change, $\Delta T_{\mathrm{GEO}}$}

To examine the response to palaeogeographic change (Fig. S3), for each model we first identify the pair of simulations for each model that represents the largest change in palaeogeography across the EOT. For CESM this is an idealised gateway change from a closed Tasman Gateway and Drake Passage to open Tasman Gateway and Drake Passage. This forcing results in a cooling in the Pacific sector of the Southern Ocean and a slight warming in the rest of the Southern Ocean, but these changes are all small compared with those caused by $\mathrm{CO}_{2}$ or ice sheet changes. For UVic, the forcing is an idealised gateway change from a closed to an open Drake Passage. This has a large impact on SSTs in the Southern Ocean, with cooling south of southern Africa and a N-S dipole of warming and cooling in the Pacific sector of the Southern Ocean, associated with the transition from a gyre circulation to an Antarctic Circumpolar Current. For FOAM, the forcing consists of a localised change in West Antarctica in which continent becomes ocean. However, despite the relatively small forcing the response is quite substantial, leading to global cooling of about $1{ }^{\circ} \mathrm{C}$ (Fig. 6), especially in the southwestern Pacific. For HadCM3BL, the forcing is global in nature but consists of relatively small changes to continental position and topography and bathymetry associated with plate tectonic movements from the Priabonian (34-38 Ma) to the Chattian (23-28 Ma). As a global mean the response is very small, but regionally it is quite large; for example there is a N-S dipole response in the North Pacific, cooling in the North Atlantic and warming in the Southern Ocean. These changes are associated with the strengthening of deepwater formation in the Atlantic sector of the Southern Ocean. NorESM-L shows a relatively muted response but a substantial cooling of about $2{ }^{\circ} \mathrm{C}$ in the southwestern Pacific.

Given that all models have carried out different simulations to differing forcings, interpreting the differences in response is challenging. However, the ensemble mean response, shown in Fig. 7c, can be interpreted as the best estimate of the SAT response to palaeogeographic change across the EOT, given the uncertainty in the palaeogeographic forcing itself, as well as in the different models. The only substantial region of robust change is in the tropical Atlantic, where all models indicate a cooling response of about $1{ }^{\circ} \mathrm{C}$.

\subsection{Model-data comparison across the EOT}

It is important to assess the realism (or otherwise) of the model simulations by comparison with evidence from the geological record. Such model-data comparison can also improve our understanding of the likely mechanisms that drove change. Given the "snapshot" nature of the model simulations, and uncertainties in dating and limitations due to sparse data coverage, it is necessary to use data that extend throughout the EOT and that are clearly either "pre-EOT" or "postEOT". Here we use an updated compilation of SST (Fig. 3) and terrestrial surface temperature proxies (Fig. 4), which we present in Tables S1 and S2 respectively. In total there are 24 data points from marine sources and 20 data points from terrestrial sources. Before performing the intercomparison, we first combine and average data points that either come from different proxies from the same location or from neighbouring data points when they are less than one grid cell apart. This process yields a final proxy dataset of 27 data points, shown in Table S3 in the Supplement. Each data point is then given an equal weight in determining a root mean square error skill score.

\subsubsection{Comparison of model simulations with proxy data}

The observed proxy temperature changes compared with the individual model responses to $\mathrm{CO}_{2}$, Antarctic ice and palaeogeography are shown in Figs. S1-S3. As discussed in Sect. 7.1.1, when $\mathrm{CO}_{2}$ is halved, all models predict a cooling at all sites, in agreement with the data, except NorESM$\mathrm{L}$, which warms at one of the Arctic sites. There are no data to evaluate the warming signal in the South Pacific in HadCM3BL and NorESM-L. When an Antarctic Ice Sheet is imposed, the agreement is not so good, with all models showing warming for at least two of the sites. When palaeogeographic changes are imposed, the model-data agreement is worse again for most models, with all models showing warming for at least three of the sites. The exception is FOAM, for which all sites cool, in agreement with the data. The ensemble means capture the broad changes reasonably well, with all sites cooling for the $\mathrm{CO}_{2}$ case and all but one site cooling for the ice and palaeogeographic changes.

This model-data comparison is limited by the fact that the models have carried out idealised simulations, especially for $\mathrm{CO}_{2}$ forcing for which the halving of $\mathrm{CO}_{2}$ is somewhat arbitrary. Although some proxy $\mathrm{CO}_{2}$ records do indicate a drop of this order of magnitude (Pagani et al., 2011; Pearson et al., 2009), the associated uncertainties are large. Similarly, the changes to the Antarctic Ice Sheet imposed in the model may be greater or less than in reality, or the imposed changes in palaeogeography may be too extreme. As such, we carry out the model-data comparison such that each model SAT response to each forcing is scaled by a constant in such a way that it best fits the data. To assess the goodness of fit, we calculate a skill score, $s$, for each pair of model simulations, simply as the root mean square difference between the proxy temperature and modelled temperature, calculated from the model grid point that is in closest proximity to the data. For the purposes of the skill score we treat neighbouring sites (e.g. tropical sites 925 and 929) as a single data point by averaging the proxy and the scaled modelled temperatures at the 
Table 3. Skill scores, $s$, for the best-fit modelled changes in response to $\mathrm{CO}_{2}$, ice and palaeogeographic forcing, for each model and for the ensemble mean (a lower value of $s$ represents a better fit to data). Also shown are the values of $s$ for three idealised SAT changes. The models all achieve their best skill performance with $\mathrm{CO}_{2}$ forcing (UVic does not include $\mathrm{CO}_{2}$ forcing). Four models (CESM_B, CESM_H, FOAM and GFDL) achieve a better skill than an idealised constant temperature change, while the ensemble mean achieves better than the idealised $\cos (\phi)$ case. However, the spread in skill across the different models is narrow. Changes highlighted in bold are better than or equal to the idealised constant-change case, while the ensemble mean is better than the $\cos (\phi)$ case.

\begin{tabular}{|c|c|c|c|}
\hline Model & $\begin{array}{l}s \text { for best- } \\
\text { fit } \Delta \mathrm{T}_{\mathrm{CO}_{2}}\end{array}$ & $\begin{array}{l}s \text { for best- } \\
\text { fit } \Delta T_{\text {ice }}\end{array}$ & $\begin{array}{l}s \text { for best- } \\
\text { fit } \Delta T_{\text {geog }}\end{array}$ \\
\hline CESM_B & 0.278 & & \\
\hline CESM_H & 0.284 & 0.524 & 0.546 \\
\hline FOAM & 0.278 & 0.492 & 0.402 \\
\hline GFDL & 0.280 & & 0.546 \\
\hline HadCM3BL & 0.311 & 0.458 & 0.546 \\
\hline NorESM-L & 0.312 & & 0.546 \\
\hline UVic & & & 0.537 \\
\hline \multirow[t]{2}{*}{ Ensemble mean } & 0.274 & 0.478 & 0.546 \\
\hline & $\begin{array}{l}s \text { for idea- } \\
\text { lised } \Delta T\end{array}$ & & \\
\hline No change & 0.546 & & \\
\hline Constant change & 0.296 & & \\
\hline $\cos (\phi)$ change & 0.275 & & \\
\hline
\end{tabular}

two sites. The values of $s$ for each modelled best-fit change to the proxy SATs are shown in Table 3. When comparing models and proxies, it is informative to consider what may be called a "good agreement" and to provide a point of reference for assessing the skill scores. As such, in Table 3 we also show the skill score that would be obtained in the case of an idealised model simulating (i) no SAT change across the EOT, (ii) a global mean change that best fits the data and (iii) a zonal-mean change of the form $\Delta \mathrm{SST}=A+B \cos (\phi)$ (where $\phi$ is latitude) that best fits the data.

It is clear from Table 3 that the best modelled fit to the SAT proxy data arises from changes to $\mathrm{CO}_{2}$. In particular, the ensemble mean response to a decrease in atmospheric $\mathrm{CO}_{2}$ has the best (lowest) skill score, performing slightly better than a $\cos (\phi)$ fit. The only individual model that outperforms the $\cos (\phi)$ fit is CESM_H when including both $\mathrm{CO}_{2}$ and ICE forcing changes (Table 4). We note, however, that a $\cos (\phi)$ fit to the data produces only a $7 \%$ improved skill score over the constant-change fit. The CESM_B, CESM_H, FOAM and GFDL models perform somewhat better than the constantchange fit to the data, while HadCM3BL and NorESM-L all perform slightly worse than this, but their skill scores are within a margin of $\sim 5 \%$ of the constant-change fit. The $\mathrm{CO}_{2}$ change provides by far the best temperature fit over the ICE and GEO changes. The UVic model does not apply a $\mathrm{CO}_{2}$ change, and it consequently achieves a poorer skill score. We note, however, that the ICE changes improve the skill score in the CESM_H and HadCM3BL models, while the GEOG changes improve the skill score in the FOAM, NorESM-L and UVic models. Since those forcing factors are independent of $\mathrm{CO}_{2}$, they also improve the overall skill score in combination, as we show below. These results broadly agree with a recent Southern Ocean-only model-data comparison, which showed that $\mathrm{CO}_{2}$ forcing provided the best explanation of temperature changes across the EOT, with secondary improvements made from ice and palaeogeography changes (Kennedy-Asser et al., 2020).

\subsubsection{Mechanisms of change}

The above analysis implies that the change in SST at the EOT can be best explained by a decrease in $\mathrm{CO}_{2}$, as opposed to changes in ice or palaeogeography. However, it is possible that changes in ice or palaeogeography, combined with $\mathrm{CO}_{2}$ change, may fit even better with the data. To test this possibility, we assume that the various responses add together linearly and find the best scaled combination of each mechanism; i.e. we find $\alpha, \beta$ and $\gamma$ such that the skill score, $s$, of $\left(\alpha \Delta \mathrm{T}_{\mathrm{CO}_{2}}+\beta \Delta T_{\text {ice }}+\gamma \Delta T_{\mathrm{geo}}\right)$ is minimised. The result of this exercise for each model and for the ensemble mean is shown in Table 4. This shows that CESM_H and HadCM3BL achieve a better fit to the data when including the full response to ice sheet change and no palaeogeographic change, while FOAM and NorESM-L achieve a better fit when including a palaeogeographic change and no ice sheet change. The ensemble mean agrees best with the proxies when incorporating a $\mathrm{CO}_{2}$ shift of 885 to $560 \mathrm{ppm}(\alpha=0.66)$, with the GEO forcing providing further improvement to the fit $(\gamma=0.12)$, while the ICE forcing does not improve the ensemble mean skill score. This best-fit ensemble mean change is shown in Fig. 8. Given the close agreement between the models in fitting a $\mathrm{CO}_{2}$ change to the data, we can estimate from the full model spread that the $\mathrm{CO}_{2}$ drop was by a factor of $1.58 \pm 0.15$. If for example we assume an Oligocene $\mathrm{CO}_{2}$ value of 2 times pre-industrial levels, the $\mathrm{CO}_{2}$ drop would be from $885 \pm 90$ to 560 ppmv. However, we would caution that this estimate reflects the model spread in matching this particular set of data and that the true uncertainty is larger. Additionally, the models that included changes due to ice sheet forcing or palaeogeographic forcing achieved some improvement in fitting the data, but this played a lesser role than $\mathrm{CO}_{2}$ forcing, as measured by these skill metrics.

A 325 ppmv decrease is within the range of $\mathrm{CO}_{2}$ proxy estimates, shown in Fig. 5, with alkenone records in particular suggesting a drop of this magnitude across the EOT (Pagani et al., 2011; Zhang et al., 2013). Boron and stomatal records indicate that such a change is plausible but is likely of lesser magnitude. The recent multiproxy compilation of Foster et al. (2017) uses a smoothed regression to derive "best fit" $\mathrm{CO}_{2}$ estimates of 893 ppmv and 806 ppm during the late Eocene 
Table 4. Skill scores, $s$, for the best-fit modelled changes in response to a combination of $\mathrm{CO}_{2}$, ice and palaeogeographic forcing, for each model and for the ensemble mean (a lower value of $s$ represents a better fit to data). Also shown are the values of $\alpha, \beta$ and $\gamma$ that give the best fit, and the $\mathrm{CO}_{2}$ change corresponding to $\alpha$, assuming a post-EOT value of $560 \mathrm{ppmv}$. Also shown are the values of $s$ for three idealised SAT changes. Changes highlighted in bold are better than or equal to the idealised constant-change case, while CESM_H and the ensemble mean achieve better than the idealised $\cos (\phi)$ case.

\begin{tabular}{|c|c|c|c|c|}
\hline Model & $\begin{array}{r}s \text { for best-fit } \alpha \Delta T \mathrm{CO}_{2}+ \\
\beta \Delta T_{\text {ice }}+\gamma \Delta T_{\text {geo }}\end{array}$ & $\alpha\left[\mathrm{CO}_{2}\right.$ change ppmv $]$ & $\beta$ & $\gamma$ \\
\hline CESM_B & 0.278 & $0.70[910$ to 560$]$ & & \\
\hline CESM_H & 0.270 & 0.56 [826 to 560$]$ & 0.90 & 0 \\
\hline FOAM & 0.277 & 0.60 [849 to 560$]$ & 0 & 0.30 \\
\hline GFDL & 0.280 & $0.52[803$ to 560$]$ & & 0 \\
\hline HadCM3BL & 0.307 & $0.56[826$ to 560$]$ & 0.61 & 0 \\
\hline NorESM-L & 0.311 & $0.66[885$ to 560$]$ & 0 & 0.25 \\
\hline UVic & 0.537 & & & 0.68 \\
\hline \multirow[t]{2}{*}{ Ensemble mean } & 0.273 & $0.66[885$ to 560$]$ & 0.0 & 0.12 \\
\hline & $s$ for idealised $\Delta T$ & & & \\
\hline No change & 0.546 & & & \\
\hline Constant change & 0.296 & & & \\
\hline $\cos (\phi)$ change & 0.275 & & & \\
\hline
\end{tabular}

\section{Best Fit to EOT data}

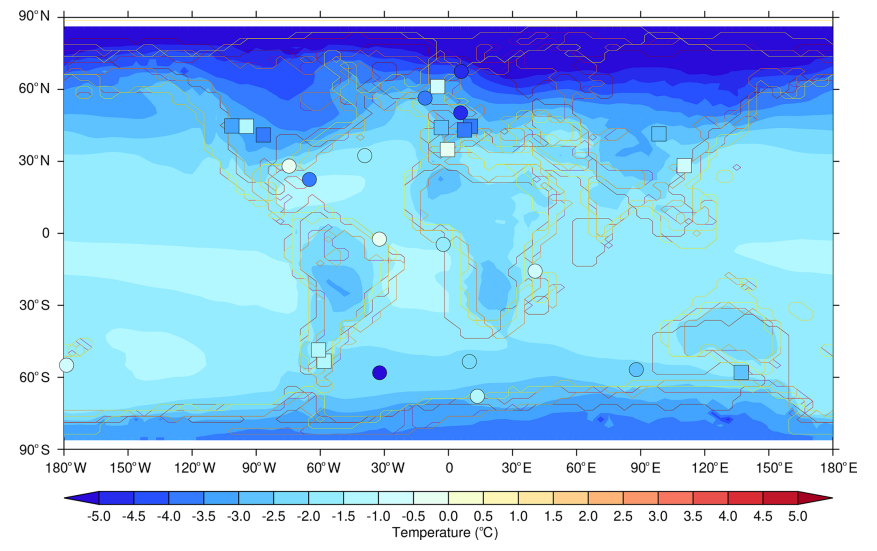

Figure 8. Ensemble mean modelled SAT response to a $\mathrm{CO}_{2}$ decrease from 885 to $560 \mathrm{ppmv}$, representing the best fit to the proxy data. The marine proxy data are shown as filled circles, while the terrestrial proxy data are shown as filled squares. Coastlines from each model are plotted to illustrate the uncertainties associated with the palaeogeographic reconstructions.

(38-34 Ma) and early Oligocene (33.5-30 Ma) respectively, or a decrease of $\sim 10 \%$. Thus, our model-derived $\mathrm{CO}_{2}$ decrease is likely to be an overestimate of the change across the EOT. There are several reasons why this mismatch may occur in our model ensemble, which we discuss in Sect. 7.2.3.

\subsubsection{Uncertainties associated with the modelling}

There are several uncertainties that should be considered when interpreting the results above. Some of these are dis- cussed here. There is uncertainty in the models themselves. These models could be characterised as AR4 class or even TAR class in that they were state of the art at the time of the fourth or third IPCC assessment report, as opposed to the most recent AR5 or the upcoming AR6. The use of less complex models can be an advantage for deep-time palaeoclimate work, as these models allow greater length of simulation, which is especially important for the deep ocean, where the initial condition may be far from the equilibrium state, which is unknown at the start of the simulation. However, there is a trade-off between simulation length and model complexity, and some of the model simulations presented here are relatively short (e.g. HadCM3BL; Table 2). A potential manifestation of this lack of complexity relates to the modelled change in land-sea contrast. The EOT temperature change from marine records is slightly larger $\left(-2.5^{\circ} \mathrm{C}\right)$ than that recorded from land temperature proxies $\left(-2.3^{\circ} \mathrm{C}\right)$. This in part reflects the heterogeneous pattern of changes in plant species, from which the land temperature proxies are derived, but is in general a globally robust signal. On the other hand, the temperature changes recorded in the model simulations show the opposite; land temperature changes are more sensitive to greenhouse cooling than ocean temperature changes. This makes it challenging to achieve a close fit to all of the temperature records available.

There are several possible reasons why our model-derived $\mathrm{CO}_{2}$ decrease is larger than the "best fit" to the Foster et al. (2017) $\mathrm{CO}_{2}$ proxy compilation. First, the models may be under-sensitive to $\mathrm{CO}_{2}$ forcing, as has been suggested in previous attempts to model the Eocene (Huber and Caballero, 2011; Lunt et al., 2012). The model ensemble climate sensitivity to doubling $\mathrm{CO}_{2}$ is $3.3^{\circ} \mathrm{C}$. A recent synthesis 
of Palaeocene-Eocene proxy records suggests that climate sensitivity during the latest Palaeocene, Palaeocene-Eocene Thermal Maximum and early Eocene Climate Optimum was 4.5, 3.6 and $3.1{ }^{\circ} \mathrm{C}$ respectively (Inglis et al., 2020). In addition the $66 \%$ confidence interval of climate sensitivity was $\sim 2-7^{\circ} \mathrm{C}$ over the three intervals combined. Thus, our model ensemble compares well with the best estimates of the early Eocene climate sensitivity but is towards the lower end of the "likely" confidence interval, suggesting a considerably higher climate sensitivity is possible. Second, the models do not permit dynamic feedbacks between $\mathrm{CO}_{2}$ forcing and the growth of an ice sheet, which in reality would cause icealbedo, land-albedo and cloud radiative forcing feedbacks. These missing feedbacks may amplify the global temperature change when crossing a critical threshold of glaciation. Since these models prescribe their ice sheets as on or off, such feedbacks are not possible here. However, it is still useful to examine which forcing mechanisms provide the best explanation of the proxy record. In this sense, it is notable that $\mathrm{CO}_{2}$ forcing provides the best explanation of the farfield cooling away from Antarctica, while imposing an ice sheet has a lesser effect on the global mean (Goldner et al., 2014).

The boundary conditions applied to the models is a large source of uncertainty. The spread in palaeogeographic forcing between models is a testament to the fact that the palaeogeography both pre-EOT and post-EOT is relatively uncertain (see Sects. 2.1 and 2.2). Recent climate model simulations of the early Eocene suggest that the palaeogeographic forcing plays a similarly important role to $\mathrm{CO}_{2}$ forcing in capturing Eocene warm climates (Lunt et al., 2021). These simulations suggest that $3-5^{\circ} \mathrm{C}$ of the warming from preindustrial to Eocene climates comes from non- $\mathrm{CO}_{2}$ forcing, i.e. forcing from changes to geography; land surface properties; and the removal of ice sheets. Therefore, while increasing the climate sensitivity may be part of solving the Eocene model-data mismatch, improving the palaeogeographic boundary conditions is also a high priority for obtaining a better model-data agreement. The proxy dataset we have used is also limited in areal coverage. As such, the models remain untested in several key regions, such as the North and tropical Pacific or the Indian Ocean. New data in the regions predicted to warm in response to a $\mathrm{CO}_{2}$ drop in HadCM3BL and NorESM-L would be particularly useful for discriminating between models. The model-data comparison does not consider any uncertainty in the proxy estimates themselves. In reality, each site is associated with a different and substantial uncertainty in its estimate of SST change across the EOT.

Here we have considered only the change in temperature across the EOT, rather than absolute temperatures. However, this can mask biases in the simulated base state of the preEOT and post-EOT simulations. Not all models do a good job of simulating the base state (see e.g. discussion of meridional temperature gradients in Sect. 6.2). Although the ensemble results achieve the best fit from $\mathrm{CO}_{2}$ forcing (with a small contribution form ice sheet forcing), it is worth noting that the ultimate cause of the $\mathrm{CO}_{2}$ drop itself remains unclear; it could itself be driven by changes to geological sources and sinks, changes in weathering rates, or feedbacks associated with ocean and land sinks due to circulation changes (see Sect. 6.3).

\section{Conclusions}

Earth's modern icehouse climate is defined by the presence of significant ice masses on land at both poles, but that ice is now retreating. Understanding the drivers and scale of polar ice growth during the initial inception of this icehouse at the EOT, which involved cooling and glaciation under a yet still warm Eocene-Oligocene climate, can provide crucial insights into ice sheet stability and behaviour in a warm climate, something that is more critical than ever. Here, we have reviewed the current literature regarding the EOT, in terms of stratigraphic definitions, geological records of palaeogeographic and Earth system change, and modelling insights into mechanisms of change. Marine records currently provide the most extensive global record of temperature change across the EOT, with a SST cooling found across most regions. The marine records suggest a global average temperature change of approximately $-2.5^{\circ} \mathrm{C}$ across the EOT, although individual records range from approximately 0 to $-8^{\circ} \mathrm{C}$ change. Terrestrial records of temperature change are more geographically limited, with a concentration of records in the midlatitude Northern Hemisphere and very little coverage of the Southern Hemisphere. The terrestrial records average change is $-2.3^{\circ} \mathrm{C}$, but, like the marine records, the change recorded at individual locations ranges from approximately 0 to $-8^{\circ} \mathrm{C}$ across the EOT. Records of $\mathrm{CO}_{2}$ across the EOT also indicate some differences between marine and terrestrial records. Marine records suggest a higher concentration of $\mathrm{CO}_{2}$ overall and a clearer transition towards lower $\mathrm{CO}_{2}$ across the EOT. Terrestrial records, by contrast, indicate a lower $\mathrm{CO}_{2}$ concentration overall and a more gradual $\mathrm{CO}_{2}$ decline with no obvious shift coinciding with the EOT. There is an ongoing need to reconcile the different $\mathrm{CO}_{2}$ signals found in the marine and terrestrial realms.

A new model-data comparison presented in this paper reveals that a halving of atmospheric $\mathrm{CO}_{2}$ across the EOT has a substantially greater effect on global mean and regional SAT than either the onset of Antarctic glaciation or changes in palaeogeography. The response to $\mathrm{CO}_{2}$ forcing is robust across models, with cooling increasing towards higher latitudes, helping to explain high-latitude cooling in the marine records. While individual models achieved a better fit to the data by including palaeogeographic forcing and ice sheet forcing, these changes are more variable across the models. As a result, the best fit in the ensemble mean is dominated by decreasing $\mathrm{CO}_{2}$ by a factor of 1.58 , with ice sheet forc- 
ing and palaeogeography forcing playing a secondary role. Assuming an Oligocene value of $560 \mathrm{ppmv}$, the corresponding pre-EOT value is 885 ppmv. However, we do not exclude the importance of contributions from other forcings. Indeed, two models in the ensemble achieve their best fit to the temperature records with a combination of $\mathrm{CO}_{2}$ and icesheet-induced changes, while two models show an improved fit when palaeogeographic changes are combined with $\mathrm{CO}_{2}$ forcing. Palaeogeographic changes and ice sheet feedbacks are inherently regional and harder to aggregate across different model experiments. Nevertheless, it remains possible that gateway-induced ocean circulation change is somehow implicated in $\mathrm{CO}_{2}$ decline. For a more complete understanding of these feedbacks, future climate modelling of the EOT must incorporate dynamic feedbacks between these different forcing factors. 
Appendix A: List of acronyms

$\begin{array}{ll}\text { ACC } & \text { Antarctic Circumpolar Current } \\ \text { AMOC } & \text { Atlantic meridional overturning circulation } \\ \text { CCD } & \text { Calcite compensation depth } \\ \text { CMMT } & \text { Cold-month mean temperature } \\ \text { CLAMP } & \text { Climate Leaf Analysis Multivariate Program } \\ \text { EAIS } & \text { East Antarctic Ice Sheet } \\ \text { EOGM } & \text { Early Oligocene glacial maximum } \\ \text { EOB } & \text { Eocene-Oligocene boundary } \\ \text { EOT } & \text { Eocene-Oligocene transition } \\ \text { EOIS } & \text { Early Oligocene oxygen isotope step } \\ \text { GSSP } & \text { Global boundary stratotype section and point } \\ \text { MAT } & \text { mean annual temperature } \\ \text { MECO } & \text { Middle Eocene climatic optimum } \\ \text { NLR } & \text { Nearest living relative } \\ \text { ODP } & \text { Ocean Drilling Program } \\ \text { PrOM } & \text { Priabonian oxygen isotope maximum } \\ \text { SAT } & \text { Surface air temperature } \\ \text { SST } & \text { Sea surface temperature }\end{array}$


Data availability. The data compilation plotted in the paper are included in the Supplement. The model data are available upon request from the corresponding authors listed in Table 2.

Supplement. The supplement related to this article is available online at: https://doi.org/10.5194/cp-17-269-2021-supplement.

Author contributions. The manuscript was conceived and planned by DKH, AMDB, HKC and MS, in collaboration with all authors. Section 1 was led by HKC, PNP and PAW. Section 2 was led by DKH, MB, HDS and AvdH. Section 3 was led by KKS, HKC and CHL. Section 4 was led by MS, MJP and LK, with contributions from KM. Section 5 was led by MS, CHL and LK. Section 6 was led by DKH and AMDB. Section 7 was led by DJL and DKH. Compilations of SST records were made by KKS and $\mathrm{MH}$, and terrestrial records by MJP, US and MH, coordinated by DKH. $\delta^{18} \mathrm{O}$ records were compiled by EP. Model simulation data were contributed by DKH, ATKA, JBL, MB, MH, WPS and ZZ. All authors contributed to editing and review of the manuscript.

Competing interests. The authors declare that they have no conflict of interest.

Acknowledgements. This work originated from a workshop on the Eocene-Oligocene transition in Stockholm in February 2017, funded by the Bolin Centre for Climate Research, Research Area 6.

Financial support. This research has been supported by the Bolin Centre for Climate Research (Research Area 6), the Vetenskapsrådet (grant no. 2016-03912), the Svenska Forskningsrådet Formas (grant no. 2018-01621) and the Danish Council for Independent Research - Natural Sciences (DFF/FNU; grant no. 11-107497).

The article processing charges for this open-access publication were covered by Stockholm University.

Review statement. This paper was edited by Ran Feng and reviewed by Zhonghui Liu and two anonymous referees.

\section{References}

Abels, H. A., Dupont-Nivet, G., Xiao, G., Bosboom, R., and Krijgsman, W.: Step-wise change of Asian interior climate preceding the Eocene-Oligocene Transition (EOT), Palaeogeogr. Palaeoclimatol. Palaeoecol., 299, 399-412, https://doi.org/10.1016/j.palaeo.2010.11.028, 2011.

Abelson, M. and Erez, J.: The onset of modern-like Atlantic meridional overturning circulation at the Eocene-Oligocene transition: Evidence, causes, and possible implications for global cooling, Geochem. Geophy. Geosy., 18, 2177-2199, https://doi.org/10.1002/2017GC006826, 2017.

Adams, C. G., Butterlin, J., and Samanta, B. K.: Larger Foraminifera and Events at the Eocene/Oligocene Boundary in the Indo-West Pacific Region, in: terminal eocene events, vol. 9, edited by: Pomerol, C., Premoli-Silva, S., Elsevier, Amsterdam, the Netherlands, 237-252, 1986.

Agnini, C., Fornaciari, E., Raffi, I., Catanzariti, R., Pälike, H., Backman, J., and Rio, D.: Biozonation and biochronology of Paleogene calcareous nannofossils from low and middle latitudes, Newslett. Stratigr., 47, 131-181, https://doi.org/10.1127/00780421/2014/0042, 2014.

Agnini, C., Backman, J., Boscolo-Galazzo, F., Condon, D. J., Fornaciari, E., Galeotti, S., Giusberti, L., Grandesso, P., Lanci, L., Luciani, V., Monechi, S., Muttoni, G., Pälike, H., Letizia Pampaloni, M., Papazzoni, C. A., Pearson, P. N., Pignatti, J., Premoli Silva, I., Raffi, I., Rio, D., Rook, L., Sahy, D., Spofforth, D. J. A., Stefani, C., and Wade, B. S.: Proposal for the Global Boundary Stratotype Section and Point (GSSP) for the Priabonian Stage (Eocene) at the Alano section (Italy), Episodes, https://doi.org/10.18814/epiiugs/2020/020074, online first, 2020.

Akhmetiev, M. A. and Beniamovski, V. N.: Paleogene floral assemblages around epicontinental seas and straits in Northern Central Eurasia: proxies for climatic and paleogeographic evolution, Geol. Acta, 7, 297-309, https://doi.org/10.1344/105.000000278, 2009.

Anagnostou, E., John, E. H., Edgar, K. M., Foster, G. L., Ridgwell, A., Inglis, G. N., Pancost, R. D., Lunt, D. J., and Pearson, P. N.: Changing atmospheric $\mathrm{CO}_{2}$ concentration was the primary driver of early Cenozoic climate, Nature, 533, 380-384, https://doi.org/10.1038/nature17423, 2016.

Anderson, J. B., Warny, S., Askin, R. A., Wellner, J. S., Bohaty, S. M., Kirshner, A. E., Livsey, D. N., Simms, A. R., Smith, T. R., Ehrmann, W., Lawver, L. A., Barbeau, D., Wise, S. W., Kulhanek, D. K., Weaver, F. M., and Majewski, W.: Progressive Cenozoic cooling and the demise of Antarctica's last refugium, P. Natl. Acad. Sci. USA, 108, 11356-11360, https://doi.org/10.1073/pnas.1014885108, 2011.

Armstrong McKay, D. I., Tyrrell, T., and Wilson, P. A.: Global carbon cycle perturbation across the EoceneOligocene climate transition, Paleoceanography, 31, 311-329, https://doi.org/10.1002/2015PA002818, 2016.

Baatsen, M., van Hinsbergen, D. J. J., von der Heydt, A. S., Dijkstra, H. A., Sluijs, A., Abels, H. A., and Bijl, P. K.: Reconstructing geographical boundary conditions for palaeoclimate modelling during the Cenozoic, Clim. Past, 12, 1635-1644, https://doi.org/10.5194/cp-12-1635-2016, 2016.

Baatsen, M., von der Heydt, A. S., Huber, M., Kliphuis, M. A., Bijl, P. K., Sluijs, A., and Dijkstra, H. A.: The middle-to-late Eocene greenhouse climate, modelled using the CESM 1.0.5, Clim. Past Discuss., https://doi.org/10.5194/cp-2020-29, in review, 2020.

Baatsen, M. L. J., von der Heydt, A. S., Kliphuis, M., Viebahn, J., and Dijkstra, H. A.: Multiple states in the late Eocene ocean circulation, Glob. Planet. Change, 163, 18-28, https://doi.org/10.1016/j.gloplacha.2018.02.009, 2018.

Bailey, I., Hole, G. M., Foster, G. L., Wilson, P. A., Storey, C. D., Trueman, C. N., and Raymo, M. E.: An alternative suggestion for the Pliocene onset of major northern hemisphere glaciation based on the geochemical provenance of North At- 
lantic Ocean ice-rafted debris, Quat. Sci. Rev., 75, 181-194, https://doi.org/10.1016/j.quascirev.2013.06.004, 2013.

Barker, P. F. and Burrell, J.: The opening of Drake Passage, Mar. Geol., 25, 15-34, https://doi.org/10.1016/0025-3227(77)900457, 1977.

Barker, P. F. and Thomas, E.: Origin, signature and palaeoclimatic influence of the Antarctic Circumpolar Current, Earth-Science Rev., 66, 143-162, https://doi.org/10.1016/j.earscirev.2003.10.003, 2004.

Barker, P. F., Filippelli, G. M., Florindo, F., Martin, E. E., and Scher, H. D.: Onset and role of the Antarctic Circumpolar Current, Deep-Sea Res. Pt II, 54, 2388-2398, https://doi.org/10.1016/j.dsr2.2007.07.028, 2007.

Barreda, V. and Palazzesi, L.: Patagonian Vegetation Turnovers during the Paleogene-Early Neogene: Origin of Arid-Adapted Floras, Bot. Rev., 73, 31-50, 2007.

Basak, C. and Martin, E. E.: Antarctic weathering and carbonate compensation at the Eocene-Oligocene transition, Nat. Geosci., 6, 121, https://doi.org/10.1038/ngeo1707, 2013.

Beerling, D. J.: Preface to Vegetation-climate-atmosphere interactions: past, present and future, the proceedings of a Discussion Meeting held at the Royal Society, Philos. Trans. R. Soc. B-Biol. Sci., 353, 3-4, https://doi.org/10.1098/rstb.1998.0185, 1998.

Beerling, D. J. and Royer, D. L.: Convergent Cenozoic $\mathrm{CO}_{2}$ history, Nat. Geosci., 4, 418, https://doi.org/10.1038/ngeo1186, 2011.

Beerling, D. J., Fox, A., Stevenson, D. S., and Valdes, P. J.: Enhanced chemistry-climate feedbacks in past greenhouse worlds, P. Natl. Acad. Sci. USA, 108, 9770-9775, https://doi.org/10.1073/pnas.1102409108, 2011.

Berggren, W. A. and Pearson, P. N.: A Revised Tropical to Subtropical Paleogene Planktonic Foraminiferal Zonation, J. Foraminifer. Res., 35, 279-298, https://doi.org/10.2113/35.4.279, 2005.

Berggren, W. A., Wade, B. S., and Pearson, P. N.: Oligocene chronostratigraphy and planktonic foraminiferal biostratigraphy: Historical review and current state-of-the-art, in: Atlas of Oligocene Planktonic Foraminifera, edited by: Wade, B. S., Olsson, R. K., Pearson, P. N., Huber, B. T., and Berggren, W. A., Cushman Foundation for Foraminiferal Research, Lawrence, USA, 29-54, 2018.

Bernard, T., Steer, P., Gallagher, K., Szulc, A., Whitham, A., and Johnson, C.: Evidence for Eocene-Oligocene glaciation in the landscape of the East Greenland margin, Geology, 44, 895-898, https://doi.org/10.1130/G38248.1, 2016.

Berner, R. A. and Kothavala, Z.: GEOCARB III: a revised model of atmospheric $\mathrm{CO}_{2}$ over Phanerozoic time, Am. J. Sci., 301, 182204, https://doi.org/10.2475/ajs.301.2.182, 2001.

Bierman, P. R., Shakun, J. D., Corbett, L. B., Zimmerman, S. R., and Rood, D. H.: A persistent and dynamic East Greenland Ice Sheet over the past 7.5 million years, Nature, 540, 256, https://doi.org/10.1038/nature20147, 2016.

Bijl, P. K., Schouten, S., Sluijs, A., Reichart, G.-J., Zachos, J. C., and Brinkhuis, H.: Early Palaeogene temperature evolution of the southwest Pacific Ocean, Nature, 461, 776-779, https://doi.org/10.1038/nature08399, 2009.

Bijl, P. K., Bendle, J. A. P., Bohaty, S. M., Pross, J., Schouten, S., Tauxe, L., Stickley, C. E., McKay, R. M., Röhl, U., Olney, M., Sluijs, A., Escutia, C., Brinkhuis, H., and Scientists, E. 318: Eocene cooling linked to early flow across the Tas- manian Gateway, P. Natl. Acad. Sci. USA, 110, 9645-9650, https://doi.org/10.1073/pnas.1220872110, 2013.

Billups, K. and Schrag, D. P.: Application of benthic foraminiferal $\mathrm{Mg} / \mathrm{Ca}$ ratios to questions of Cenozoic climate change, Earth Planet. Sci. Lett., 209, 181-195, https://doi.org/10.1016/S0012821X(03)00067-0, 2003.

Blaj, T., Backman, J., and Raffi, I.: Late Eocene to Oligocene preservation history and biochronology of calcareous nannofossils from paleo-equatorial Pacific Ocean sediments, Riv. Ital. Paleontol. Stratigr., 115, 67-85, https://doi.org/10.13130/20394942/5920, 2009.

Bo, S., Siegert, M. J., Mudd, S. M., Sugden, D., Fujita, S., Xiangbin, C., Yunyun, J., Xueyuan, T., and Yuansheng, L.: The Gamburtsev mountains and the origin and early evolution of the Antarctic Ice Sheet, Nature, 459, 690, https://doi.org/10.1038/nature08024, 2009.

Boardman, G. S. and Secord, R.: Stable isotope paleoecology of White River ungulates during the EoceneOligocene climate transition in northwestern Nebraska, Palaeogeogr. Palaeoclimatol. Palaeoecol., 375, 38-49, https://doi.org/10.1016/j.palaeo.2013.02.010, 2013.

Bohaty, S. M. and Zachos, J. C.: Significant Southern Ocean warming event in the late middle Eocene, Geology, 31, 1017-1020, https://doi.org/10.1130/G19800.1, 2003.

Bohaty, S. M., Zachos, J. C., and Delaney, M. L.: Foraminiferal $\mathrm{Mg} / \mathrm{Ca}$ evidence for Southern Ocean cooling across the Eocene-Oligocene transition, Earth Planet. Sci. Lett., 317-318, 251-261, https://doi.org/10.1016/j.epsl.2011.11.037, 2012.

Borrelli, C., Cramer, B. S., and Katz, M. E.: Bipolar Atlantic deepwater circulation in the middle-late Eocene: Effects of Southern Ocean gateway openings, Paleoceanography, 29, 308-327, https://doi.org/10.1002/2012PA002444, 2014.

Botsyun, S., Sepulchre, P., Donnadieu, Y., Risi, C., Licht, A., and Caves Rugenstein, J. K.: Revised paleoaltimetry data show low Tibetan Plateau elevation during the Eocene, Science, 363, eaaq1436, https://doi.org/10.1126/science.aaq1436, 2019.

Boyden, J. A., Müller, R. D., Gurnis, M., Torsvik, T. H., Clark, J. A., Turner, M., Ivey-Law, H., Watson, R. J., and Cannon, J. S.: Next-generation plate-tectonic reconstructions using GPlates, in Geoinformatics: Cyberinfrastructure for the Solid Earth Sciences, edited by: Keller, G. R. and Baru, C., Cambridge University Press, Cambridge, UK, 95-114, 2011.

Boyle, P. R., Romans, B. W., Tucholke, B. E., Norris, R. D., Swift, S. A. and Sexton, P. F.: Cenozoic North Atlantic deep circulation history recorded in contourite drifts, offshore Newfoundland, Canada, Mar. Geol., 385, 185-203, https://doi.org/10.1016/j.margeo.2016.12.014, 2017.

Bozukov, V., Utescher, T., and Ivanov, D.: Late Eocene to early Miocene climate and vegetation of Bulgaria, Rev. Palaeobot. Palynol., 153, 360-374, https://doi.org/10.1016/j.revpalbo.2008.10.005, 2009.

Brassell, S. C.: Climatic influences on the Paleogene evolution of alkenones, Paleoceanography, 29, 255-272, https://doi.org/10.1002/2013PA002576, 2014.

Brassell, S. C., Eglinton, G., Marlowe, I. T., Pflaumann, U., and Sarnthein, M.: Molecular stratigraphy: a new tool for climatic assessment, Nature, 320, 129, https://doi.org/10.1038/320129a0, 1986. 
Breedlovestrout, R. L., Evraets, B. J., and Parrish, J. T.: New Paleogene paleoclimate analysis of western Washington using physiognomic characteristics from fossil leaves, Palaeogeogr. Palaeoclimatol. Palaeoecol., 392, 22-40, https://doi.org/10.1016/j.palaeo.2013.08.013, 2013.

Brinkhuis, H., Schouten, S., Collinson, M. E., Sluijs, A., Damsté, J. S. S., Dickens, G. R., Huber, M., Cronin, T. M., Onodera, J., Takahashi, K., Bujak, J. P., Stein, R., van der Burgh, J., Eldrett, J. S., Harding, I. C., Lotter, A. F., Sangiorgi, F., Cittert, H. van K., de Leeuw, J. W., Matthiessen, J., Backman, J., Moran, K., and the Expedition 302 Scientists: Episodic fresh surface waters in the Eocene Arctic Ocean, Nature, 441, 606-609, https://doi.org/10.1038/nature04692, 2006.

Broecker, W. S. and Peng, T.-H.: Tracers in the sea, Eldigio Press, Columbia University, Palisades, NY, 1982.

Cande, S. C. and Kent, D. V: Revised calibration of the geomagnetic polarity timescale for the Late Cretaceous and Cenozoic, J. Geophys. Res.-Sol. Ea., 100, 6093-6095, https://doi.org/10.1029/94JB03098, 1995.

Carter, A., Riley, T. R., Hillenbrand, C.-D., and Rittner, M.: Widespread Antarctic glaciation during the Late Eocene, Earth Planet. Sci. Lett., 458, 49-57, https://doi.org/10.1016/j.epsl.2016.10.045, 2017.

Chamberlain, C. P., Mix, H. T., Mulch, A., Hren, M. T., KentCorson, M. L., Davis, S. J., Horton, T. W., and Graham, S. A.: The Cenozoic climatic and topographic evolution of the western North American Cordillera, Am. J. Sci., 312, 213-262, https://doi.org/10.2475/02.2012.05, 2012.

Coccione, R.: The genera Hantkenina and Cribrohantkenina (foraminifera) in the Massignano Section (Ancona, Italy), in: International Subcommission on Paleogeography and Stratigraphy, Eocene/Oligocene Meeting, October 1987, Ancona, Italy, 81-96, 1988.

Collinson, M. E. and Hooker, J. J.: Paleogene vegetation of Eurasia: framework for mammalian faunas, Deinsea, 10, 41-84, 2003.

Colwyn, D. A. and Hren, M. T.: An abrupt decrease in Southern Hemisphere terrestrial temperature during the EoceneOligocene transition, Earth Planet. Sci. Lett., 512, 227-235, https://doi.org/10.1016/j.eps1.2019.01.052, 2019.

Costa, E., Garcés, M., Sáez, A., Cabrera, L., and López-Blanco, M.: The age of the "Grande Coupure" mammal turnover: New constraints from the Eocene-Oligocene record of the Eastern Ebro Basin (NE Spain), Palaeogeogr. Palaeoclimatol. Palaeoecol., 301, 97-107, https://doi.org/10.1016/j.palaeo.2011.01.005, 2011.

Cotton, L. J. and Pearson, P. N.: Extinction of larger benthic foraminifera at the Eocene/Oligocene boundary, Palaeogeogr. Palaeoclimatol. Palaeoecol., 311, 281-296, https://doi.org/10.1016/j.palaeo.2011.09.008, 2011.

Cotton, L. J., Pearson, P. N., and Renema, W.: Stable isotope stratigraphy and larger benthic foraminiferal extinctions in the Melinau Limestone, Sarawak, J. Asian Earth Sci., 79, 65-71, https://doi.org/10.1016/j.jseaes.2013.09.025, 2014.

Coxall, H. K. and Pearson, P. N.: The Eocene-Oligocene transition, Deep Time Perspect. Clim. Chang. Marrying Signal From Comput. Model. Biol. Proxies, The Micropalaeontological Society, Special Publications, The Geological Society, London, UK, 351387, 2007.
Coxall, H. K. and Wilson, P. A.: Early Oligocene glaciation and productivity in the eastern equatorial Pacific: Insights into global carbon cycling, Paleoceanography, 26, PA2221, https://doi.org/10.1029/2010PA002021, 2011.

Coxall, H. K., Wilson, P. A., Palike, H., Lear, C. H., and Backman, J.: Rapid stepwise onset of Antarctic glaciation and deeper calcite compensation in the Pacific Ocean, Nature, 433, 53-57, https://doi.org/10.1038/nature03135, 2005.

Coxall, H. K., Huck, C. E., Huber, M., Lear, C. H., LegardaLisarri, A., O'Regan, M., Sliwinska, K. K., van de Flierdt, T., de Boer, A. M., Zachos, J. C., and Backman, J.: Export of nutrient rich Northern Component Water preceded early Oligocene Antarctic glaciation, Nat. Geosci., 11, 190-196, https://doi.org/10.1038/s41561-018-0069-9, 2018.

Cramer, B. S., Toggweiler, J. R., Wright, J. D., Katz, M. E., and Miller, K. G.: Ocean overturning since the Late Cretaceous: Inferences from a new benthic foraminiferal isotope compilation, Paleoceanography, 24, PA4216, https://doi.org/10.1029/2008PA001683, 2009.

Cramwinckel, M. J., Huber, M., Kocken, I. J., Agnini, C., Bijl, P. K., Bohaty, S. M., Frieling, J., Goldner, A., Hilgen, F. J., Kip, E. L., Peterse, F., van der Ploeg, R., Röhl, U., Schouten, S., and Sluijs, A.: Synchronous tropical and polar temperature evolution in the Eocene, Nature, 559, 382-386, https://doi.org/10.1038/s41586018-0272-2, 2018.

Cristini, L., Grosfeld, K., Butzin, M., and Lohmann, G.: Influence of the opening of the Drake Passage on the Cenozoic Antarctic Ice Sheet: A modeling approach, Palaeogeogr. Palaeoclimatol. Palaeoecol., 339-341, 66-73, https://doi.org/10.1016/j.palaeo.2012.04.023, 2012.

Crosby, A. G., McKenzie, D., and Sclater, J. G.: The relationship between depth, age and gravity in the oceans, Geophys. J. Int., 166, 553-573, https://doi.org/10.1111/j.1365246X.2006.03015.x, 2006.

Cyr, A. J., Currie, B. S., and Rowley, D. B.: Geochemical Evaluation of Fenghuoshan Group Lacustrine Carbonates, North-Central Tibet: Implications for the Paleoaltimetry of the Eocene Tibetan Plateau, J. Geol., 113, 517-533, https://doi.org/10.1086/431907, 2005.

Dalziel, I. W. D., Lawver, L. A., Pearce, J. A., Barker, P. F., Hastie, A. R., Barfod, D. N., Schenke, H.-W., and Davis, M. B.: A potential barrier to deep Antarctic circumpolar flow until the late Miocene?, Geology, 41, 947-950, https://doi.org/10.1130/G34352.1, 2013.

Darby, D. A.: Ephemeral formation of perennial sea ice in the Arctic Ocean during the middle Eocene, Nat. Geosci., 7, 210, https://doi.org/10.1038/ngeo2068, 2014.

DeConto, R. M. and Pollard, D.: Rapid Cenozoic glaciation of Antarctica induced by declining atmospheric $\mathrm{CO}_{2}$, Nature, 421, 245-249, https://doi.org/10.1038/nature01290, 2003.

DeConto, R. M., Pollard, D., Wilson, P. A., Palike, H., Lear, C. H., and Pagani, M.: Thresholds for Cenozoic bipolar glaciation, Nature, 455, 652-656, https://doi.org/10.1038/nature07337, 2008.

De Schepper, S., Gibbard, P. L., Salzmann, U., and Ehlers, J.: A global synthesis of the marine and terrestrial evidence for glaciation during the Pliocene Epoch, Earth-Science Rev., 135, 83102, https://doi.org/10.1016/j.earscirev.2014.04.003, 2014.

Dingle, R. V, Marenssi, S. A., and Lavelle, M.: High latitude Eocene climate deterioration: evidence from the north- 
ern Antarctic Peninsula, J. South Am. Earth Sci., 11, 571-579, https://doi.org/10.1016/S0895-9811(98)00035-2, 1998.

Diester-Haass, L. and Zahn, R.: Eocene-Oligocene transition in the Southern Ocean: History of water mass circulation and biological productivity, Geology, 24, 163-166, https://doi.org/10.1130/00917613(1996)024<0163:EOTITS>2.3.CO;2, 1996.

Doria, G., Royer, D. L., Wolfe, A. P., Fox, A., Westgate, J. A., and Beerling, D. J.: Declining atmospheric $\mathrm{CO}_{2}$ during the late Middle Eocene climate transition, Am. J. Sci., 311, 63-75, https://doi.org/10.2475/01.2011.03, 2011.

Dunkley Jones, T., Bown, P. R., Pearson, P. N., Wade, B. S., Coxall, H. K. and Lear, C. H.: Major shifts in calcareous phytoplankton assemblages through the EoceneOligocene transition of Tanzania and their implications for lowlatitude primary production, Paleoceanography, 23, PA4204, https://doi.org/10.1029/2008PA001640, 2008.

Dupont-Nivet, G., Krijgsman, W., Langereis, C. G., Abels, H. A., Dai, S., and Fang, X.: Tibetan plateau aridification linked to global cooling at the Eocene-Oligocene transition, Nature, 445, 635, https://doi.org/10.1038/nature05516, 2007.

Dupont-Nivet, G., Hoorn, C., and Konert, M.: Tibetan uplift prior to the Eocene-Oligocene climate transition: Evidence from pollen analysis of the Xining Basin, Geology, 36, 987-990, https://doi.org/10.1130/G25063A.1, 2008.

Eagles, G., Livermore, R. A., Fairhead, J. D., and Morris, P.: Tectonic evolution of the west Scotia Sea, J. Geophys. Res.-Sol. Ea., 110, B02401, https://doi.org/10.1029/2004JB003154, 2005.

Ehlers, J. and Gibbard, P. L.: The extent and chronology of Cenozoic Global Glaciation, Quat. Int., 164-165, 6-20, https://doi.org/10.1016/j.quaint.2006.10.008, 2007.

Ehrmann, W. U. and Mackensen, A.: Sedimentological evidence for the formation of an East Antarctic ice sheet in Eocene/Oligocene time, Palaeogeogr. Palaeoclimatol. Palaeoecol., 93, 85-112, https://doi.org/10.1016/0031-0182(92)90185-8, 1992.

Elderfield, H., Ferretti, P., Greaves, M., Crowhurst, S., McCave, I. N., Hodell, D., and Piotrowski, A. M.: Evolution of Ocean Temperature and Ice Volume Through the Mid-Pleistocene Climate Transition, Science, 337, 704-709, https://doi.org/10.1126/science.1221294, 2012.

Eldrett, J. S., Harding, I. C., Wilson, P. A., Butler, E., and Roberts, A. P.: Continental ice in Greenland during the Eocene and Oligocene, Nature, 446, 176, https://doi.org/10.1038/nature05591, 2007.

Eldrett, J. S., Greenwood, D. R., Harding, I. C., and Huber, M.: Increased seasonality through the Eocene to Oligocene transition in northern high latitudes, Nature, 459, 969-973, https://doi.org/10.1038/nature08069, 2009.

Elsworth, G., Galbraith, E., Halverson, G., and Yang, S.: Enhanced weathering and $\mathrm{CO}_{2}$ drawdown caused by latest Eocene strengthening of the Atlantic meridional overturning circulation, Nat. Geosci., 10, 213-216, https://doi.org/10.1038/ngeo2888, 2017.

England, M. H., Hutchinson, D. K., Santoso, A., and Sijp, W. P.: Ice-Atmosphere Feedbacks Dominate the Response of the Climate System to Drake Passage Closure, J. Clim., 30, 5775-5790, https://doi.org/10.1175/JCLI-D-15-0554.1, 2017.

Erdei, B., Utescher, T., Hably, L., Tamas, J., Roth-Nebelsick, A., and Grein, M.: Early Oligocene continental climate of the Palaeogene Basin (Hungary and Slovenia) and the surrounding area, Turk. J. Earth Sci., 21, 153-186, https://doi.org/10.3906/yer-1005-29, 2012.

Eronen, J. T., Janis, C. M., Chamberlain, C. P., and Mulch, A.: Mountain uplift explains differences in Palaeogene patterns of mammalian evolution and extinction between North America and Europe, Proc. R. Soc. B-Biol. Sci., 282, 20150136, https://doi.org/10.1098/rspb.2015.0136, 2015.

Escutia, C., Brinkhuis, H., Klaus, A., and the IODP Expedition 318 Scientists: IODP Expedition 318: From Greenhouse to Icehouse at the Wilkes Land Antarctic Margin, Sci. Drill., 12, 1523, https://doi.org/10.2204/iodp.sd.12.02.2011, 2011.

Evans, D., Wade, B. S., Henehan, M., Erez, J., and Müller, W.: Revisiting carbonate chemistry controls on planktic foraminifera $\mathrm{Mg} / \mathrm{Ca}$ : implications for sea surface temperature and hydrology shifts over the Paleocene-Eocene Thermal Maximum and Eocene-Oligocene transition, Clim. Past, 12, 819-835, https://doi.org/10.5194/cp-12-819-2016, 2016.

Evans, D., Sagoo, N., Renema, W., Cotton, L. J., Müller, W., Todd, J. A., Saraswati, P. K., Stassen, P., Ziegler, M., Pearson, P. N., Valdes, P. J., and Affek, H. P.: Eocene greenhouse climate revealed by coupled clumped isotope- $\mathrm{Mg} / \mathrm{Ca}$ thermometry, Proc. Natl. Acad. Sci. USA, 115, 1174-1179, https://doi.org/10.1073/pnas.1714744115, 2018.

Exon, N. F., Kennett, J. P., and Malone, M. J.: Leg 189 Synthesis: Cretaceous - Holocene history of the Tasmanian gateway, in: Proceedings of the Ocean Drilling Program: Scientific Results, 189, available at: http://www-odp.tamu.edu/publications/ 189_SR/synth/synth.htm (last access: 10 April 2020), 2004.

Falkowski, P. G., Katz, M. E., Knoll, A. H., Quigg, A., Raven, J. A., Schofield, O., and Taylor, F. J. R.: The Evolution of Modern Eukaryotic Phytoplankton, Science, 305, 354-360, https://doi.org/10.1126/science.1095964, 2004.

Fan, M., Ayyash, S. A., Tripati, A., Passey, B. H., and Griffith, E. M.: Terrestrial cooling and changes in hydroclimate in the continental interior of the United States across the Eocene-Oligocene boundary, GSA Bull., 130, 1073-1084, https://doi.org/10.1130/B31732.1, 2017.

Fan, M., Feng, R., Geissman, J. W., and Poulsen, C. J.: Late Paleogene emergence of a North American loess plateau, Geology, 48, 273-277, https://doi.org/10.1130/G47102.1, 2020.

Farnsworth, A., Lunt, D. J., O’Brien, C., Foster, G. L., Inglis, G. N., Markwick, P., Pancost, R. D., and Robinson, S. A.: Climate sensitivity on geological timescales controlled by non-linear feedbacks and ocean circulation, Geophys. Res. Lett., 46, 9880-9889, https://doi.org/10.1029/2019GL083574, 2019.

Ferreira, D., Cessi, P., Coxall, H. K., de Boer, A., Dijkstra, H. A., Drijfhout, S. S., Eldevik, T., Harnik, N., McManus, J. F., Marshall, D. P., Nilsson, J., Roquet, F., Schneider, T., and Wills, R. C.: Atlantic-Pacific Asymmetry in Deep Water Formation, Annu. Rev. Earth Planet. Sci., 46, 327-352, https://doi.org/10.1146/annurev-earth-082517-010045, 2018.

Figueirido, B., Janis, C. M., Pérez-Claros, J. A., De Renzi, M., and Palmqvist, P.: Cenozoic climate change influences mammalian evolutionary dynamics, P. Natl. Acad. Sci. USA, 109, 722-727, https://doi.org/10.1073/pnas.1110246108, 2012.

Foster, G. L. and Rae, J. W. B.: Reconstructing Ocean pH with Boron Isotopes in Foraminifera, Annu. Rev. Earth 
Planet. Sci., 44, 207-237, https://doi.org/10.1146/annurev-earth060115-012226, 2016.

Foster, G. L., Lear, C. H., and Rae, J. W. B.: The evolution of $\mathrm{pCO}_{2}$, ice volume and climate during the middle Miocene, Earth Planet. Sci. Lett., 341-344, 243-254, https://doi.org/10.1016/j.epsl.2012.06.007, 2012.

Foster, G. L., Royer, D. L., and Lunt, D. J.: Future climate forcing potentially without precedent in the last 420 million years, Nat. Commun., 8, 14845, https://doi.org/10.1038/ncomms14845, 2017.

Francis, J. E., Marenssi, S., Levy, R., Hambrey, M., Thorn, V. C., Mohr, B., Brinkhuis, H., Warnaar, J., Zachos, J., Bohaty, S., and DeConto, R.: From Greenhouse to Icehouse - The Eocene/Oligocene in Antarctica, Chapter 8 in: Antarctic Climate Evolution, vol. 8, edited by: Florindo, F., Siegert, M., Elsevier, Amsterdam, the Netherlands, 309-368, 2008.

Franks, P. J., Royer, D. L., Beerling, D. J., Van de Water, P. K., Cantrill, D. J., Barbour, M. M., and Berry, J. A.: New constraints on atmospheric $\mathrm{CO}_{2}$ concentration for the Phanerozoic, Geophys. Res. Lett., 41, 4685-4694, https://doi.org/10.1002/2014GL060457, 2014.

Fyke, J. G., D’Orgeville, M., and Weaver, A. J.: Drake Passage and Central American Seaway controls on the distribution of the oceanic carbon reservoir, Glob. Planet. Change, 128, 72-82, https://doi.org/10.1016/j.gloplacha.2015.02.011, 2015.

Galeotti, S., DeConto, R., Naish, T., Stocchi, P., Florindo, F., Pagani, M., Barrett, P., Bohaty, S. M., Lanci, L., Pollard, D., Sandroni, S., Talarico, F. M., and Zachos, J. C.: Antarctic Ice Sheet variability across the EoceneOligocene boundary climate transition, Science, 352, 76-80, https://doi.org/10.1126/science.aab0669, 2016.

Gallagher, S. J., Wade, B., Qianyu, L., Holdgate, G. R., Bown, P., Korasidis, V. A., Scher, H., Houben, A. J. P., McGowran, B., and Allan, T.: Eocene to Oligocene high paleolatitude neritic record of Oi-1 glaciation in the Otway Basin southeast Australia, Glob. Planet. Change, 191, 103218, https://doi.org/10.1016/j.gloplacha.2020.103218, 2020.

Gallagher, T. M. and Sheldon, N. D.: A new paleothermometer for forest paleosols and its implications for Cenozoic climate, Geology, 41, 647-650, https://doi.org/10.1130/G34074.1, 2013.

Gasson, E., Siddall, M., Lunt, D. J., Rackham, O. J. L., Lear, C. H., and Pollard, D.: Exploring uncertainties in the relationship between temperature, ice volume, and sea level over the past 50 million years, Rev. Geophys., 50, RG1005, https://doi.org/10.1029/2011RG000358, 2012.

Gasson, E., Lunt, D. J., DeConto, R., Goldner, A., Heinemann, M., Huber, M., LeGrande, A. N., Pollard, D., Sagoo, N., Siddall, M., Winguth, A., and Valdes, P. J.: Uncertainties in the modelled $\mathrm{CO}_{2}$ threshold for Antarctic glaciation, Clim. Past, 10, 451-466, https://doi.org/10.5194/cp-10-451-2014, 2014.

Ghosh, P., Adkins, J., Affek, H., Balta, B., Guo, W., Schauble, E. A., Schrag, D., and Eiler, J. M.: 13C-18O bonds in carbonate minerals: A new kind of paleothermometer, Geochim. Cosmochim. Acta, 70, 1439-1456, https://doi.org/10.1016/j.gca.2005.11.014, 2006.

Gion, A. M., Williams, S. E., and Müller, R. D.: A reconstruction of the Eurekan Orogeny incorporating deformation constraints, Tectonics, 36, 304-320, https://doi.org/10.1002/2015TC004094, 2017.
Goddéris, Y., Donnadieu, Y., Le Hir, G., Lefebvre, V., and Nardin, E.: The role of palaeogeography in the Phanerozoic history of atmospheric $\mathrm{CO}_{2}$ and climate, Earth-Sci. Rev., 128, 122-138, https://doi.org/10.1016/j.earscirev.2013.11.004, 2014.

Goldner, A., Herold, N., and Huber, M.: Antarctic glaciation caused ocean circulation changes at the Eocene-Oligocene transition, Nature, 511, 574-577, https://doi.org/10.1038/nature13597, 2014.

Gradstein, F. M., Ogg, J. G., Schmitz, M., and Ogg, G.: The geologic time scale 2012, Elsevier, Amsterdam, the Netherlands, 2012.

Greenop, R., Hain, M. P., Sosdian, S. M., Oliver, K. I. C., Goodwin, P., Chalk, T. B., Lear, C. H., Wilson, P. A., and Foster, G. L.: A record of Neogene seawater $\delta 11 \mathrm{~B}$ reconstructed from paired $\delta^{11} \mathrm{~B}$ analyses on benthic and planktic foraminifera, Clim. Past, 13, 149-170, https://doi.org/10.5194/cp-13-149-2017, 2017.

Greenwood, D. R. and Wing, S. L.: Eocene continental climates and latitudinal temperature gradients, Geology, 23, 1044-1048, https://doi.org/10.1130/00917613(1995)023<1044:ECCALT>2.3.CO;2, 1995.

Grein, M., Oehm, C., Konrad, W., Utescher, T., Kunzmann, L., and Roth-Nebelsick, A.: Atmospheric $\mathrm{CO}_{2}$ from the late Oligocene to early Miocene based on photosynthesis data and fossil leaf characteristics, Palaeogeogr. Palaeoclimatol. Palaeoecol., 374, 41-51, https://doi.org/10.1016/j.palaeo.2012.12.025, 2013.

Griener, K. W., Nelson, D. M., and Warny, S.: Declining moisture availability on the Antarctic Peninsula during the Late Eocene, Palaeogeogr. Palaeoclimatol. Palaeoecol., 383-384, 7278, https://doi.org/10.1016/j.palaeo.2013.05.004, 2013.

Grimes, S. T., Hooker, J. J., Collinson, M. E., and Mattey, D. P.: Summer temperatures of late Eocene to early Oligocene freshwaters, Geology, 33, 189-192, https://doi.org/10.1130/G21019.1, 2005.

Gurnis, M., Yang, T., Cannon, J., Turner, M., Williams, S., Flament, N., and Müller, R. D.: Global tectonic reconstructions with continuously deforming and evolving rigid plates, Comput. Geosci., 116, 32-41, https://doi.org/10.1016/j.cageo.2018.04.007, 2018.

Haiblen, A. M., Opdyke, B. N., Roberts, A. P., Heslop, D., and Wilson, P. A.: Midlatitude Southern Hemisphere Temperature Change at the End of the Eocene Greenhouse Shortly Before Dawn of the Oligocene Icehouse, Paleoceanogr. Paleoclimatol., 34, 1995-2004, https://doi.org/10.1029/2019PA003679, 2019.

Hegewald, A. and Jokat, W.: Relative sea level variations in the Chukchi region - Arctic Ocean - since the late Eocene, Geophys. Res. Lett., 40, 803-807, https://doi.org/10.1002/grl.50182, 2013.

Helland, P. E. and Holmes, M. A.: Surface textural analysis of quartz sand grains from ODP Site 918 off the southeast coast of Greenland suggests glaciation of southern Greenland at 11 Ma, Palaeogeogr. Palaeoclimatol. Palaeoecol., 135, 109-121, https://doi.org/10.1016/S0031-0182(97)00025-4, 1997.

Héran, M., Lécuyer, C., and Legendre, S.: Cenozoic long-term terrestrial climatic evolution in Germany tracked by $\delta^{18} \mathrm{O}$ of rodent tooth phosphate, Palaeogeogr. Palaeoclimatol. Palaeoecol., 285, 331-342, https://doi.org/10.1016/j.palaeo.2009.11.030, 2010.

Herman, A. B., Spicer, R. A., Aleksandrova, G. N., Yang, J., Kodrul, T. M., Maslova, N. P., Spicer, T. E. V, Chen, G., and Jin, J.-H.: Eocene-early Oligocene climate and vegetation change in southern China: Evidence from the Maoming 
Basin, Palaeogeogr. Palaeoclimatol. Palaeoecol., 479, 126-137, https://doi.org/10.1016/j.palaeo.2017.04.023, 2017.

Herold, N., Buzan, J., Seton, M., Goldner, A., Green, J. A. M., Müller, R. D., Markwick, P., and Huber, M.: A suite of early Eocene $(\sim 55 \mathrm{Ma})$ climate model boundary conditions, Geosci. Model Dev., 7, 2077-2090, https://doi.org/10.5194/gmd-7-20772014, 2014.

Heureux, A. M. C. and Rickaby, R. E. M.: Refining our estimate of atmospheric $\mathrm{CO}_{2}$ across the Eocene-Oligocene climatic transition, Earth Planet. Sci. Lett., 409, 329-338, https://doi.org/10.1016/j.epsl.2014.10.036, 2015.

Hill, D. J., Haywood, A. M., Valdes, P. J., Francis, J. E., Lunt, D. J., Wade, B. S., and Bowman, V. C.: Paleogeographic controls on the onset of the Antarctic circumpolar current, Geophys. Res. Lett., 40, 5199-5204, https://doi.org/10.1002/grl.50941, 2013.

Hincke, A. J. C., Broere, T., Kürschner, W. M., Donders, T. H., and Wagner-Cremer, F.: Multi-year leaflevel response to sub-ambient and elevated experimental $\mathrm{CO}_{2}$ in Betula nana, PLoS One, 11, e0157400, https://doi.org/10.1371/journal.pone.0157400, 2016.

Hinojosa, L. F. and Villagrán, C.: Did South American Mixed Paleofloras evolve under thermal equability or in the absence of an effective Andean barrier during the Cenozoic?, Palaeogeogr. Palaeoclimatol. Palaeoecol., 217, 1-23, https://doi.org/10.1016/j.palaeo.2004.11.013, 2005.

Hohbein, M. W., Sexton, P. F., and Cartwright, J. A.: Onset of North Atlantic Deep Water production coincident with inception of the Cenozoic global cooling trend, Geology, 40, 255-258, https://doi.org/10.1130/G32461.1, 2012.

Hollis, C. J., Handley, L., Crouch, E. M., Morgans, H. E. G., Baker, J. A., Creech, J., Collins, K. S., Gibbs, S. J., Huber, M., Schouten, S., Zachos, J. C., and Pancost, R. D.: Tropical sea temperatures in the high-latitude South Pacific during the Eocene, Geology, 37, 99-102, https://doi.org/10.1130/G25200A.1, 2009.

Hollis, C. J., Taylor, K. W. R., Handley, L., Pancost, R. D., Huber, M., Creech, J. B., Hines, B. R., Crouch, E. M., Morgans, H. E. G., Crampton, J. S., Gibbs, S., Pearson, P. N., and Zachos, J. C.: Early Paleogene temperature history of the Southwest Pacific Ocean: Reconciling proxies and models, Earth Planet. Sci. Lett., 349-350, 53-66, https://doi.org/10.1016/j.epsl.2012.06.024, 2012.

Hollis, C. J., Dunkley Jones, T., Anagnostou, E., Bijl, P. K., Cramwinckel, M. J., Cui, Y., Dickens, G. R., Edgar, K. M., Eley, Y., Evans, D., Foster, G. L., Frieling, J., Inglis, G. N., Kennedy, E. M., Kozdon, R., Lauretano, V., Lear, C. H., Littler, K., Lourens, L., Meckler, A. N., Naafs, B. D. A., Pälike, H., Pancost, R. D., Pearson, P. N., Röhl, U., Royer, D. L., Salzmann, U., Schubert, B. A., Seebeck, H., Sluijs, A., Speijer, R. P., Stassen, P., Tierney, J., Tripati, A., Wade, B., Westerhold, T., Witkowski, C., Zachos, J. C., Zhang, Y. G., Huber, M., and Lunt, D. J.: The DeepMIP contribution to PMIP4: methodologies for selection, compilation and analysis of latest Paleocene and early Eocene climate proxy data, incorporating version 0.1 of the DeepMIP database, Geosci. Model Dev., 12, 3149-3206, https://doi.org/10.5194/gmd-12-3149-2019, 2019.

Homes, A. M., Cieraad, E., Lee, D. E., Lindqvist, J. K., Raine, J. I., Kennedy, E. M., and Conran, J. G.: A diverse fern flora including macrofossils with in situ spores from the late Eocene of southern New Zealand, Rev. Palaeobot. Palynol., 220, 16-28, https://doi.org/10.1016/j.revpalbo.2015.04.007, 2015.

Hooker, J. J., Collinson, M. E., and Sille, N. P.: EoceneOligocene mammalian faunal turnover in the Hampshire Basin, UK: calibration to the global time scale and the major cooling event, J. Geol. Soc. London., 161, 161-172, https://doi.org/10.1144/0016-764903-091, 2004.

Hoorn, C., Straathof, J., Abels, H. A., Xu, Y., Utescher, T., and Dupont-Nivet, G.: A late Eocene palynological record of climate change and Tibetan Plateau uplift (Xining Basin, China), Palaeogeogr. Palaeoclimatol. Palaeoecol., 344-345, 1638, https://doi.org/10.1016/j.palaeo.2012.05.011, 2012.

Houben, A. J. P., van Mourik, C. A., Montanari, A., Coccioni, R., and Brinkhuis, H.: The Eocene-Oligocene transition: Changes in sea level, temperature or both?, Palaeogeogr. Palaeoclimatol. Palaeoecol., 335-336, 75-83, https://doi.org/10.1016/j.palaeo.2011.04.008, 2012.

Hren, M. T., Sheldon, N. D., Grimes, S. T., Collinson, M. E., Hooker, J. J., Bugler, M., and Lohmann, K. C.: Terrestrial cooling in Northern Europe during the EoceneOligocene transition, P. Natl. Acad. Sci. USA, 110, 7562-7567, https://doi.org/10.1073/pnas.1210930110, 2013.

Huang, X., Gohl, K., and Jokat, W.: Variability in Cenozoic sedimentation and paleo-water depths of the Weddell Sea basin related to pre-glacial and glacial conditions of Antarctica, Glob. Planet. Change, 118, 25-41, https://doi.org/10.1016/j.gloplacha.2014.03.010, 2014.

Huber, M.: A Hotter Greenhouse?, Science, 321, 353-354, https://doi.org/10.1126/science.1161170, 2008.

Huber, M. and Caballero, R.: The early Eocene equable climate problem revisited, Clim. Past, 7, 603-633, https://doi.org/10.5194/cp-7-603-2011, 2011.

Huber, M. and Nof, D.: The ocean circulation in the southern hemisphere and its climatic impacts in the Eocene, Palaeogeogr. Palaeoclimatol. Palaeoecol., 231, 9-28, https://doi.org/10.1016/j.palaeo.2005.07.037, 2006.

Huber, M. and Sloan, L. C.: Climatic responses to tropical sea surface temperature changes on a "greenhouse" Earth, Paleoceanography, 15, 443-450, https://doi.org/10.1029/1999PA000455, 2000.

Huber, M. and Sloan, L. C.: Heat transport, deep waters, and thermal gradients: Coupled simulation of an Eocene greenhouse climate, Geophys. Res. Lett., 28, 3481-3484, https://doi.org/10.1029/2001GL012943, 2001.

Huber, M., Sloan, L., and Shellito, C.: Early Paleogene oceans and climate: A fully coupled modeling approach using the NCAR CCSM, in: Causes and consequences of globally warm climates in the Early Paleogene, Geol. Soc. Am. Spec. Pap., 369, 25-47, 2003.

Huber, M., Brinkhuis, H., Stickley, C. E., Döös, K., Sluijs, A., Warnaar, J., Schellenberg, S. A., and Williams, G. L.: Eocene circulation of the Southern Ocean: Was Antarctica kept warm by subtropical waters?, Paleoceanography, 19, PA4026, https://doi.org/10.1029/2004PA001014, 2004.

Hurley, S. J., Elling, F. J., Könneke, M., Buchwald, C., Wankel, S. D., Santoro, A. E., Lipp, J. S., Hinrichs, K.U., and Pearson, A.: Influence of ammonia oxidation rate on thaumarchaeal lipid composition and the $\mathrm{TEX}_{86}$ tem- 
perature proxy, P. Natl. Acad. Sci. USA, 113, 7762-7767, https://doi.org/10.1073/pnas.1518534113, 2016.

Hutchinson, D. K., de Boer, A. M., Coxall, H. K., Caballero, R., Nilsson, J., and Baatsen, M.: Climate sensitivity and meridional overturning circulation in the late Eocene using GFDL CM2.1, Clim. Past, 14, 789-810, https://doi.org/10.5194/cp-14789-2018, 2018.

Hutchinson, D. K., Coxall, H. K., O’Regan, M., Nilsson, J., Caballero, R. and de Boer, A. M.: Arctic closure as a trigger for Atlantic overturning at the Eocene-Oligocene Transition, Nat. Commun., 10, 3797, https://doi.org/10.1038/s41467-019-11828z, 2019.

Hyeong, K., Kuroda, J., Seo, I., and Wilson, P. A.: Response of the Pacific inter-tropical convergence zone to global cooling and initiation of Antarctic glaciation across the Eocene Oligocene Transition, Sci. Rep., 6, 30647, https://doi.org/10.1038/srep30647, 2016.

Inglis, G. N., Farnsworth, A., Lunt, D., Foster, G. L., Hollis, C. J., Pagani, M., Jardine, P. E., Pearson, P. N., Markwick, P., Galsworthy, A. M. J., Raynham, L., Taylor, K. W. R., and Pancost, R. D.: Descent toward the Icehouse: Eocene sea surface cooling inferred from GDGT distributions, Paleoceanography, 30, 10001020, https://doi.org/10.1002/2014PA002723, 2015.

Inglis, G. N., Bragg, F., Burls, N. J., Cramwinckel, M. J., Evans, D., Foster, G. L., Huber, M., Lunt, D. J., Siler, N., Steinig, S., Tierney, J. E., Wilkinson, R., Anagnostou, E., de Boer, A. M., Dunkley Jones, T., Edgar, K. M., Hollis, C. J., Hutchinson, D. K., and Pancost, R. D.: Global mean surface temperature and climate sensitivity of the early Eocene Climatic Optimum (EECO), Paleocene-Eocene Thermal Maximum (PETM), and latest Paleocene, Clim. Past, 16, 1953-1968, https://doi.org/10.5194/cp16-1953-2020, 2020.

IPCC: Climate Change 2013: The Physical Science Basis. Contribution of Working Group I to the Fifth Assessment Report of the Intergovernmental Panel on Climate Change, edited by: Stocker, T. F., Qin, D., Plattner, G.-K., Tignor, M., Allen, S. K., Boschung, J., Nauels, A., Xia, Y., Bex, V., Midgley, P. M., Cambridge University Press, Cambridge, United Kingdom and New York, NY, USA, 2013.

Jacobs, B. F., Pan, A. D., and Scotese, C. R.: A review of the Cenozoic vegetation history of Africa, in: Cenozoic mammals of Africa, edited by: Werdelin, W. J., Sanders, L., University of California Press, Berkeley, CA, 57-72, 2010.

Jakobsson, M., Backman, J., Rudels, B., Nycander, J., Frank, M., Mayer, L., Jokat, W., Sangiorgi, F., O/'Regan, M., Brinkhuis, H., King, J., and Moran, K.: The early Miocene onset of a ventilated circulation regime in the Arctic Ocean, Nature, 447, 986-990, https://doi.org/10.1038/nature05924, 2007.

Japsen, P., Bonow, J. M., Green, P. F., Chalmers, J. A., and Lidmar-Bergström, K.: Elevated, passive continental margins: Long-term highs or Neogene uplifts? New evidence from West Greenland, Earth Planet. Sci. Lett., 248, 330-339, https://doi.org/10.1016/j.epsl.2006.05.036, 2006.

Japsen, P., Green, P. F., and Bonow, J. M.: Investigation of the Burial and Exhumation History of East Greenland Based On Apatitefission Track Analysis, Stratigraphic Landform Analysis and the Geological Record, OTC Arct. Technol. Conf., 23-25 March 2015, Copenhagen, Denmark, 8, https://doi.org/10.4043/25562MS, 2015.
Jin, J.-H., Herman, A. B., Spicer, R. A., and Kodrul, T. M.: Palaeoclimate background of the diverse Eocene floras of South China, Sci. Bull., 62, 1501-1503, https://doi.org/10.1016/j.scib.2017.11.002, 2017.

John, E. H., Pearson, P. N., Coxall, H. K., Birch, H., Wade, B. S., and Foster, G. L.: Warm ocean processes and carbon cycling in the Eocene, Philos. Trans. R. Soc. A-Math. Phys., 371, 20130099, https://doi.org/10.1098/rsta.2013.0099, 2013.

John, E. H., Wilson, J. D., Pearson, P. N., and Ridgwell, A.: Temperature-dependent remineralization and carbon cycling in the warm Eocene oceans, Palaeogeogr. Palaeoclimatol. Palaeoecol., 413, 158-166, https://doi.org/10.1016/j.palaeo.2014.05.019, 2014.

Jones, A. P., Dunkley Jones, T., Coxall, H., Pearson, P. N., Nala, D., and Hoggett, M.: Low-Latitude Calcareous Nannofossil Response in the Indo-Pacific Warm Pool Across the EoceneOligocene Transition of Java, Indonesia, Paleoceanogr. Paleoclimatol., 34, 1833-1847, https://doi.org/10.1029/2019PA003597, 2019.

Katz, M. E., Miller, K. G., Wright, J. D., Wade, B. S., Browning, J. V, Cramer, B. S., and Rosenthal, Y.: Stepwise transition from the Eocene greenhouse to the Oligocene icehouse, Nat. Geosci., 1, 329, https://doi.org/10.1038/ngeo179, 2008.

Katz, M. E., Cramer, B. S., Toggweiler, J. R., Esmay, G., Liu, C., Miller, K. G., Rosenthal, Y., Wade, B. S., and Wright, J. D.: Impact of Antarctic Circumpolar Current development on late Paleogene ocean structure, Science, 332, 1076-1079, https://doi.org/10.1126/science.1202122, 2011.

Kennedy-Asser, A. T., Lunt, D. J., Farnsworth, A., and Valdes, P. J.: Assessing Mechanisms and Uncertainty in Modeled Climatic Change at the Eocene-Oligocene Transition, Paleoceanogr. Paleoclimatol., 34, 16-34, https://doi.org/10.1029/2018PA003380, 2019.

Kennedy-Asser, A. T., Lunt, D. J., Valdes, P. J., Ladant, J.B., Frieling, J., and Lauretano, V.: Changes in the highlatitude Southern Hemisphere through the Eocene-Oligocene transition: a model-data comparison, Clim. Past, 16, 555-573, https://doi.org/10.5194/cp-16-555-2020, 2020.

Kennedy, A. T., Farnsworth, A., Lunt, D. J., Lear, C. H., and Markwick, P. J.: Atmospheric and oceanic impacts of Antarctic glaciation across the Eocene-Oligocene transition, Philos. Trans. R. Soc. A, 373, 20140419, https://doi.org/10.1098/rsta.2014.0419, 2015.

Kennett, J. P.: Cenozoic Evolution of Antarctic Glaciation, the Circum-Antarctic Ocean, and Their Impact on Global Paleoceanography, J. Geophys. Res., 82, 3843-3860, https://doi.org/10.1029/JC082i027p03843, 1977.

Kennett, J. P. and Shackleton, N. J.: Oxygen isotopic evidence for the development of the psychrosphere $38 \mathrm{Myr}$ ago, Nature, 260, 513, https://doi.org/10.1038/260513a0, 1976.

Kennett, J. P., Houtz, R. E., Andrews, P. B., Edwards, A. R., Gostin, V. A., Hajos, M., Hampton, M., Jenkins, D. G., Margolis, S. V, Ovenshine, A. T., and Perch-Nielsen, K.: Cenozoic paleoceanography in the Southwest Pacific Ocean, Antarctic glaciation, and the development of the CircumAntarctic Current, Initial Rep. Deep Sea Drill. Proj., 29, 1155, https://doi.org/10.2973/dsdp.proc.29.144.1975, 1975.

Kiehl, J. T. and Shields, C. A.: Sensitivity of the PalaeoceneEocene Thermal Maximum climate to cloud properties, 
Philos. Trans. R. Soc. A-Math. Phys., 371, 20130093, https://doi.org/10.1098/rsta.2013.0093, 2013.

Kim, J.-H., van der Meer, J., Schouten, S., Helmke, P., Willmott, V., Sangiorgi, F., Koç, N., Hopmans, E. C., and Damsté, J. S. S.: New indices and calibrations derived from the distribution of crenarchaeal isoprenoid tetraether lipids: Implications for past sea surface temperature reconstructions, Geochim. Cosmochim. Acta, 74, 4639-4654, https://doi.org/10.1016/j.gca.2010.05.027, 2010.

Kim, S. L., Eberle, J. J., Bell, D. M., Fox, D. A., and Padilla, A.: Evidence from shark teeth for a brackish Arctic Ocean in the Eocene greenhouse, Geology, 42, 695-698, https://doi.org/10.1130/G35675.1, 2014.

Kobashi, T., Grossman, E. L., Dockery, D. T., and Ivany, L. C.: Water mass stability reconstructions from greenhouse (Eocene) to icehouse (Oligocene) for the northern Gulf Coast continental shelf (USA), Paleoceanography, 19, PA1022, https://doi.org/10.1029/2003PA000934, 2004.

Kocsis, L., Ozsvárt, P., Becker, D., Ziegler, R., Scherler, L., and Codrea, V.: Orogeny forced terrestrial climate variation during the late Eocene-early Oligocene in Europe, Geology, 42, 727730, https://doi.org/10.1130/G35673.1, 2014.

Kohn, M. J., Josef, J. A., Madden, R., Kay, R., Vucetich, G., and Carlini, A. A.: Climate stability across the EoceneOligocene transition, southern Argentina, Geology, 32, 621-624, https://doi.org/10.1130/G20442.1, 2004.

Kohn, M. J., Strömberg, C. A. E., Madden, R. H., Dunn, R. E., Evans, S., Palacios, A., and Carlini, A. A.: Quasistatic Eocene-Oligocene climate in Patagonia promotes slow faunal evolution and mid-Cenozoic global cooling, Palaeogeogr. Palaeoclimatol. Palaeoecol., 435, 24-37, https://doi.org/10.1016/j.palaeo.2015.05.028, 2015.

Konrad, W., Roth-Nebelsick, A., and Grein, M.: Modelling of stomatal density response to atmospheric $\mathrm{CO}_{2}$, J. Theor. Biol., 253, 638-658, https://doi.org/10.1016/j.jtbi.2008.03.032, 2008.

Korasidis, V. A., Wallace, M. W., Wagstaff, B. E., and Hill, R. S.: Terrestrial cooling record through the Eocene-Oligocene transition of Australia, Glob. Planet. Change, 173, 61-72, https://doi.org/10.1016/j.gloplacha.2018.12.007, 2019.

Kovar-Eder, J.: Early Oligocene plant diversity along the Upper Rhine Graben: The fossil flora of Rauenberg, Germany, Acta Palaeobot., 56, 329, https://doi.org/10.1515/acpa-20160011, 2016.

Kraatz, B. P. and Geisler, J. H.: Eocene-Oligocene transition in Central Asia and its effects on mammalian evolution, Geology, 38, 111-114, https://doi.org/10.1130/G30619.1, 2010.

Krylov, A. A., Andreeva, I. A., Vogt, C., Backman, J., Krupskaya, V. V, Grikurov, G. E., Moran, K., and Shoji, H.: A shift in heavy and clay mineral provenance indicates a middle Miocene onset of a perennial sea ice cover in the Arctic Ocean, Paleoceanography, 23, PA1S06, https://doi.org/10.1029/2007PA001497, 2008.

Kunzmann, L., Kvaček, Z., Teodoridis, V., Müller, C., and Moraweck, K.: Vegetation dynamics of riparian forest in central Europe during the late Eocene, Palaeontogr. Abteilung B, 295, 69-89, https://doi.org/10.1127/palb/295/2016/69, 2016.

Kürschner, W. M., Kvaček, Z., and Dilcher, D. L.: The impact of Miocene atmospheric carbon dioxide fluctuations on climate and the evolution of terrestrial ecosystems, P. Natl. Acad. Sci. USA, 105, 449-453, https://doi.org/10.1073/pnas.0708588105, 2008.
Kvaček, Z., Teodoridis, V., Mach, K., Přikryl, T., and Dvořák, Z:: Tracing the Eocene-Oligocene transition: a case study from North Bohemia, Bull. Geosci., 89, 21-66, https://doi.org/10.3140/bull.geosci.1411, 2014.

Ladant, J.-B., Donnadieu, Y., and Dumas, C.: Links between $\mathrm{CO}_{2}$, glaciation and water flow: reconciling the Cenozoic history of the Antarctic Circumpolar Current, Clim. Past, 10, 1957-1966, https://doi.org/10.5194/cp-10-1957-2014, 2014a.

Ladant, J.-B., Donnadieu, Y., Lefebvre, V., and Dumas, C.: The respective role of atmospheric carbon dioxide and orbital parameters on ice sheet evolution at the EoceneOligocene transition, Paleoceanography, 29, 810-823, https://doi.org/10.1002/2013PA002593, 2014b.

Langton, S. J., Rabideaux, N. M., Borrelli, C., and Katz, M. E.: Southeastern Atlantic deep-water evolution during the latemiddle Eocene to earliest Oligocene (Ocean Drilling Program Site 1263 and Deep Sea Drilling Project Site 366), Geosphere, 12, 1032-1047, https://doi.org/10.1130/GES01268.1, 2016.

Larsen, H. C., Saunders, A. D., Clift, P. D., Beget, J., Wei, W., and Spezzaferri, S.: Seven Million Years of Glaciation in Greenland, Science, 264, 952-955, https://doi.org/10.1126/science.264.5161.952, 1994.

Lasabuda, A., Laberg, J. S., Knutsen, S.-M., and Høgseth, G.: Early to middle Cenozoic paleoenvironment and erosion estimates of the southwestern Barents Sea: Insights from a regional mass-balance approach, Mar. Pet. Geol., 96, 501-521, https://doi.org/10.1016/j.marpetgeo.2018.05.039, 2018.

Lear, C. H., Elderfield, H., and Wilson, P. A.: Cenozoic DeepSea Temperatures and Global Ice Volumes from $\mathrm{Mg} / \mathrm{Ca}$ in Benthic Foraminiferal Calcite, Science, 287, 269-272, https://doi.org/10.1126/science.287.5451.269, 2000.

Lear, C. H., Rosenthal, Y., Coxall, H. K., and Wilson, P. A.: Late Eocene to early Miocene ice sheet dynamics and the global carbon cycle, Paleoceanography, 19, PA4015, https://doi.org/10.1029/2004PA001039, 2004.

Lear, C. H., Bailey, T. R., Pearson, P. N., Coxall, H. K., and Rosenthal, Y.: Cooling and ice growth across the Eocene-Oligocene transition, Geology, 36, 251, https://doi.org/10.1130/G24584A.1, 2008.

Lear, C. H., Mawbey, E. M., and Rosenthal, Y.: Cenozoic benthic foraminiferal $\mathrm{Mg} / \mathrm{Ca}$ and $\mathrm{Li} / \mathrm{Ca}$ records: Toward unlocking temperatures and saturation states, Paleoceanography, 25, PA4215, https://doi.org/10.1029/2009PA001880, 2010.

Lear, C. H., Coxall, H. K., Foster, G. L., Lunt, D. J., Mawbey, E. M., Rosenthal, Y., Sosdian, S. M., Thomas, E., and Wilson, P. A.: Neogene ice volume and ocean temperatures: Insights from infaunal foraminiferal $\mathrm{Mg}$ / Ca paleothermometry, Paleoceanography, 30, 1437-1454, https://doi.org/10.1002/2015PA002833, 2015.

Lefebvre, V., Donnadieu, Y., Sepulchre, P., Swingedouw, D., and Zhang, Z.-S.: Deciphering the role of southern gateways and carbon dioxide on the onset of the Antarctic Circumpolar Current, Paleoceanography, 27, PA4201, https://doi.org/10.1029/2012PA002345, 2012.

Lielke, K., Manchester, S., and Meyer, H.: Reconstructing the environment of the northern Rocky Mountains during the Eocene/Oligocene transition: constraints from the palaeobotany and geology of south-western Montana, USA, Acta Palaeobot., 52, 317-358, 2012. 
Linnemann, U., Su, T., Kunzmann, L., Spicer, R. A., Ding, W.-N., Spicer, T. E. V, Zieger, J., Hofmann, M., Moraweck, K., Gärtner, A., Gerdes, A., Marko, L., Zhang, S.-T., Li, S.-F., Tang, H., Huang, J., Mulch, A., Mosbrugger, V., and Zhou, Z.-K.: New U-Pb dates show a Paleogene origin for the modern Asian biodiversity hot spots, Geology, 46, 3-6, https://doi.org/10.1130/G39693.1, 2017.

Liu, W., Xie, S.-P., Liu, Z., and Zhu, J.: Overlooked possibility of a collapsed Atlantic Meridional Overturning Circulation in warming climate, Sci. Adv., 3, e1601666, https://doi.org/10.1126/sciadv.1601666, 2017.

Liu, X. Y., Gao, Q., Han, M., and Jin, J. H.: Estimates of late middle Eocene $p \mathrm{CO}_{2}$ based on stomatal density of modern and fossil Nageia leaves, Clim. Past, 12, 241-253, https://doi.org/10.5194/cp-12-241-2016, 2016.

Liu, Z., Tuo, S., Zhao, Q., Cheng, X., and Huang, W.: Deep-water Earliest Oligocene Glacial Maximum (EOGM) in South Atlantic, Chinese Sci. Bull., 49, 2190-2197, https://doi.org/10.1007/BF03185787, 2004.

Liu, Z., Pagani, M., Zinniker, D., DeConto, R., Huber, M., Brinkhuis, H., Shah, S. R., Leckie, R. M., and Pearson, A.: Global Cooling During the EoceneOligocene Climate Transition, Science, 323, 1187-1190, https://doi.org/10.1126/science.1166368, 2009.

Liu, Z., He, Y., Jiang, Y., Wang, H., Liu, W., Bohaty, S. M., and Wilson, P. A.: Transient temperature asymmetry between hemispheres in the Palaeogene Atlantic Ocean, Nat. Geosci., 11, 656660, https://doi.org/10.1038/s41561-018-0182-9, 2018.

Livermore, R., Hillenbrand, C.-D., Meredith, M., and Eagles, G.: Drake Passage and Cenozoic climate: An open and shut case?, Geochem. Geophy. Geosy., 8, Q01005, https://doi.org/10.1029/2005GC001224, 2007.

Lunt, D. J., Ridgwell, A., Valdes, P. J., and Seale, A.: "Sunshade World": A fully coupled GCM evaluation of the climatic impacts of geoengineering, Geophys. Res. Lett., 35, L12710, https://doi.org/10.1029/2008GL033674, 2008.

Lunt, D. J., Dunkley Jones, T., Heinemann, M., Huber, M., LeGrande, A., Winguth, A., Loptson, C., Marotzke, J., Roberts, C. D., Tindall, J., Valdes, P., and Winguth, C.: A modeldata comparison for a multi-model ensemble of early Eocene atmosphere-ocean simulations: EoMIP, Clim. Past, 8, 17171736, https://doi.org/10.5194/cp-8-1717-2012, 2012.

Lunt, D. J., Farnsworth, A., Loptson, C., Foster, G. L., Markwick, P., O'Brien, C. L., Pancost, R. D., Robinson, S. A., and Wrobel, N.: Palaeogeographic controls on climate and proxy interpretation, Clim. Past, 12, 1181-1198, https://doi.org/10.5194/cp-12-11812016, 2016.

Lunt, D. J., Bragg, F., Chan, W.-L., Hutchinson, D. K., Ladant, J.B., Morozova, P., Niezgodzki, I., Steinig, S., Zhang, Z., Zhu, J., Abe-Ouchi, A., Anagnostou, E., de Boer, A. M., Coxall, H. K., Donnadieu, Y., Foster, G., Inglis, G. N., Knorr, G., Langebroek, P. M., Lear, C. H., Lohmann, G., Poulsen, C. J., Sepulchre, P., Tierney, J. E., Valdes, P. J., Volodin, E. M., Dunkley Jones, T., Hollis, C. J., Huber, M., and Otto-Bliesner, B. L.: DeepMIP: model intercomparison of early Eocene climatic optimum (EECO) large-scale climate features and comparison with proxy data, Clim. Past, 17, 203-227, https://doi.org/10.5194/cp17-203-2021, 2021.
Lyell, C. and Deshayes, G. P.: Principles of Geology: being an attempt to explain the former changes of the Earth's surface, by reference to causes now in operation, John Murray, London, 1830.

Macphail, M.: Australian palaeoclimates: Cretaceous to Tertiary a review of palaeobotanical and related evidence to the year 2000, CRC LEME Open File Report 151, CRC LEME, Bentley, WA, Australia, 2007.

Maher, K. and Chamberlain, C. P.: Hydrologic Regulation of Chemical Weathering and the Geologic Carbon Cycle, Science, 343, 1502-1504, https://doi.org/10.1126/science.1250770, 2014.

Mai, D. H.: Tertiäre Vegetationsgeschichte Europas, Feddes Repert., 106, 331, https://doi.org/10.1002/fedr.19951060333, 1995.

Markwick, P. J.: The palaeogeographic and palaeoclimatic significance of climate proxies for data-model comparisons, in: Deeptime perspectives on climate change: marrying the signal from computer models and biological proxies, Micropalaeontol. Soc. Spec. Publ., London, 251-312, 2007.

Markwick, P. J.: Palaeogeography in exploration, Geol. Mag., 156, 366-407, https://doi.org/10.1017/S0016756818000468, 2019.

Markwick, P. J. and Valdes, P. J.: Palaeo-digital elevation models for use as boundary conditions in coupled ocean-atmosphere GCM experiments: a Maastrichtian (late Cretaceous) example, Palaeogeogr. Palaeoclimatol. Palaeoecol., 213, 37-63, https://doi.org/10.1016/j.palaeo.2004.06.015, 2004.

Martin, H. A.: Cenozoic climatic change and the development of the arid vegetation in Australia, J. Arid Environ., 66, 533-563, https://doi.org/10.1016/j.jaridenv.2006.01.009, 2006.

Martini, E.: Standard Tertiary and Quaternary calcareous nannoplankton zonation, in: Proc. II Planktonic Conference, Roma 1970, Tecnoscienza, Roma, edited by: Farinacci, A., 739-785, 1971.

Maslin, M. A., Li, X. S., Loutre, M.-F., and Berger, A.: The contribution of orbital forcing to the progressive intensification of Northern Hemisphere glaciation, Quat. Sci. Rev., 17, 411-426, https://doi.org/10.1016/S0277-3791(97)00047-4, 1998.

Maxbauer, D. P., Royer, D. L., and LePage, B. A.: High Arctic forests during the middle Eocene supported by moderate levels of atmospheric $\mathrm{CO}_{2}$, Geology, 42, 1027-1030, https://doi.org/10.1130/G36014.1, 2014.

McElwain, J. C. and Chaloner, W. G.: Stomatal Density and Index of Fossil Plants Track Atmospheric Carbon Dioxide in the Palaeozoic, Ann. Bot., 76, 389-395, https://doi.org/10.1006/anbo.1995.1112, 1995.

McElwain, J. C. and Steinthorsdottir, M.: Paleoecology, Ploidy, Paleoatmospheric Composition, and Developmental Biology: A Review of the Multiple Uses of Fossil Stomata, Plant Physiol., 174, 650-664, 2017.

McKay, R. M., Barrett, P. J., Levy, R. S., Naish, T. R., Golledge, N. R., and Pyne, A.: Antarctic Cenozoic climate history from sedimentary records: ANDRILL and beyond, Philos. Trans. R. Soc. A-Math. Phys., 374, 20140301, https://doi.org/10.1098/rsta.2014.0301, 2016.

McKinley, C. C., Thomas, D. J., LeVay, L. J., and Rolewicz, Z.: Nd isotopic structure of the Pacific Ocean 40-10 Ma, and evidence for the reorganization of deep North Pacific Ocean circulation between 36 and 25 Ma, Earth Planet. Sci. Lett., 521, 139-149, https://doi.org/10.1016/j.epsl.2019.06.009, 2019. 
Meng, J. and McKenna, M. C.: Faunal turnovers of Palaeogene mammals from the Mongolian Plateau, Nature, 394, 364-367, https://doi.org/10.1038/28603, 1998.

Merico, A., Tyrrell, T., and Wilson, P. A.: Eocene/Oligocene ocean de-acidification linked to Antarctic glaciation by sea-level fall, Nature, 452, 979-982, https://doi.org/10.1038/nature06853, 2008.

Meyers, J. A.: Terrestrial Eocene-Oligocene vegetation and climate in the Pacific Northwest, in: From Greenhouse to Icehouse: The Marine Eocene-Oligocene Transition, edited by: Prothero, D. R., Ivany, L. C., Nesbitt, E. A.,Columbia University Press, New York, 171-185, 2003.

Mihlbachler, M. C., Rivals, F., Solounias, N., and Semprebon, G. M.: Dietary Change and Evolution of Horses in North America, Science, 331, 1178-1181, https://doi.org/10.1126/science.1196166, 2011.

Mikolajewicz, U., Maier-Reimer, E., Crowley, T. J., and Kim, K.-Y.: Effect of Drake and Panamanian Gateways on the circulation of an ocean model, Paleoceanography, 8, 409-426, https://doi.org/10.1029/93PA00893, 1993.

Miller, K. G., Janecek, T. R., Katz, M. E., and Keil, D. J.: Abyssal circulation and benthic foraminiferal changes near the Paleocene/Eocene boundary, Paleoceanography, 2, 741-761, https://doi.org/10.1029/PA002i006p00741, 1987.

Miller, K. G., Wright, J. D., and Fairbanks, R. G.: Unlocking the Ice House: Oligocene-Miocene oxygen isotopes, eustasy, and margin erosion, J. Geophys. Res.-Sol. Ea., 96, 6829-6848, https://doi.org/10.1029/90JB02015, 1991.

Miller, K. G., Browning, J. V, Aubry, M.-P., Wade, B. S., Katz, M. E., Kulpecz, A. A., and Wright, J. D.: Eocene-Oligocene global climate and sea-level changes: St. Stephens Quarry, Alabama, GSA Bull., 120, 34-53, https://doi.org/10.1130/B26105.1, 2008.

Moraweck, K., Grein, M., Konrad, W., Kvaček, J., KovaEder, J., Neinhuis, C., Traiser, C., and Kunzmann, L.: Leaf traits of long-ranging Paleogene species and their relationship with depositional facies, climate and atmospheric $\mathrm{CO}_{2}$ level, Palaeontogr. Abteilung B, 298, 93-172, https://doi.org/10.1127/palb/2019/0062, 2019.

Mudelsee, M., Bickert, T., Lear, C. H., and Lohmann, G.: Cenozoic climate changes: A review based on time series analysis of marine benthic $\delta^{18} \mathrm{O}$ records, Rev. Geophys., 52, 333-374, https://doi.org/10.1002/2013RG000440, 2014.

Müller, P. J., Kirst, G., Ruhland, G., von Storch, I., and Rosell-Melé, A.: Calibration of the alkenone paleotemperature index U37K' based on core-tops from the eastern South Atlantic and the global ocean $\left(60^{\circ} \mathrm{N}-60^{\circ} \mathrm{S}\right)$, Geochim. Cosmochim. Acta, 62, 17571772, https://doi.org/10.1016/S0016-7037(98)00097-0, 1998.

Müller, R. D., Sdrolias, M., Gaina, C., and Roest, W. R.: Age, spreading rates, and spreading asymmetry of the world's ocean crust, Geochem. Geophy. Geosy., 9, Q04006, https://doi.org/10.1029/2007GC001743, 2008.

Negri, F. R., Bocquentin-Villanueva, J., Ferigolo, J., and Antoine, P.-O.: A Review of Tertiary Mammal Faunas and Birds from Western Amazonia, in: Amazonia: Landscape and Species Evolution, Wiley-Blackwell Publishing Ltd., West Sussex, UK, 243258, 2009.

Nocchi, M., Parisi, G., Monaco, P., Monechi, S., Madile, M., Napoleone, G., Ripepe, M., Orlando, M., Premoli Silva, I., and Bice, D. M.: The Eocene-Oligocene Boundary in the Umbrian
Pelagic Sequences, Italy, in: terminal eocene events, vol. 9, edited by: Pomerol, C., Premoli-Silva, S., Elsevier, Amsterdam, the Netherlands, 25-40, 1986.

Nof, D., Van Gorder, S., and de Boer, A.: Does the Atlantic meridional overturning cell really have more than one stable steady state?, Deep-Sea Res. Pt. I, 54, 2005-2021, https://doi.org/10.1016/j.dsr.2007.08.006, 2007.

Norris, R. D. and Wilson, P. A.: Low-latitude seasurface temperatures for the mid-Cretaceous and the evolution of planktic foraminifera, Geology, 26, 823-826, https://doi.org/10.1130/00917613(1998)026<0823:LLSSTF>2.3.CO;2, 1998.

O'Brien, C. L., Huber, M., Thomas, E., Pagani, M., Super, J. R., Elder, L. E., and Hull, P. M.: The enigma of Oligocene climate and global surface temperature evolution, P. Natl. Acad. Sci. USA, 117, 25302-25309, https://doi.org/10.1073/pnas.2003914117, 2020.

O'Regan, M., Williams, C. J., Frey, K. E., and Jakobsson, M.: A Synthesis of the Long-Term Paleoclimatic Evolution of the Arctic, Oceanography, 24, 66-80, https://doi.org/10.5670/oceanog.2011.57, 2011.

Oboh-Ikuenobe, F. E. and Jaramillo, C. A.: Palynological patterns in the uppermost Eocene to lower Oligocene sedimentary, in: From Greenhouse to Icehouse: The Marine Eocene-Oligocene Transition, Columbia University Press, New York, USA, 269, 2003.

Olivarez Lyle, A. and Lyle, M. W.: Missing organic carbon in Eocene marine sediments: Is metabolism the biological feedback that maintains end-member climates?, Paleoceanography, 21, PA2007, https://doi.org/10.1029/2005PA001230, 2006.

Olivetti, V., Balestrieri, M. L., Rossetti, F., and Talarico, F. M.: Tectonic and climatic signals from apatite detrital fission track analysis of the Cape Roberts Project core records, South Victoria Land, Antarctica, Tectonophysics, 594, 80-90, https://doi.org/10.1016/j.tecto.2013.03.017, 2013.

Olivetti, V., Balestrieri, M. L., Rossetti, F., Thomson, S. N., Talarico, F. M., and Zattin, M.: Evidence of a full West Antarctic Ice Sheet back to the early Oligocene: insight from double dating of detrital apatites in Ross Sea sediments, Terra Nov., 27, 238246, https://doi.org/10.1111/ter.12153, 2015.

Opdyke, B. N. and Wilkinson, B. H.: Surface area control of shallow cratonic to deep marine carbonate accumulation, Paleoceanography, 3, 685-703, https://doi.org/10.1029/PA003i006p00685, 1988.

Pagani, M., Zachos, J. C., Freeman, K. H., Tipple, B., and Bohaty, S.: Marked Decline in Atmospheric Carbon Dioxide Concentrations During the Paleogene, Science, 309, 600-603, https://doi.org/10.1126/science.1110063, 2005.

Pagani, M., Huber, M., Liu, Z., Bohaty, S. M., Henderiks, J., Sijp, W., Krishnan, S., and DeConto, R. M.: The Role of Carbon Dioxide During the Onset of Antarctic Glaciation, Science, 334, 1261-1264, https://doi.org/10.1126/science.1203909, 2011.

Page, M., Licht, A., Dupont-Nivet, G., Meijer, N., Barbolini, N., Hoorn, C., Schauer, A., Huntington, K., Bajnai, D., Fiebig, J., Mulch, A., and Guo, Z.: Synchronous cooling and decline in monsoonal rainfall in northeastern Tibet during the fall into the Oligocene icehouse, Geology, 47, 203-206, https://doi.org/10.1130/G45480.1, 2019.

Palike, H., Lyle, M. W., Nishi, H., Raffi, I., Ridgwell, A., Gamage, K., Klaus, A., Acton, G., Anderson, L., Backman, J., Baldauf, J., 
Beltran, C., Bohaty, S. M., BownPaul, Busch, W., Channell, J. E. T., Chun, C. O. J., Delaney, M., Dewangan, P., Dunkley Jones, T., Edgar, K. M., Evans, H., Fitch, P., Foster, G. L., Gussone, N., Hasegawa, H., Hathorne, E. C., Hayashi, H., Herrle, J. O., Holbourn, A., Hovan, S., Hyeong, K., Iijima, K., Ito, T., Kamikuri, S., Kimoto, K., Kuroda, J., Leon-Rodriguez, L., Malinverno, A., Moore Jr, T. C., Murphy, B. H., Murphy, D. P., Nakamura, H., Ogane, K., Ohneiser, C., Richter, C., Robinson, R., Rohling, E. J., Romero, O., Sawada, K., Scher, H., Schneider, L., Sluijs, A., Takata, H., Tian, J., Tsujimoto, A., Wade, B. S., Westerhold, T., Wilkens, R., Williams, T., Wilson, P. A., Yamamoto, Y., Yamamoto, S., Yamazaki, T., and Zeebe, R. E.: A Cenozoic record of the equatorial Pacific carbonate compensation depth, Nature, 488, 609-614, https://doi.org/10.1038/nature11360, 2012.

Pan, A. D., Jacobs, B. F., Dransfield, J., and Baker, W. J.: The fossil history of palms (Arecaceae) in Africa and new records from the Late Oligocene (28-27 Mya) of north-western Ethiopia, Bot. J. Linn. Soc., 151, 69-81, https://doi.org/10.1111/j.10958339.2006.00523.x, 2006.

Passchier, S., Bohaty, S. M., Jiménez-Espejo, F., Pross, J., Röhl, U., van de Flierdt, T., Escutia, C., and Brinkhuis, H.: Early Eocene to middle Miocene cooling and aridification of East Antarctica, Geochem. Geophy. Geosy., 14, 1399-1410, https://doi.org/10.1002/ggge.20106, 2013.

Passchier, S., Ciarletta, D. J., Miriagos, T. E., Bijl, P. K., and Bohaty, S. M.: An Antarctic stratigraphic record of stepwise ice growth through the Eocene-Oligocene transition, GSA Bull., 129, 318 330, https://doi.org/10.1130/B31482.1, 2017.

Pearson, A. and Ingalls, A. E.: Assessing the Use of Archaeal Lipids as Marine Environmental Proxies, Annu. Rev. Earth Planet. Sci., 41, 359-384, https://doi.org/10.1146/annurev-earth050212-123947, 2013.

Pearson, P. N. and Palmer, M. R.: Middle Eocene Seawater $\mathrm{pH}$ and Atmospheric Carbon Dioxide Concentrations, Science, 284, 1824-1826, https://doi.org/10.1126/science.284.5421.1824, 1999.

Pearson, P. N. and Palmer, M. R.: Atmospheric carbon dioxide concentrations over the past 60 million years, Nature, 406, 695, https://doi.org/10.1038/35021000, 2000.

Pearson, P. N., Ditchfield, P. W., Singano, J., Harcourt-Brown, K. G., Nicholas, C. J., Olsson, R. K., Shackleton, N. J., and Hall, M. A.: Warm tropical sea surface temperatures in the Late Cretaceous and Eocene epochs, Nature, 413, 481-487, https://doi.org/10.1038/35097000, 2001.

Pearson, P. N., van Dongen, B. E., Nicholas, C. J., Pancost, R. D., Schouten, S., Singano, J. M., and Wade, B. S.: Stable warm tropical climate through the Eocene Epoch, Geology, 35, 211-214, https://doi.org/10.1130/G23175A.1, 2007.

Pearson, P. N., McMillan, I. K., Wade, B. S., Jones, T. D., Coxall, H. K., Bown, P. R., and Lear, C. H.: Extinction and environmental change across the Eocene-Oligocene boundary in Tanzania, Geology, 36, 179-182, https://doi.org/10.1130/G24308A.1, 2008.

Pearson, P. N., Foster, G. L., and Wade, B. S.: Atmospheric carbon dioxide through the Eocene-Oligocene climate transition, Nature, 461, 1110-1113, https://doi.org/10.1038/nature08447, 2009.

Peck, V. L., Yu, J., Kender, S., and Riesselman, C. R.: Shifting ocean carbonate chemistry during the EoceneOligocene climate transition: Implications for deep-ocean
Mg / Ca paleothermometry, Paleoceanography, 25, PA4219, https://doi.org/10.1029/2009PA001906, 2010.

Pérez, L. F., Nielsen, T., Knutz, P. C., Kuijpers, A., and Damm, V.: Large-scale evolution of the central-east Greenland margin: New insights to the North Atlantic glaciation history, Glob. Planet. Change, 163, 141-157, https://doi.org/10.1016/j.gloplacha.2017.12.010, 2018.

Petersen, S. V and Schrag, D. P.: Antarctic ice growth before and after the Eocene-Oligocene transition: New estimates from clumped isotope paleothermometry, Paleoceanography, 30, 1305-1317, https://doi.org/10.1002/2014PA002769, 2015.

Piepjohn, K., von Gosen, W., and Tessensohn, F.: The Eurekan deformation in the Arctic: an outline, J. Geol. Soc. London, 173, 1007-1024, https://doi.org/10.1144/jgs2016-081, 2016.

Piga, E.: How Hot is Hot? Tropical Ocean Temperatures and Plankton Communities in the Eocene Epoch, PhD Thesis, Cardiff University, available at: http://orca.cf.ac.uk/136990/, last access: 20 December 2020.

Pocknall, D. T.: Palynostratigraphy of the Te Kuiti Group (late Eocene-Oligocene), Waikato Basin, New Zealand, New Zeal. J. Geol. Geophys., 34, 407-417, https://doi.org/10.1080/00288306.1991.9514479, 1991.

Pollard, D.: A retrospective look at coupled ice sheetclimate modeling, Clim. Change, 100, 173-194, https://doi.org/10.1007/s10584-010-9830-9, 2010.

Pollard, D. and DeConto, R. M.: Hysteresis in Cenozoic Antarctic ice-sheet variations, Glob. Planet. Change, 45, 9-21, https://doi.org/10.1016/j.gloplacha.2004.09.011, 2005.

Pomerol, C. and Premoli Silva, I. (eds.): The Eocene-Oligocene Transition: Events and Boundary, in: termbal eocene events, vol. 9, Elsevier,, Amsterdam, the Netherlands, 1-24, 1986.

Postigo Mijarra, J. M., Barrón, E., Gómez Manzaneque, F., and Morla, C.: Floristic changes in the Iberian Peninsula and Balearic Islands (south-west Europe) during the Cenozoic, J. Biogeogr., 36, 2025-2043, https://doi.org/10.1111/j.13652699.2009.02142.x, 2009.

Pound, M. J. and Salzmann, U.: Heterogeneity in global vegetation and terrestrial climate change during the late Eocene to early Oligocene transition, Sci. Rep., 7, 43386, https://doi.org/10.1038/srep43386, 2017.

Premoli Silva, I. and Jenkins, D. G.: Decision on the EoceneOligocene boundary stratotype, Episodes, 16, 379-382, 1993.

Pross, J., Contreras, L., Bijl, P. K., Greenwood, D. R., Bohaty, S. M., Schouten, S., Bendle, J. A., Röhl, U., Tauxe, L., Raine, J. I., Huck, C. E., van de Flierdt, T., Jamieson, S. S. R., Stickley, C. E., van de Schootbrugge, B., Escutia, C., and Brinkhuis, H.: Persistent near-tropical warmth on the Antarctic continent during the early Eocene epoch, Nature, 488, 73, https://doi.org/10.1038/nature11300, 2012.

Prothero, D.: Cenozoic Mammals and Climate Change: The Contrast between Coarse-Scale versus High-Resolution Studies Explained by Species Sorting, Geosciences, 2, 25-41, https://doi.org/10.3390/geosciences2020025, 2012.

Prothero, D. R.: Did impacts, volcanic eruptions, or climate change affect mammalian evolution?, Palaeogeogr. Palaeoclimatol. Palaeoecol., 214, 283-294, https://doi.org/10.1016/j.palaeo.2004.04.010, 2004.

Pusz, A. E., Thunell, R. C., and Miller, K. G.: Deep water temperature, carbonate ion, and ice volume changes across the Eocene- 
Oligocene climate transition, Paleoceanography, 26, PA2205, https://doi.org/10.1029/2010PA001950, 2011.

Qin, W., Carlson, L. T., Armbrust, E. V., Devol, A. H., Moffett, J. W., Stahl, D. A., and Ingalls, A. E.: Confounding effects of oxygen and temperature on the TEX86 signature of marine Thaumarchaeota, P. Natl. Acad. Sci. USA, 112, 10979-10984, https://doi.org/10.1073/pnas.1501568112, 2015.

Quade, J., Breecker, D. O., Daëron, M., and Eiler, J.: The paleoaltimetry of Tibet: An isotopic perspective, Am. J. Sci., 311, 77115, https://doi.org/10.2475/02.2011.01, 2011.

Quade, J., Leary, R., Dettinger, M. P., Orme, D., Krupa, A., DeCelles, P. G., Kano, A., Kato, H., Waldrip, R., Huang, W., and Kapp, P.: Resetting Southern Tibet: The serious challenge of obtaining primary records of Paleoaltimetry, Glob. Planet. Change, 191, 103194, https://doi.org/10.1016/j.gloplacha.2020.103194, 2020.

Quattrocchio, M. E., Martínez, M. A., Hinojosa, L. F., and Jaramillo, C.: Quantitative analysis of Cenozoic palynofloras from Patagonia, southern South America, Palynology, 37, 246258, https://doi.org/10.1080/01916122.2013.787126, 2013.

Raymo, M. E.: The Initiation of Northern Hemisphere Glaciation, Annu. Rev. Earth Planet. Sci., 22, 353-383, https://doi.org/10.1146/annurev.ea.22.050194.002033, 1994.

Raymo, M. E. and Ruddiman, W. F.: Tectonic forcing of late Cenozoic climate, Nature, 359, 117-122, https://doi.org/10.1038/359117a0, 1992.

Retallack, G. J.: Late Eocene and Oligocene paleosols from Badlands National Park, South Dakota, Geological Society of America, Boulder, Colorado, USA, 1983.

Retallack, G. J.: A 300-million-year record of atmospheric carbon dioxide from fossil plant cuticles, Nature, 411, 287, https://doi.org/10.1038/35077041, 2001.

Retallack, G. J., Wynn, J. G., and Fremd, T. J.: Glacialinterglacial-scale paleoclimatic change without large ice sheets in the Oligocene of central Oregon, Geology, 32, 297-300, https://doi.org/10.1130/G20247.1, 2004.

Ridgway, K. D. and Sweet, A. R.: Climatically induced floristic changes across the Eocene-Oligocene transition in the northern high latitudes, Yukon Territory, Canada, GSA Bull., 107, 676-696, https://doi.org/10.1130/00167606(1995)107<0676:CIFCAT>2.3.CO;2, 1995.

Robert, C. and Kennett, J. P.: Antarctic continental weathering changes during Eocene-Oligocene cryosphere expansion: Clay mineral and oxygen isotope evidence, Geology, 25, 587-590, https://doi.org/10.1130/00917613(1997)025<0587:ACWCDE>2.3.CO;2, 1997.

Roberts, C. D., LeGrande, A. N., and Tripati, A. K.: Climate sensitivity to Arctic seaway restriction during the early Paleogene, Earth Planet. Sci. Lett., 286, 576-585, https://doi.org/10.1016/j.epsl.2009.07.026, 2009.

Roth-Nebelsick, A., Utescher, T., Mosbrugger, V., Diester-Haass, L., and Walther, H.: Changes in atmospheric $\mathrm{CO}_{2}$ concentrations and climate from the Late Eocene to Early Miocene: palaeobotanical reconstruction based on fossil floras from Saxony, Germany, Palaeogeogr. Palaeoclimatol. Palaeoecol., 205, 43-67, https://doi.org/10.1016/j.palaeo.2003.11.014, 2004.

Roth-Nebelsick, A., Grein, M., Utescher, T., and Konrad, W.: Stomatal pore length change in leaves of Eotrigonobalanus furcinervis (Fagaceae) from the Late Eocene to the
Latest Oligocene and its impact on gas exchange and $\mathrm{CO}_{2}$ reconstruction, Rev. Palaeobot. Palynol., 174, 106-112, https://doi.org/10.1016/j.revpalbo.2012.01.001, 2012.

Roth-Nebelsick, A., Oehm, C., Grein, M., Utescher, T., Kunzmann, L., Friedrich, J.-P., and Konrad, W.: Stomatal density and index data of Platanus neptuni leaf fossils and their evaluation as a $\mathrm{CO}_{2}$ proxy for the Oligocene, Rev. Palaeobot. Palynol., 206, 1-9, https://doi.org/10.1016/j.revpalbo.2014.03.001, 2014.

Roth-Nebelsick, A., Grein, M., Traiser, C., Moraweck, K., Kunzmann, L., Kovar-Eder, J., Kvaček, J., Stiller, S., and Neinhuis, C.: Functional leaf traits and leaf economics in the Paleogene - A case study for Central Europe, Palaeogeogr. Palaeoclimatol. Palaeoecol., 472, 1-14, https://doi.org/10.1016/j.palaeo.2017.02.008, 2017.

Rowley, D. B. and Currie, B. S.: Palaeo-altimetry of the late Eocene to Miocene Lunpola basin, central Tibet, Nature, 439, 677-681, https://doi.org/10.1038/nature04506, 2006.

Royer, D. L., Wing, S. L., Beerling, D. J., Jolley, D. W., Koch, P. L., Hickey, L. J., and Berner, R. A.: Paleobotanical Evidence for Near Present-Day Levels of Atmospheric $\mathrm{CO}_{2}$ During Part of the Tertiary, Science, 292, 2310-2313, https://doi.org/10.1126/science.292.5525.2310, 2001.

Royer, D. L., Berner, R. A., Montañez, I. P., Tabor, N. J., and Beerling, D. J.: $\mathrm{CO}_{2}$ as a primary driver of phanerozoic climate, GSA Today, 14, 4-10, https://doi.org/10.1130/10525173(2004)014<4:CAAPDO>2.0.CO;2, 2004.

Sagoo, N., Valdes, P., Flecker, R., and Gregoire, L. J.: The Early Eocene equable climate problem: can perturbations of climate model parameters identify possible solutions?, Philos. Trans. R. Soc. A-Math. Phys., 371, 20130123, https://doi.org/10.1098/rsta.2013.0123, 2013.

Schaefer, J. M., Finkel, R. C., Balco, G., Alley, R. B., Caffee, M. W., Briner, J. P., Young, N. E., Gow, A. J., and Schwartz, R.: Greenland was nearly ice-free for extended periods during the Pleistocene, Nature, 540, 252, https://doi.org/10.1038/nature20146, 2016.

Scher, H. D., Bohaty, S. M., Zachos, J. C., and Delaney, M. L.: Twostepping into the icehouse: East Antarctic weathering during progressive ice-sheet expansion at the Eocene-Oligocene transition, Geology, 39, 383-386, https://doi.org/10.1130/G31726.1, 2011.

Scher, H. D., Bohaty, S. M., Smith, B. W., and Munn, G. H.: Isotopic interrogation of a suspected late Eocene glaciation, Paleoceanography, 29, 628-644, https://doi.org/10.1002/2014PA002648, 2014.

Scher, H. D., Whittaker, J. M., Williams, S. E., Latimer, J. C., Kordesch, W. E. C., and Delaney, M. L.: Onset of Antarctic Circumpolar Current 30 million years ago as Tasmanian Gateway aligned with westerlies, Nature, 523, 580-583, https://doi.org/10.1038/nature14598, 2015.

Schouten, S., Hopmans, E. C., Schefuß, E., and Sinninghe Damsté, J. S.: Distributional variations in marine crenarchaeotal membrane lipids: a new tool for reconstructing ancient sea water temperatures?, Earth Planet. Sci. Lett., 204, 265-274, https://doi.org/10.1016/S0012-821X(02)00979-2, 2002.

Scotese, C.: Atlas of Earth History, PALEOMAP Project, University of Texas, Arlington, USA, ISBN 0-9700020-0-9, 2001

Scotese, C. R. and Wright, N. M.: PALEOMAP Paleodigital Elevation Models (PaleoDEMS) for the Phanerozoic PALEOMAP Project, available at: https://www.earthbyte.org/ 
paleodem-resource-scotese-and-wright-2018 (access date: 15 August 2019), 2018.

Scotese, C. R., Gahagan, L. M., and Larson, R. L.: Plate tectonic reconstructions of the Cretaceous and Cenozoic ocean basins, Tectonophysics, 155, 27-48, https://doi.org/10.1016/00401951(88)90259-4, 1988.

Selkin, P. A., Strömberg, C. A. E., Dunn, R., Kohn, M. J., Carlini, A. A., Davies-Vollum, K. S., and Madden, R. H.: Climate, dust, and fire across the Eocene-Oligocene transition, Patagonia, Geology, 43, 567-570, https://doi.org/10.1130/G36664.1, 2015.

Seton, M., Müller, R. D., Zahirovic, S., Gaina, C., Torsvik, T., Shephard, G., Talsma, A., Gurnis, M., Turner, M., Maus, S., and Chandler, M.: Global continental and ocean basin reconstructions since 200Ma, Earth-Sci. Rev., 113, 212-270, https://doi.org/10.1016/j.earscirev.2012.03.002, 2012.

Sewall, J. O., Sloan, L. C., Huber, M., and Wing, S.: Climate sensitivity to changes in land surface characteristics, Glob. Planet. Change, 26, 445-465, https://doi.org/10.1016/S09218181(00)00056-4, 2000.

Sexton, P. F., Wilson, P. A., and Pearson, P. N.: Microstructural and geochemical perspectives on planktic foraminiferal preservation: “Glassy” versus “Frosty," Geochem. Geophy. Geosy., 7, Q12P19, https://doi.org/10.1029/2006GC001291, 2006.

Shackleton, N. J. and Kennett, J. P.: Paleotemperature History of the Cenozoic and the Initiation of Antarctic Glaciation: Oxygen and Carbon Isotope Analyses in DSDP Sites 277, 279 and 281, Initial Rep. Deep Sea Drill. Proj., 29, 743, https://doi.org/10.2973/dsdp.proc.29.117.1975, 1975.

Shackleton, N. J., Backman, J., Zimmerman, H., Kent, D. V, Hall, M. A., Roberts, D. G., Schnitker, D., Baldauf, J. G., Desprairies, A., Homrighausen, R., Huddlestun, P., Keene, J. B., Kaltenback, A. J., Krumsiek, K. A. O., Morton, A. C., Murray, J. W., and Westberg-Smith, J.: Oxygen isotope calibration of the onset of ice-rafting and history of glaciation in the North Atlantic region, Nature, 307, 620-623, https://doi.org/10.1038/307620a0, 1984.

Sheldon, N. D. and Tabor, N. J.: Quantitative paleoenvironmental and paleoclimatic reconstruction using paleosols, Earth-Sci. Rev., 95, 1-52, https://doi.org/10.1016/j.earscirev.2009.03.004, 2009.

Sheldon, N. D., Costa, E., Cabrera, L., and Garcés, M.: Continental Climatic and Weathering Response to the Eocene-Oligocene Transition, J. Geol., 120, 227-236, https://doi.org/10.1086/663984, 2012.

Sheldon, N. D., Grimes, S. T., Hooker, J. J., Collinson, M. E., Bugler, M. J., Hren, M. T., Price, G. D., and Sutton, P. A.: Coupling of marine and continental oxygen isotope records during the Eocene-Oligocene transition, GSA Bull., 128, 502-510, https://doi.org/10.1130/B31315.1, 2016.

Shellito, C. J., Sloan, L. C., and Huber, M.: Climate model sensitivity to atmospheric $\mathrm{CO}_{2}$ levels in the Early-Middle Paleogene, Palaeogeogr. Palaeoclimatol. Palaeoecol., 193, 113-123, https://doi.org/10.1016/S0031-0182(02)00718-6, 2003.

Sijp, W. P. and England, M. H.: Effect of the Drake Passage Throughflow on Global Climate, J. Phys. Oceanogr., 34, 1254-1266, https://doi.org/10.1175/15200485(2004)034<1254:EOTDPT>2.0.CO;2, 2004.

Sijp, W. P., England, M. H., and Toggweiler, J. R.: Effect of Ocean Gateway Changes under Greenhouse Warmth, J. Clim., 22, 6639-6652, https://doi.org/10.1175/2009JCLI3003.1, 2009.
Sijp, W. P., England, M. H., and Huber, M.: Effect of the deepening of the Tasman Gateway on the global ocean, Paleoceanography, 26, PA4207, https://doi.org/10.1029/2011PA002143, 2011.

Sijp, W. P., von der Heydt, A. S., Dijkstra, H. A., Flögel, S., Douglas, P. M. J., and Bijl, P. K.: The role of ocean gateways on cooling climate on long time scales, Glob. Planet. Change, 119, 1-22, https://doi.org/10.1016/j.gloplacha.2014.04.004, 2014.

Sijp, W. P., von der Heydt, A. S., and Bijl, P. K.: Model simulations of early westward flow across the Tasman Gateway during the early Eocene, Clim. Past, 12, 807-817, https://doi.org/10.5194/cp-12-807-2016, 2016.

Śliwińska, K. K., Thomsen, E., Schouten, S., Schoon, P. L., and Heilmann-Clausen, C.: Climate- and gateway-driven cooling of Late Eocene to earliest Oligocene sea surface temperatures in the North Sea Basin, Sci. Rep., 9, 4458, https://doi.org/10.1038/s41598-019-41013-7, 2019.

Sluijs, A., Schouten, S., Donders, T. H., Schoon, P. L., Röhl, U., Reichart, G.-J., Sangiorgi, F., Kim, J.-H., Sinninghe Damsté, J. S., and Brinkhuis, H.: Warm and wet conditions in the Arctic region during Eocene Thermal Maximum 2, Nat. Geosci., 2, 777, https://doi.org/10.1038/ngeo668, 2009.

Solgaard, A. M., Bonow, J. M., Langen, P. L., Japsen, P., and Hvidberg, C. S.: Mountain building and the initiation of the Greenland Ice Sheet, Palaeogeogr. Palaeoclimatol. Palaeoecol., 392, 161176, https://doi.org/10.1016/j.palaeo.2013.09.019, 2013.

Sorlien, C. C., Luyendyk, B. P., Wilson, D. S., Decesari, R. C., Bartek, L. R., and Diebold, J. B.: Oligocene development of the West Antarctic Ice Sheet recorded in eastern Ross Sea strata, Geology, 35, 467-470, https://doi.org/10.1130/G23387A.1, 2007.

Sosdian, S. M., Greenop, R., Hain, M. P., Foster, G. L., Pearson, P. N., and Lear, C. H.: Constraining the evolution of Neogene ocean carbonate chemistry using the boron isotope $\mathrm{pH}$ proxy, Earth Planet. Sci. Lett., 498, 362-376, https://doi.org/10.1016/j.epsl.2018.06.017, 2018.

Spray, J. F., Bohaty, S. M., Davies, A., Bailey, I., Romans, B. W., Cooper, M. J., Milton, J. A., and Wilson, P. A.: North Atlantic Evidence for a Unipolar Icehouse Climate State at the Eocene-Oligocene Transition, Paleoceanogr. Paleoclimatology, 34, 1124-1138, https://doi.org/10.1029/2019PA003563, 2019.

Srokosz, M. A. and Bryden, H. L.: Observing the Atlantic Meridional Overturning Circulation yields a decade of inevitable surprises, Science, 348, 1255575, https://doi.org/10.1126/science.1255575, 2015.

Stärz, M., Jokat, W., Knorr, G., and Lohmann, G.: Threshold in North Atlantic-Arctic Ocean circulation controlled by the subsidence of the Greenland-Scotland Ridge, Nat. Commun., 8, 15681, https://doi.org/10.1038/ncomms15681, 2017.

Steinthorsdottir, M. and Vajda, V.: Early Jurassic (late Pliensbachian) $\mathrm{CO}_{2}$ concentrations based on stomatal analysis of fossil conifer leaves from eastern Australia, Gondwana Res., 27, 932939, https://doi.org/10.1016/j.gr.2013.08.021, 2015.

Steinthorsdottir, M., Jeram, A. J., and McElwain, J. C.: Extremely elevated $\mathrm{CO}_{2}$ concentrations at the Triassic/Jurassic boundary, Palaeogeogr. Palaeoclimatol. Palaeoecol., 308, 418-432, https://doi.org/10.1016/j.palaeo.2011.05.050, 2011.

Steinthorsdottir, M., Wohlfarth, B., Kylander, M. E., Blaauw, M., and Reimer, P. J.: Stomatal proxy record of $\mathrm{CO}_{2}$ concentrations from the last termination suggests an important role for 
$\mathrm{CO}_{2}$ at climate change transitions, Quat. Sci. Rev., 68, 43-58, https://doi.org/10.1016/j.quascirev.2013.02.003, 2013.

Steinthorsdottir, M., Porter, A. S., Holohan, A., Kunzmann, L., Collinson, M., and McElwain, J. C.: Fossil plant stomata indicate decreasing atmospheric $\mathrm{CO}_{2}$ prior to the Eocene-Oligocene boundary, Clim. Past, 12, 439-454, https://doi.org/10.5194/cp12-439-2016, 2016.

Steinthorsdottir, M., Vajda, V., Pole, M., and Holdgate, G.: Moderate levels of Eocene $\mathrm{pCO}_{2}$ indicated by Southern Hemisphere fossil plant stomata, Geology, 47, 914-918, https://doi.org/10.1130/G46274.1, 2019.

Steinthorsdottir, M., Jardine, P. E., and Rember, W. C.: NearFuture $\mathrm{pCO}_{2}$ during the hot Mid Miocene Climatic Optimum, Paleoceanogr. Paleoclimatol., 36, e2020PA003900, https://doi.org/10.1029/2020PA003900, 2021.

Stickley, C. E., Brinkhuis, H., Schellenberg, S. A., Sluijs, A., Röhl, U., Fuller, M., Grauert, M., Huber, M., Warnaar, J., and Williams, G. L.: Timing and nature of the deepening of the Tasmanian Gateway, Paleoceanography, 19, PA4027, https://doi.org/10.1029/2004PA001022, 2004.

Stickley, C. E., St John, K., Koç, N., Jordan, R. W., Passchier, S., Pearce, R. B., and Kearns, L. E.: Evidence for middle Eocene Arctic sea ice from diatoms and ice-rafted debris, Nature, 460, 376-379, https://doi.org/10.1038/nature08163, 2009.

St. John, K.: Cenozoic ice-rafting history of the central Arctic Ocean: Terrigenous sands on the Lomonosov Ridge, Paleoceanography, 23, PA1S05, https://doi.org/10.1029/2007PA001483, 2008.

Stocchi, P., Escutia, C., Houben, A. J. P., Vermeersen, B. L. A., Bijl, P. K., Brinkhuis, H., DeConto, R. M., Galeotti, S., Passchier, S., Pollard, D., Brinkhuis, H., Escutia, C., Klaus, A., Fehr, A., Williams, T., Bendle, J. A. P., Bijl, P. K., Bohaty, S. M., Carr, S. A., Dunbar, R. B., Flores, J. A., Gonzàlez, J. J., Hayden, T. G., Iwai, M., Jimenez-Espejo, F. J., Katsuki, K., Kong, G. S., McKay, R. M., Nakai, M., Olney, M. P., Passchier, S., Pekar, S. F., Pross, J., Riesselman, C., Röhl, U., Sakai, T., Shrivastava, P. K., Stickley, C. E., Sugisaki, S., Tauxe, L., Tuo, S., van de Flierdt, T., Welsh, K., and Yamane, M.: Relative sea-level rise around East Antarctica during Oligocene glaciation, Nat. Geosci., 6, 380, https://doi.org/10.1038/ngeo1783, 2013.

Strömberg, C. A. E., Dunn, R. E., Madden, R. H., Kohn, M. J., and Carlini, A. A.: Decoupling the spread of grasslands from the evolution of grazer-type herbivores in South America, Nat. Commun., 4, 1478, https://doi.org/10.1038/ncomms2508, 2013.

Strother, S. L., Salzmann, U., Sangiorgi, F., Bijl, P. K., Pross, J., Escutia, C., Salabarnada, A., Pound, M. J., Voss, J., and Woodward, J.: A new quantitative approach to identify reworking in Eocene to Miocene pollen records from offshore Antarctica using red fluorescence and digital imaging, Biogeosciences, 14, 2089-2100, https://doi.org/10.5194/bg-14-2089-2017, 2017.

Su, T., Li, S.-F., Tang, H., Huang, Y.-J., Li, S.-H., Deng, C.-L., and Zhou, Z.-K.: Hemitrapa Miki (Lythraceae) from the earliest Oligocene of southeastern Qinghai-Tibetan Plateau and its phytogeographic implications, Rev. Palaeobot. Palynol., 257, 57-63, https://doi.org/10.1016/j.revpalbo.2018.06.001, 2018.

Sun, J. and Windley, B. F.: Onset of aridification by 34 Ma across the Eocene-Oligocene transition in Central Asia, Geology, 43, 1015-1018, https://doi.org/10.1130/G37165.1, 2015.
Sun, J., Ni, X., Bi, S., Wu, W., Ye, J., Meng, J., and Windley, B. F.: Synchronous turnover of flora, fauna, and climate at the Eocene-Oligocene Boundary in Asia, Sci. Rep., 4, 7463, https://doi.org/10.1038/srep07463, 2014.

Swart, P. K.: Global synchronous changes in the carbon isotopic composition of carbonate sediments unrelated to changes in the global carbon cycle, P. Natl. Acad. Sci. USA, 105, 13741-13745, https://doi.org/10.1073/pnas.0802841105, 2008.

Swart, P. K. and Eberli, G.: The nature of the $\delta 13 \mathrm{C}$ of periplatform sediments: Implications for stratigraphy and the global carbon cycle, Sediment. Geol., 175, 115-129, https://doi.org/10.1016/j.sedgeo.2004.12.029, 2005.

Teodoridis, V. and Kvaček, Z.: Palaeoenvironmental evaluation of cainozoic plant assemblages from the Bohemian Massif (Czech Republic) and adjacent Germany, Bull. Geosci., 90, 695-720, https://doi.org/10.3140/bull.geosci.1553, 2015.

Thomas, D. J., Korty, R., Huber, M., Schubert, J. A., and Haines, B.: Nd isotopic structure of the Pacific Ocean 70-30 Ma and numerical evidence for vigorous ocean circulation and ocean heat transport in a greenhouse world, Paleoceanography, 29, 454-469, https://doi.org/10.1002/2013PA002535, 2014.

Thomson, S. N., Reiners, P. W., Hemming, S. R., and Gehrels, G. E.: The contribution of glacial erosion to shaping the hidden landscape of East Antarctica, Nat. Geosci., 6, 203, https://doi.org/10.1038/ngeo1722, 2013.

Tierney, J. E. and Tingley, M. P.: A TEX86 surface sediment database and extended Bayesian calibration, Sci. Data, 2, 150029, https://doi.org/10.1038/sdata.2015.29, 2015.

Tiffney, B. H. and Wing, S. L.: Paleoenvironment of the Oligocene Jebel Qatrani Formation, Fayum depression, northern Egypt, based on floral remains, in: 23rd meeting of the Geological Society of America, 21-24 October 1991, San Diego, CA, USA, 1991.

Tigchelaar, M., von der Heydt, A. S., and Dijkstra, H. A.: A new mechanism for the two-step $\delta^{11} \mathrm{~B}$ signal at the Eocene-Oligocene boundary, Clim. Past, 7, 235-247, https://doi.org/10.5194/cp-7235-2011, 2011.

Toggweiler, J. R. and Bjornsson, H.: Drake Passage and palaeoclimate, J. Quat. Sci., 15, 319-328, https://doi.org/10.1002/10991417(200005)15:4<319::AID-JQS545>3.0.CO;2-C, 2000.

Torsvik, T. H., Van der Voo, R., Preeden, U., Mac Niocaill, C., Steinberger, B., Doubrovine, P. V, van Hinsbergen, D. J. J., Domeier, M., Gaina, C., Tohver, E., Meert, J. G., McCausland, P. J. A., and Cocks, L. R. M.: Phanerozoic polar wander, palaeogeography and dynamics, Earth-Sci. Rev., 114, 325-368, https://doi.org/10.1016/j.earscirev.2012.06.007, 2012.

Tripati, A. and Darby, D.: Evidence for ephemeral middle Eocene to early Oligocene Greenland glacial ice and pan-Arctic sea ice, Nat. Commun., 9, 1038, https://doi.org/10.1038/s41467018-03180-5, 2018.

Tripati, A., Backman, J., Elderfield, H., and Ferretti, P.: Eocene bipolar glaciation associated with global carbon cycle changes, Nature, 436, 341, https://doi.org/10.1038/nature03874, 2005.

Tripati, A. K., Eagle, R. A., Morton, A., Dowdeswell, J. A., Atkinson, K. L., Bahé, Y., Dawber, C. F., Khadun, E., Shaw, R. M. H., Shorttle, O. and Thanabalasundaram, L.: Evidence for glaciation in the Northern Hemisphere back to $44 \mathrm{Ma}$ from ice-rafted debris in the Greenland Sea, Earth Planet. Sci. Lett., 265, 112-122, https://doi.org/10.1016/j.epsl.2007.09.045, 2008. 
Vahlenkamp, M., Niezgodzki, I., De Vleeschouwer, D., Bickert, T., Harper, D., Kirtland Turner, S., Lohmann, G., Sexton, P., Zachos, J., and Pälike, H.: Astronomically paced changes in deep-water circulation in the western North Atlantic during the middle Eocene, Earth Planet. Sci. Lett., 484, 329-340, https://doi.org/10.1016/j.epsl.2017.12.016, 2018a.

Vahlenkamp, M., Niezgodzki, I., De Vleeschouwer, D., Lohmann, G., Bickert, T., and Pälike, H.: Ocean and climate response to North Atlantic seaway changes at the onset of longterm Eocene cooling, Earth Planet. Sci. Lett., 498, 185-195, https://doi.org/10.1016/j.epsl.2018.06.031, 2018b.

Via, R. K. and Thomas, D. J.: Evolution of Atlantic thermohaline circulation: Early Oligocene onset of deep-water production in the North Atlantic, Geology, 34, 441-444, https://doi.org/10.1130/G22545.1, 2006.

Viebahn, J. P., von der Heydt, A. S., Le Bars, D., and Dijkstra, H. A.: Effects of Drake Passage on a strongly eddying global ocean, Paleoceanography, 31, 564-581, https://doi.org/10.1002/2015PA002888, 2016.

van Hinsbergen, D. J. J., de Groot, L. V, van Schaik, S. J., Spakman, W., Bijl, P. K., Sluijs, A., Langereis, C. G., and Brinkhuis, H.: A Paleolatitude Calculator for Paleoclimate Studies., PLoS One, 10, e0126946, https://doi.org/10.1371/journal.pone.0126946, 2015.

Waddell, L. M. and Moore, T. C.: Salinity of the Eocene Arctic Ocean from oxygen isotope analysis of fish bone carbonate, Paleoceanography, 23, PA1S12, https://doi.org/10.1029/2007PA001451, 2008.

Wade, B. S. and Pearson, P. N.: Planktonic foraminiferal turnover, diversity fluctuations and geochemical signals across the Eocene/Oligocene boundary in Tanzania, Mar. Micropaleontol., 68, 244-255, https://doi.org/10.1016/j.marmicro.2008.04.002, 2008.

Wade, B. S., Pearson, P. N., Berggren, W. A., and Pälike, H.: Review and revision of Cenozoic tropical planktonic foraminiferal biostratigraphy and calibration to the geomagnetic polarity and astronomical time scale, Earth-Sci. Rev., 104, 111-142, https://doi.org/10.1016/j.earscirev.2010.09.003, 2011.

Wade, B. S., Houben, A. J. P., Quaijtaal, W., Schouten, S., Rosenthal, Y., Miller, K. G., Katz, M. E., Wright, J. D., and Brinkhuis, H.: Multiproxy record of abrupt sea-surface cooling across the Eocene-Oligocene transition in the Gulf of Mexico, Geology, 40, 159-162, https://doi.org/10.1130/G32577.1, 2012.

Wagner, F., Below, R., Klerk, P. D., Dilcher, D. L., Joosten, H., Kürschner, W. M., and Visscher, H.: A natural experiment on plant acclimation: lifetime stomatal frequency response of an individual tree to annual atmospheric $\mathrm{CO}_{2}$ increase, P. Natl. Acad. Sci. USA, 93, 11705-11708, https://doi.org/10.1073/pnas.93.21.11705, 1996.

Walker, J. C. G., Hays, P. B., and Kasting, J. F.: A negative feedback mechanism for the long-term stabilization of Earth's surface temperature, J. Geophys. Res.-Ocean, 86, 9776-9782, https://doi.org/10.1029/JC086iC10p09776, 1981.

Wei, W.: Opening of the Australia-Antarctica Gateway as dated by nannofossils, Mar. Micropaleontol., 52, 133-152, https://doi.org/10.1016/j.marmicro.2004.04.008, 2004.

Wellner, J. S., Anderson, J. B., Ehrmann, W., Weaver, F. M., Kirshner, A., Livsey, D., and Simms, A. R.: History of an Evolving Ice Sheet as Recorded in SHALDRIL Cores from the Northwestern
Weddell Sea, Antarctica, in: Tectonic, Climatic, and Cryospheric Evolution of the Antarctic Peninsula, American Geophysical Union, Washington, DC, USA, 131-151, 2011.

Westerhold, T., Marwan, N., Drury, A. J., Liebrand, D., Agnini, C., Anagnostou, E., Barnet, J. S. K., Bohaty, S. M., De Vleeschouwer, D., Florindo, F., Frederichs, T., Hodell, D. A., Holbourn, A. E., Kroon, D., Lauretano, V., Littler, K., Lourens, L. J., Lyle, M., Pälike, H., Röhl, U., Tian, J., Wilkens, R. H., Wilson, P. A., and Zachos, J. C.: An astronomically dated record of Earth's climate and its predictability over the last 66 million years, Science, 369, 1383-1387, https://doi.org/10.1126/science.aba6853, 2020.

Williams, S. E., Whittaker, J. M., and Müller, R. D.: Full-fit, palinspastic reconstruction of the conjugate Australian-Antarctic margins, Tectonics, 30, TC6012, https://doi.org/10.1029/2011TC002912, 2011.

Wilson, D. S. and Luyendyk, B. P.: West antarctic paleotopography estimated at the eocene-oligocene climate transition, Geophys. Res. Lett., 36, 10-13, https://doi.org/10.1029/2009GL039297, 2009.

Wilson, D. S., Jamieson, S. S. R., Barrett, P. J., Leitchenkov, G., Gohl, K. and Larter, R. D.: Antarctic topography at the EoceneOligocene boundary, Palaeogeogr. Palaeoclimatol. Palaeoecol., 335-336, 24-34, https://doi.org/10.1016/j.palaeo.2011.05.028, 2012.

Wilson, D. S., Pollard, D., DeConto, R. M., Jamieson, S. S. R., and Luyendyk, B. P.: Initiation of the West Antarctic Ice Sheet and estimates of total Antarctic ice volume in the earliest Oligocene, Geophys. Res. Lett., 40, 4305-4309, https://doi.org/10.1002/grl.50797, 2013.

Wilson, P. A. and Norris, R. D.: Warm tropical ocean surface and global anoxia during the mid-Cretaceous period, Nature, 412, 425-429, https://doi.org/10.1038/35086553, 2001.

Wilson, P. A., Norris, R. D., and Cooper, M. J.: Testing the Cretaceous greenhouse hypothesis using glassy foraminiferal calcite from the core of the Turonian tropics on Demerara Rise, Geology, 30, 607-610, https://doi.org/10.1130/00917613(2002)030<0607:TTCGHU>2.0.CO;2, 2002.

Wing, S. L.: Eocene and Oligocene Floras and Vegetation of the Rocky Mountains, Ann. Missouri Bot. Gard., 74, 748-784, https://doi.org/10.2307/2399449, 1987.

Wing, S. L., Hasiotis, S. T., and Bown, T. M.: First ichnofossils of flank-buttressed trees (late Eocene), Fayum Depression, Egypt, Ichnos, 3, 281-286, https://doi.org/10.1080/10420949509386398, 1995.

Winguth, A., Shellito, C., Shields, C., and Winguth, C.: Climate Response at the Paleocene-Eocene Thermal Maximum to Greenhouse Gas Forcing - A Model Study with CCSM3, J. Clim., 23, 2562-2584, https://doi.org/10.1175/2009JCLI3113.1, 2010.

Wolfe, J. A.: Distribution of Major Vegetational Types During the Tertiary, in: The Carbon Cycle and Atmospheric $\mathrm{CO}_{2}$ : Natural Variations Archean to Present, American Geophysical Union, Washington, DC, USA, 357-375, 1985.

Wolfe, J. A.: Tertiary climatic changes at middle latitudes of western North America, Palaeogeogr. Palaeoclimatol. Palaeoecol., 108, 195-205, https://doi.org/10.1016/0031-0182(94)90233-X, 1994.

Woodburne, M. O., Goin, F. J., Bond, M., Carlini, A. A., Gelfo, J. N., López, G. M., Iglesias, A., and Zimicz, A. N.: Paleogene land 
mammal faunas of South America; a response to global climatic changes and indigenous floral diversity, J. Mamm. Evol., 21, 173, https://doi.org/10.1007/s10914-012-9222-1, 2014.

Woodward, F. I.: Stomatal numbers are sensitive to increases in $\mathrm{CO}_{2}$ from pre-industrial levels, Nature, 327, 617, https://doi.org/10.1038/327617a0, 1987.

Xiao, G. Q., Abels, H. A., Yao, Z. Q., Dupont-Nivet, G., and Hilgen, F. J.: Asian aridification linked to the first step of the EoceneOligocene climate Transition (EOT) in obliquity-dominated terrestrial records (Xining Basin, China), Clim. Past, 6, 501-513, https://doi.org/10.5194/cp-6-501-2010, 2010.

Yancey, T. E., Elsik, W. C., and Sancay, R. H.: The palynological record of late Eocene climate change, northwest Gulf of Mexico, in: From Greenhouse to Icehouse: The Marine EoceneOligocene Transition, Columbia University Press, New York, 252-268, 2003.

Yang, J., Spicer, R. A., Spicer, T. E. V., and Li, C.-S.: "CLAMP Online": a new web-based palaeoclimate tool and its application to the terrestrial Paleogene and Neogene of North America, Palaeobiodiv. Palaeoenviron., 91, 163, https://doi.org/10.1007/s12549011-0056-2, 2011.

Yang, S., Galbraith, E. and Palter, J.: Coupled climate impacts of the Drake Passage and the Panama Seaway, Clim. Dynam., 43, 37-52, https://doi.org/10.1007/s00382-013-1809-6, 2014.

Young, D. A., Wright, A. P., Roberts, J. L., Warner, R. C., Young, N. W., Greenbaum, J. S., Schroeder, D. M., Holt, J. W., Sugden, D. E., Blankenship, D. D., van Ommen, T. D., and Siegert, M. J.: A dynamic early East Antarctic Ice Sheet suggested by ice-covered fjord landscapes, Nature, 474, 72, https://doi.org/10.1038/nature10114, 2011.

Zaarur, S., Affek, H. P., and Brandon, M. T.: A revised calibration of the clumped isotope thermometer, Earth Planet. Sci. Lett., 382, 47-57, https://doi.org/10.1016/j.eps1.2013.07.026, 2013.

Zachos, J., Pagani, M., Sloan, L., Thomas, E., and Billups, K.: Trends, Rhythms, and Aberrations in Global Climate $65 \mathrm{Ma}$ to Present, Science, 292, 686-693, https://doi.org/10.1126/science.1059412, 2001.

Zachos, J. C. and Kump, L. R.: Carbon cycle feedbacks and the initiation of Antarctic glaciation in the earliest Oligocene, Glob. Planet. Change, 47, 51-66, https://doi.org/10.1016/j.gloplacha.2005.01.001, 2005.
Zachos, J. C., Breza, J. R., and Wise, S. W.: Early Oligocene icesheet expansion on Antarctica: Stable isotope and sedimentological evidence from Kerguelen Plateau, southern Indian Ocean, Geology, 20, 569-573, 1992.

Zachos, J. C., Quinn, T. M., and Salamy, K. A.: High-resolution $\left(10^{4}\right.$ years) deep-sea foraminiferal stable isotope records of the Eocene-Oligocene climate transition, Paleoceanography, 11, 251-266, https://doi.org/10.1029/96PA00571, 1996.

Zachos, J. C., Dickens, G. R., and Zeebe, R. E.: An early Cenozoic perspective on greenhouse warming and carbon-cycle dynamics, Nature, 451, 279-83, https://doi.org/10.1038/nature06588, 2008.

Zanazzi, A., Kohn, M. J., MacFadden, B. J., and Terry, D. O.: Large temperature drop across the Eocene-Oligocene transition in central North America, Nature, 445, 639, https://doi.org/10.1038/nature05551, 2007.

Zhang, Y. G., Pagani, M., Liu, Z., Bohaty, S. M., and DeConto, R.: A 40-million-year history of atmospheric $\mathrm{CO}_{2}$, Philos. Trans. R. Soc. London A-Math. Phys., 371, 20130096, https://doi.org/10.1098/rsta.2013.0096, 2013.

Zhang, Z., Nisancioglu, K. H., Flatøy, F., Bentsen, M., Bethke, I., and Wang, H.: Tropical seaways played a more important role than high latitude seaways in Cenozoic cooling, Clim. Past, 7, 801-813, https://doi.org/10.5194/cp-7-801-2011, 2011.

Zhang, Z., Ramstein, G., Schuster, M., Li, C., Contoux, C., and Yan, Q.: Aridification of the Sahara desert caused by Tethys Sea shrinkage during the Late Miocene, Nature, 513, 401, https://doi.org/10.1038/nature13705, 2014.

Zhang, Z. S., Nisancioglu, K., Bentsen, M., Tjiputra, J., Bethke, I., Yan, Q., Risebrobakken, B., Andersson, C., and Jansen, E.: Pre-industrial and mid-Pliocene simulations with NorESM-L, Geosci. Model Dev., 5, 523-533, https://doi.org/10.5194/gmd-5523-2012, 2012.

Zhu, J., Poulsen, C. J., and Tierney, J. E.: Simulation of Eocene extreme warmth and high climate sensitivity through cloud feedbacks, Sci. Adv., 5, eaax1874, https://doi.org/10.1126/sciadv.aax1874, 2019. 